\title{
Estado actual de los estudios de conservación de las pinturas rupestres esquemáticas del Monte Valonsadero (Soria) y propuestas para su protección y salvaguarda
}

\author{
Juan A. Gómez-Barrera*, Eugenio Sanz Pérez ${ }^{\star \star}$, Pablo L. Yagüe Hoyal **, \\ R. FORT $T^{\star \star \star \star}$ Y M. BUSTILLO ${ }^{\star \star \star \star \star}$
}

\section{RESUMEN ABSTRACT}

El primero de los autores reúne aquí su experiencia, de más de veinte años de estudio y seguimiento de las pinturas rupestres esquemáticas del Monte Valonsadero, con las sintesis

-que él mismo traza y los demás autores anotan, corrigen o ampliande los trabajos de estudio de la alteración de las areniscas que soportan los paneles pintados, de los análisis mineralógicos de sus pinturas

y de la conservación y posible medidas para su protección, cuando se aproxima el año 2001, fecha en que este interesante núcleo de arte rupestre cumplirá cincuenta años de su descubrimiento. El interés de los
The first one of the authors assembles his experience of more than twenty-year-old study made of the schematic rock paintings in Monte Valonsadero, together with the syntheses -also made by him and later revised by the other authorsfirstly of the studies of the alteration of the sandstone which support the paintings, secondly of the mineralogical analysis of the paint, and finally aiming to the preservation and possible actions for their protection. This article has an especial significance owing to the closeness of the year 2001, date on which the discovery of this interesting

* Catedrático de Geografía e Historia del I. E. S. Castilla (Soria).

** Profesor de la E. T. S. De Caminos, Canales y Puertos. Universidad Politécnica (Madrid).

*** Restaurador de Bienes Culturales.

**** Instituto de Geología Económica del C. S. I. C.

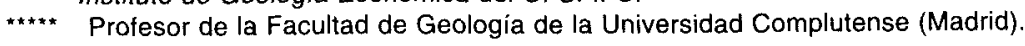


autores está centrado en la necesidad de salvaguardar este tipo de manifestaciones, para lo cual entienden como prioritario el conocimiento de su estado de conservación y la llamada de atención a la Administración a fin de que ésta desarrolle sobre aquéllas cuantas actuaciones sean precisas para cumplir con la inexorable obligación de legarlas, al menos en su situación actual, a la posterioridad.

PALABRAS CLAVE

Arte rupestre, postpaleolítico, conservación, protección, arenisca. cave art nucleus will be fifty years of age. The main interest of the authors aims at the necessity of safeguarding this type of paintings and that is why they give priority to the knowledge of the preservation level in which the paintings are and, at the same time, they make a call on the Authorities attention so that they could make any precise action to fulfil their inexorable duty to leave the paintings, at least as they are nowadays, to posterity.

KEY WORDS

Rocu art, postpalaeolithic, preservation, protection, sandstone.

Por lo que sabemos, tras exhumar de las hemerotecas sorianas un primigenio artículo de Ricardo de Apraiz publicado en el trisemanario Campo (Apraiz, 1951: 7), las pinturas rupestres esquemáticas del Monte Valonsadero (Soria) fueron descubiertas por T. Ortego Frías el domingo 5 de agosto de 1951. Se cumplirán así, el 5 de agosto del 2001, cincuenta años de su casual hallazgo, hecho éste que nos impulsó -junto a la necesidad de redacción, por encargo de la Dirección General de Patrimonio de la Junta de Castilla y León y de la Concejalía de Montes del Excmo. Ayuntamiento de Soria, de una guía razonada de sus muestras artísticasa reflexionar sobre su conservación y salvaguarda.

Este trabajo responde, en líneas generales, a esa reflexión, realizada a partir de la experiencia adquirida a lo largo de más de veinte años de estudio y seguimiento de tan importante núcleo artístico, así como al compendio de los análisis de conservación de sus esquemas y de alteración del soporte que los alberga, realizados por Pablo L. Yagüe Hoyal (restaurador de bienes culturales), Eugenio Sanz Pérez (geólogo y profesor del Dpto. de Ingeniería y Morfología del Terreno de la Escuela Técnica Superior de Ingenieros de Caminos, Canales y Puertos de Madrid), R. Fort (miembro del Instituto de Geología Económica del C.S.I.C) y M. Bustillo (profesor del Dpto. de Petrología y Geoquímica de la Facultad de Geología de la Universidad Complutense de Madrid).

En los últimos años, la propia ley 16/1985 de Patrimonio Histórico Español y, de manera especial, el avance en el diseño legal y administrativo 
de los Parques Arqueológicos (Acín Fanlo, 1990) ${ }^{1}$ y Zonas Arqueológicas (Gómez-Barrera et alii, 1992) y su aplicación a diferentes conjuntos de arte rupestre (La Valltorta, Río Vero, Albarracín, Rio Martín, etc.) ${ }^{2}$ ha impulsado, también en Soria, la necesidad de adaptación de esa normativa para una mejor conservación, protección y valoración del conjunto esquemático de Valonsadero ${ }^{3}$. La Comisión Institucional de Trabajo sobre el Plan de Valonsadero, creada y dirigida por la Concejalía de Montes del Excmo. Ayuntamiento de Soria durante el período 1996-1999, tuvo entre sus planteamientos programáticos la redacción, aprobación y puesta en práctica del Plan Especial de Ordenación y Conservación del Monte Valonsadero, cuyo objeto básico no era otro que el conocimiento, protección y disfrute del patrimonio cultural, geológico y biológico del monte, con especial incidencia en la salvaguarda, investigación y difusión de sus pinturas rupestres esquemáticas. $Y$, al margen de cualquier consideración sobre el cumplimiento político y social de tales trabajos, parece obvio que el punto de arranque de semejante programa no fuera otro que el conocimiento adecuado del estado de conservación de las referidas muestras artísticas.

En tanto que lo particular y específico del estado de conservación de las pinturas de Valonsadero pudiera arrojar alguna enseñanza para la protección y conservación de otros núcleos similares, se presentan aquí los resultados de estas investigaciones a la vez que se reflexiona de forma general sobre la mejor manera de llevar a cabo su difusión, y consiguiente disfrute por parte de los ciudadanos, y protección, por las instituciones administrativas competentes.

\section{ANTECEDENTES}

Salvo referencias concretas a la pérdida de algún motivo por lascado natural de la roca, acción del fuego de las hogueras o efectos erosivos

1 Ley 12/1997, de 3 de diciembre, de Parques Culturales de Aragón, BOA del 12 de diciembre de 1997.

2 A este respecto y con relación a los parques con arte rupestre en Aragón y su problemática general puede verse el núm. 1 (septiembre, 1998) del Boletín de Arte Rupestre de Aragón (BARA), en el que se ofrecen varios trabajos de A. Beltrán, O. Collado, M. ${ }^{a}$. N. Juste, J. Royo y R. DE MIGUEL, reseñados en la bibliografía del presente artículo.

3 En el caso particular de Valonsadero: Resolución de 15 de enero de 1991 de la Dirección General de Patrimonio y Promoción Cultural de la Consejeria de Cultura y Bienestar Social, por la que se acuerda tener por incoado expediente de declaración de bien de interés cultural como zona arqueológica a favor del Monte de Valonsadero de Soria (BOE de 18 de febrero de 1991); y Decreto 143/1994 de 30 de junio, de la Junta de Castilla y León, por el que se declara Bien de Interés Cultural con categoria de Zona Arqueológica a favor de "El Monte Valonsadero", en Soria (BOC y $L$ de 6 de junio de 1994). 
del clima, nada hay en los estudios de T. Ortego $(1951,1953,1954,1958$, $1960,1965,1969$ y 1983) que nos hable del estado de conservación en que se encontró las pinturas ni de su forma de protegerlas. Pudiera resultar significativo que nunca publicara imagen directa alguna de Peña Somera, ni siquiera el calco de sus motivos que él mismo realizó y reprodujo J. Camón Aznar en Las artes y los pueblos de la España primitiva (Madrid, 1954: 431, fig. 430). Tampoco publicó fotografía -aunque sí calco- del Abrigo // del Barranco de Valdecaballos. Y ambos hechos nos hacen pensar que ya existía, en el primero, la tristemente afamada inscripción pintada de "acotado de caza ojo» (Gómez-Barrera, 1993a: 247, fig. 149) ${ }^{4}$ y la gran cruz que, trazada con pintura blanca industrial, cubre todo el panel pictórico del segundo (Gómez-Barrera, 1989: 8, fig. 2).

Quién sí sugirió una actuación preventiva sobre tan interesante núcleo artístico fue Ricardo de Apraiz, cuando, en el artículo periodístico arriba mencionado que daba cuenta del hallazgo, pedía que no se acotase el terreno con cerramientos metálicos, ni con otros de madera, ni tampoco con los más resistentes de ladrillo o mampostería, sino que se estudiasen sus pinturas - como desde el mismo momento de su lo-

4 Aunque entonces, por desconocimiento quizá, no se prestase atención a las cuestiones aquí planteadas, resulta de gran interés historiográfico la polémica que el descubrimiento de la inscripción de Peña Somera produjo en la prensa. El domingo 25 de noviembre de 1973, el director del trisemanario Soria Hogar y Pueblo, Marcos Molinero Cardenal, publicó, en primera página, un contundente articulo que, bajo el título «Un acto vandálico: Destruidas las pinturas de Valonsadero", daba cuenta del deterioro definitivo y total de una de estas estaciones neolíticas... con la pintada en gruesas letras, sobre las mismas figuras rupestres, de un gran letrero que dice: ACOTADO DE CAZA OJO. Su encendida denuncia aludía a la indiferencia, la omisión, la despreocupación y la inoperancia de los dirigentes culturales y a ellos, y sólo a ellos, responsabilizaba de tan desgraciada pérdida. Días después, en el mismo medio ( 5 de diciembre) y en Campo Soriano (6 de diciembre), Enrique Martínez Tercero, Consejero Provincial de Bellas Artes, terciaba en la polémica, en nombre de la Comisión del Patrimonio Histórico-Artístico de Soria, lamentando y reprobando tal acto, atribuyéndolo a la ignorancia o mala voluntad de alguien y justificando que dada la situación de estas pinturas rupestres en parajes naturales y abiertos - como hay tantas otras distribuidas por el mundo- no cabe imputar responsabilidad ni a la Administración ni a Entidades culturales o de investigación, Comisiones o autoridades académicas, a menos se pretenda puerilmente que sus representantes se conviertan en guardias permanentes, noche y dia $y$ a la vez en todos y cada uno de los lugares de la Provincia. A lo que nos interesa, además de otras valoraciones, concluía la nota aludiendo al dramatismo sensacionalista del autor de la denuncia y al hecho de que ignorase que las técnicas actuales de restauración permiten la limpieza de las letras que tapan en parte las pinturas. Ellos también lo debieron ignorar pues aún hoy, 26 años después, sigue leyéndose con la misma intensidad la citada y lamentable frase. Hubo respuesta del Sr. Molinero Cardenal (en su Soria Hogar y Pueblo: "Más sobre las pinturas de Valonsadero", viernes 7 de diciembre y en Campo Soriano, martes 11 de diciembre) y contrarréplica de diferentes miembros de la Comisión (como el Delegado Provincial de Educación en Campo Soriano del jueves 13 de diciembre y de Carlos Pérez Lemouz, Secretario de la Comisión de Patrimonio en Soria, en Ya de fecha 9 de diciembre) e, incluso, al parecer, debió llegar la cuestión a los mismisimos Tribunales. Mas la pintada, como recordábamos, sigue ahi. 
calización empezó a hacer T. Ortego-y, en todo caso, que se instalase un letrero en términos parecidos a estos: Las pinturas de estas rocas datan de tiempos neolíticos. Cerca de mil inviernos de este clima rudo que a tantos venció no lograron destruirlas; ahora que conocemos su valor su conservación queda encomendada a la cultura de los que las visitaren.

No sabemos si tan sugerente cartel llegó a emplazarse alguna vez a la entrada del Monte o en las proximidades de las pinturas, mas de lo que sí tenemos constancia es del deterioro antrópico que estas muestras artísticas han sufrido a lo largo de su historia, en la mayoría de los casos más por ignorancia que por vandalismo.

Queremos creer que la inscripción pintada "acotado de caza ojo» de Peña Somera, el "Luiz Rebelo" de Los Peñascales III, los grafitos «JOR 159 4" de La Peña los Plantíos (Gómez-Barrera, 1984-1985: 156, Fig. 19) o "Luis Romera 1921» de La Cerrada de la Dehesa (Gómez-Barrera, 1994: 17), la gran cruz blanca del Abrigo /l del Barranco de Valdecaballos 0 , en fin, la multitud de hogueras realizadas al pie del Covacho del Cubillejo, Peñón de la Visera, Covachón del Puntal, La Cuerda del Torilejo, Peñón de la Solana o El Risco del Portón de la Cañada, por no citar otras que las más afectadas, fueron trazadas, ejecutadas o realizadas sin otra intención que una supuesta utilidad -en el caso de Peña Somera y Abrigo II del Barranco de Valdecaballos-, la simple y pura imitación instintiva de la transmisión de un mensaje, desconociendo la antigüedad y el valor histórico y artístico del ya existente -en los ejemplos de Los Peñascales III, La Peña los Plantíos y La Cerrada de la Dehesa-y, en lo que se refiere a las hogueras, dejándose llevar por lo adecuado del lugar con la ignorancia de lo allí existente (Fig. 1).

No estamos seguros, sin embargo, que un mejor conocimiento de lo pintado en El Mirador hubiera evitado el arranque de un fragmento de su panel principal, ni el rayado del trazo de una de las figuras masculinas del sector superior de Los Peñascales // o la inscripción a carboncillo, con vítores alusivos a la festividad del "Jueves La Saca», del Covacho del Morro (Fig. 2), sobre todo si tenemos en cuenta que para llevar a cabo cualquiera de estos dos últimos actos el "artista" hubo de superar las verjas protectoras de los abrigos. Y, en este mismo sentido, el conocimiento, mal entendido sin duda, del arte rupestre prehistórico es el que ha posibilitado que alguien, en algún momento especialmente inspirado, haya querido «jugar» a ser un «artista ancestral" dejando en las proximidades de los abrigos toscas pinturas, e incluso bajorrelieves (Gómez-Barrera, 1993b: 6-7), que a nadie engañan y sí estropean, y mucho, el conjunto artístico y natural de Valonsadero. 

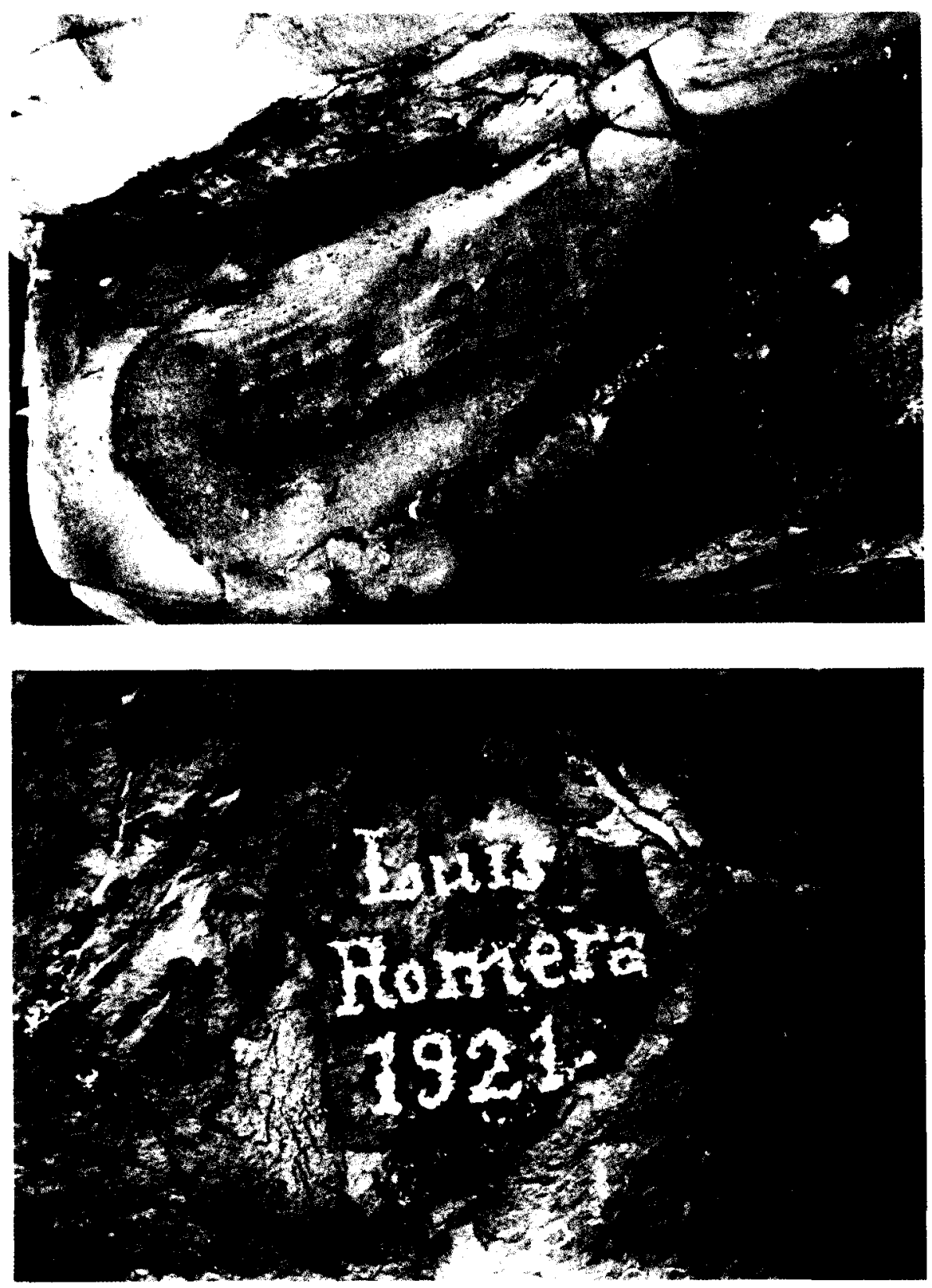

Figura 1. Grafitos modernos, pintados a carbón o grabados por picado, en los paneles con arte esquemático de Los Peñascales III y La Cerrada de la Dehesa (Fotografías de P.L. Yagüe y J.A. Gómez-Barrera, respectivamente). 


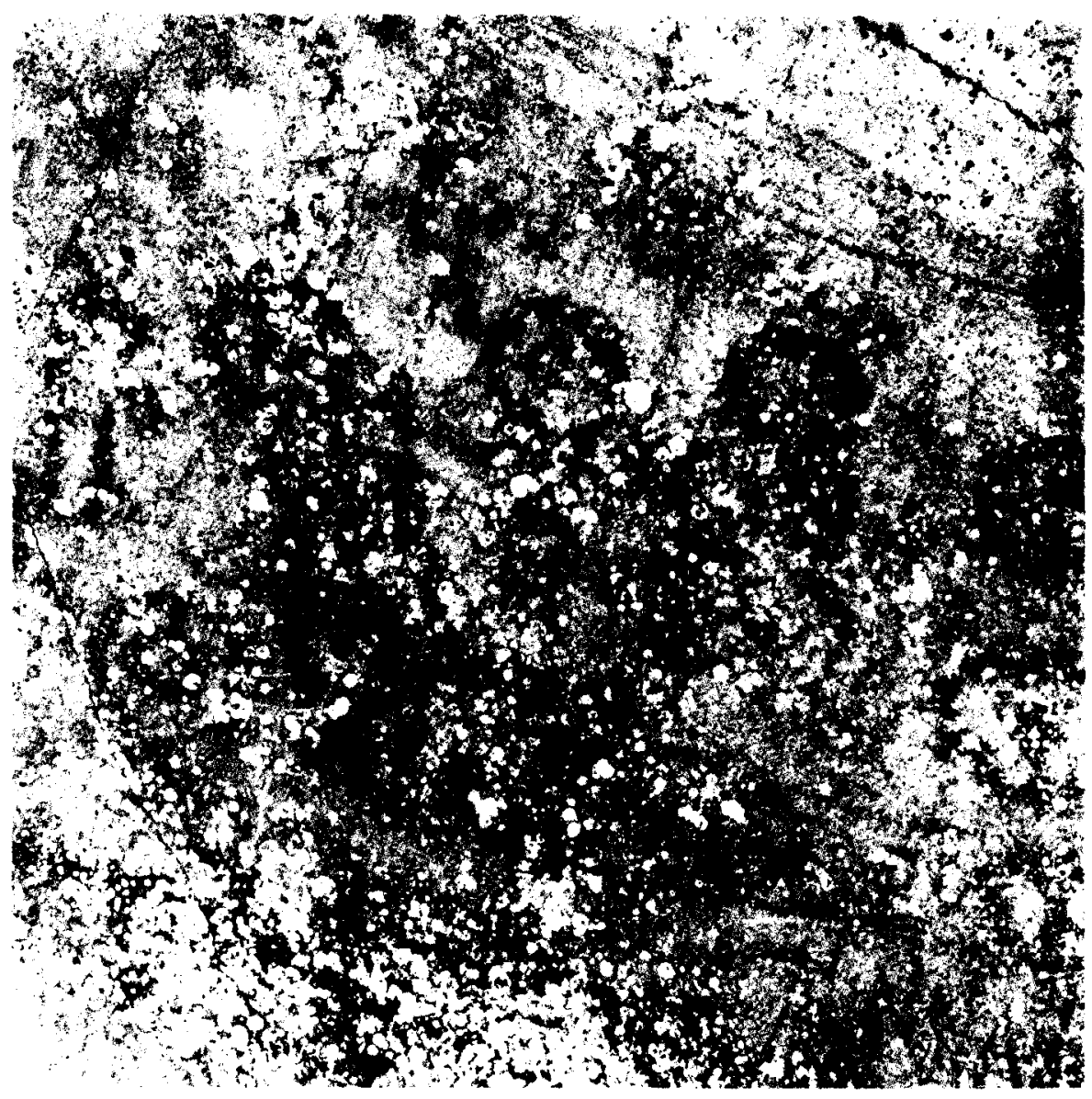

Figura 2. Inscripción a carboncillo, con vitores alusivos a las Fiestas de San Juan de Soria, trazada sobre los motivos centrales del Covachón del Puntal, donde, por lo demás, se desarrolla peligrosamente una amplia colonia de líquenes blancos (Fotografia A. Plaza).

En el verano de 1981 denunciamos, ante el Excmo. Ayuntamiento de Soria, el arranque -o, en el mejor de los casos, el desprendimiento- de un fragmento triangular de la escena de caza de El Mirador ${ }^{5}$. Aunque el

Para la historiografia particular de Valonsadero - y también para la reconstrucción hipotética de sus pinturas - puede contemplarse las imágenes del sector referido de El Mirador que publicara Ortego en 1951 (Lám. III: fig. 2. ${ }^{a}$ ) y 1952 (fig. 18) y en su propio, y fraccionado, calco, editado por vez primera, y ünica, en 1958 (fig. 67:3). En 1982 publicamos nuestro primer calco, realizado en 1980 (Gómez-Barrera, 1982: fig. 21), y ya recogemos en él un ligero desconchado que se verá aún mayor en la lám. VI:B (pág. 270), fotografía captada por A. Plaza en enero de 1982. 
daño era, y es, irreparable (Fig. 3) la denuncia surtió efectos inmediatos y en diciembre de ese mismo año se instalaban en Valonsadero las doce primeras verjas ${ }^{6}$ que habrían de cerrar los abrigos del Peñón del Majuelo, Abrigo del Tubo, Las Covatillas, Covachón del Puntal, La Lastra, El Mirador, La Umbría del Colladillo, Peña Somera, Peñón de la Visera, Peñón del Majuelo y Los Peñascales 1-ll y III. Sucesivas actuaciones del propio Ayuntamiento, del Museo Numantino y de la Junta de Castilla y León completarían la protección del resto de los abrigos ${ }^{7}$.

Aunque pueda parecer lo contrario, nunca nos pareció el cerramiento de los abrigos el método más adecuado para evitar el deterioro antrópico de las pinturas. Las verjas, en sí, resultan un reclamo inmediato, excitan la curiosidad del paseante casual y pueden dar lugar a una reacción destructiva, en aquellas personas no dispuestas a aceptar una barrera física en un monte público (Casanovas y Alonso, 1984). Las verjas, en Valonsadero, se instalaron siempre con el asesoramiento técnico adecuado y con la pretensión, no tanto de aislar al visitante de los paneles pintados, cuanto de evitar los accidentes comunes al desconocimiento de su existencia o de su nula valoración (Fig. 4). Con ellas se ha impedido el continuo roce de la pared-soporte por el ganado, la realización de hogueras a sus pies y la humidificación de sus paredes, con lo que además de prevenir han ayudado a la recuperación del color de alguna de las figuras, hasta hace no mucho ennegrecidas por el humo (Gómez-Barrera, 1992a: $25-28$, Figs. 8 y 10) ${ }^{8}$.

Cuenta $F$. Terrel, en uno de sus artículos periodísticos reeditados recientemente por Diario de Soria (1994: 8-9), cómo durante los años veinte se privó a los ganaderos del tradicional arriendo de los pastos del monte, al adjudicarse éste a un conocido empresario para la explotación de la

6 La noticia fue ampliamente tratada en Plaza Mayor (núm. 1, diciembre 1981 y núm. 15, octubre de 1982), Boletín Informativo del Excmo. Ayuntamiento de Soria.

7 En la actualidad, y como consecuencia de la actuación de la citada Comisión Institucional, se está cerrando el Abrigo $W$ del Peñón de la Sendilla y se ha prolongado la verja del Abrigo del Tubo, al haberse descubierto nuevas pinturas fuera del recinto hasta ahora protegido. Estas realizaciones no han de ser las últimas y sí más bien el comienzo de un nuevo plan de protección que ha de llevar consigo el cerramiento de aquellos abrigos (Los Isaces I y II, Abrigo / del Barranco de Valdecaballos, Abrigo del Cubillejo, Las Marmitas, Abrigo de Los Peñones, Abrigo del Pozo. Peñón de la Solana, Risco del Portón de la Cañada y Murallón del Puntal) que bien por situarse muy alejados de las zonas de máxima afluencia de público o bien por contener un número escaso de figuras y poco visibles se había desestimado, en principio, su cercado. Una segunda actuación debería afectar a La Cueva Larga y Cueva Grande de Oteruelos y al último de los abrigos descubiertos en Fuentetoba: La Cerrada de la Dehesa.

8 Este fue el caso de La Cuerda del Torilejo, Covachón del Puntal, Peñón de la Visera y, de manera especial, del Rísco del Portón de la Cañada del que pudimos calcar sus pinturas, por vez primera, en 1989. 

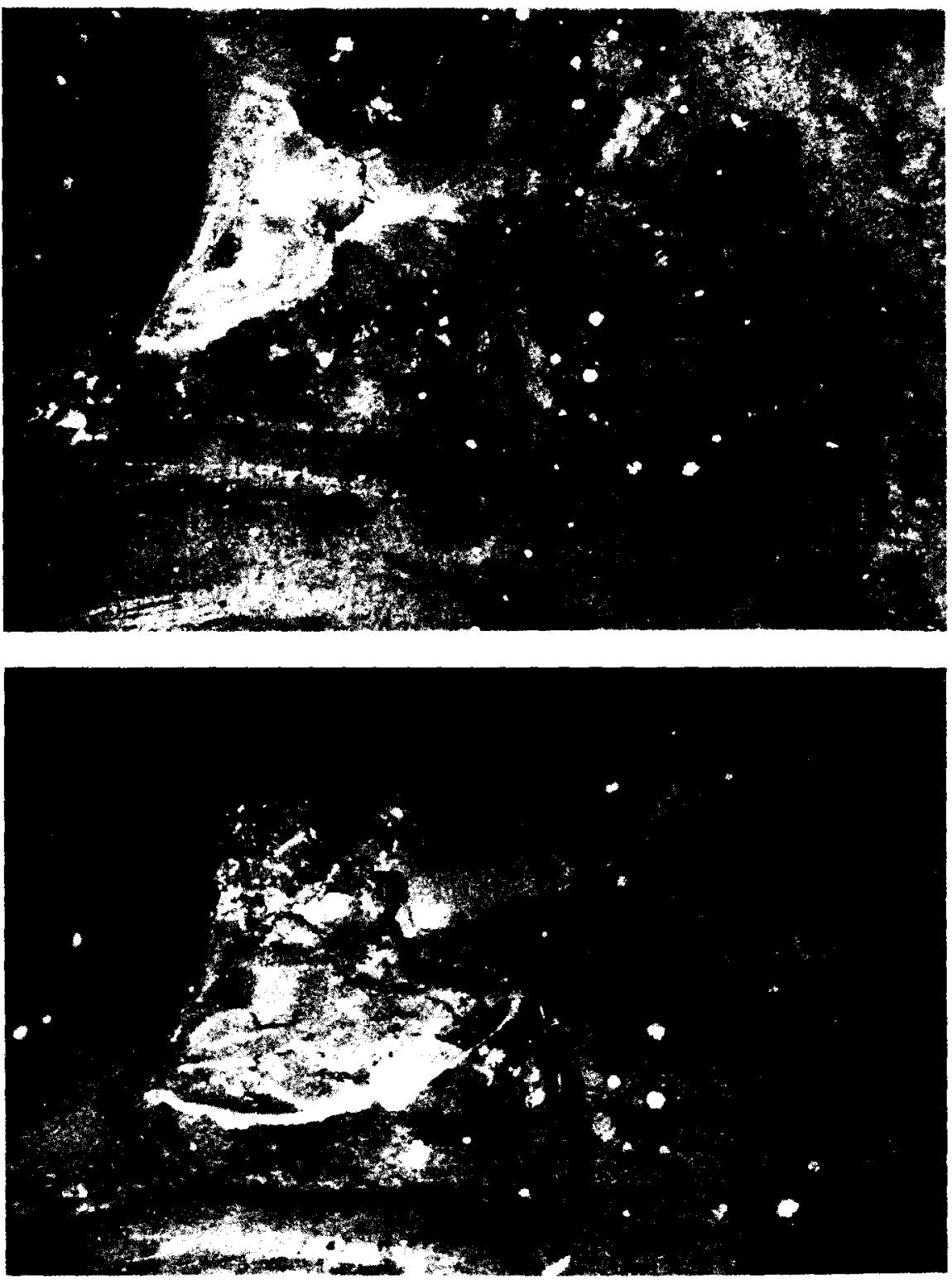

Figura 3. La fotografía superior, tomada por J.A. Gómez-Barrera en octubre de 1979, denunciaba ya un amplio lascado en el panel central de El Mirador; la fotografia inferior, del mismo autor, recoge el mismo sector del abrigo con posterioridad al verano de 1981 y en ella puede apreciarse el aumento considerable del desprendimiento intencionado de la costra pintada. Obsérvese, también, y en ambas imágenes, el intenso rayado producido por un instrumento metálico sobre alguno de los motivos. 

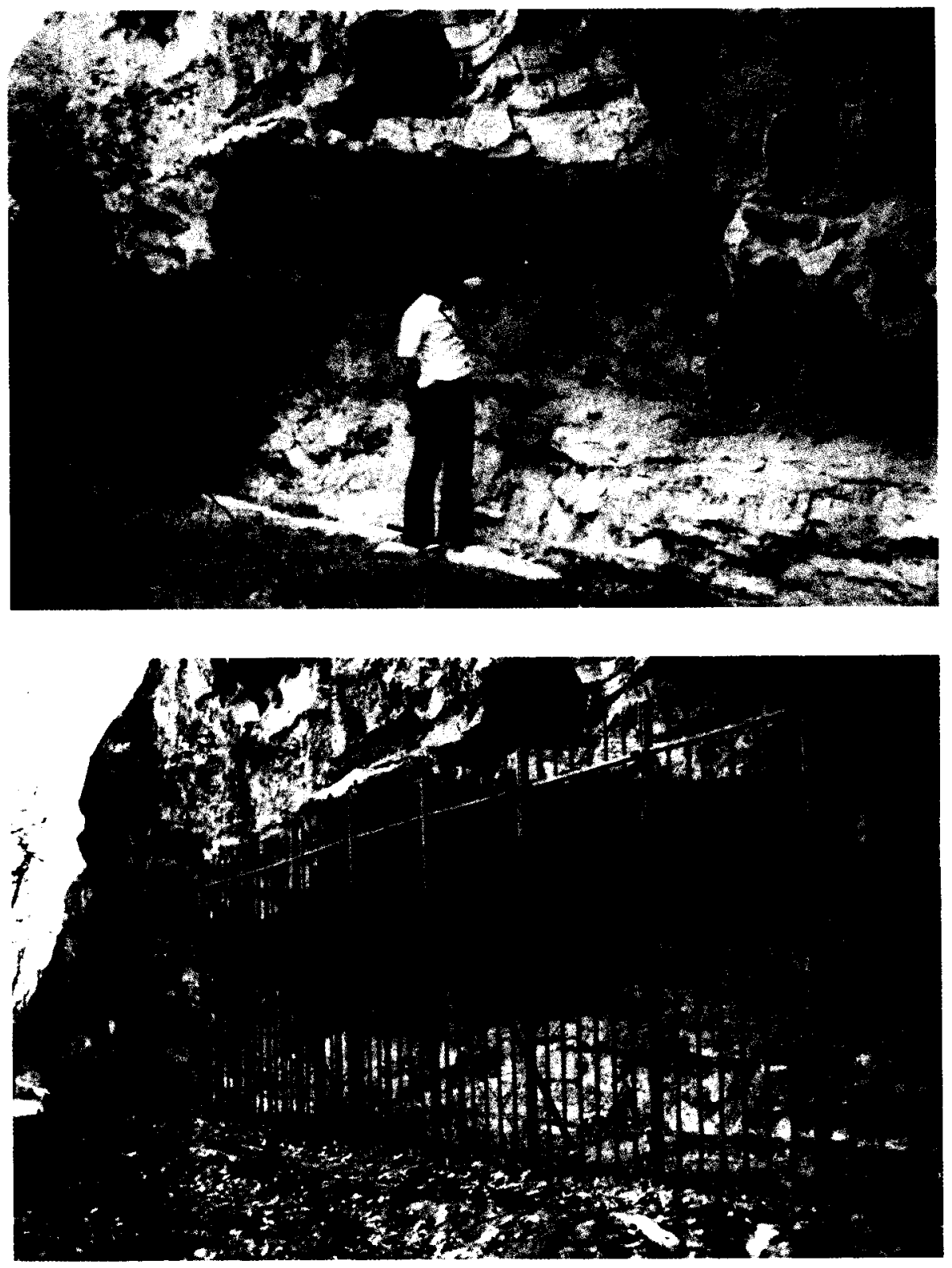

Figura 4. Vistas de El Mirador antes (verano de 1980) y después (otoño de 1981) de la colocación de sus verjas protectoras (Fotografías de J.J. Ruiz Ezquerro y Juan A. GómezBarrera). 
caza. En poco tiempo las praderas y lomas del lugar se vieron pobladas de conejos que eran cazados algunos en cacerías organizadas, o por los cazadores amigos del arrendatario, y los más por medio de hurones. Sin entrar en más detalles, no es difícil responsabilizar a esta práctica del daño antrópico causado a las pinturas de Peña Somera, con el anuncio "acotado de caza ojo".

Mas en este caso nos quedan, si bien estropeadas, las pinturas. $Y$ hemos de alegrarnos porque conocemos, también, que, posiblemente desde el siglo XII, se vendría explotando la arenisca del lugar. Nada dice el Fuero - que habla de pastos, usos forestales, caza y pesca-, ni las Ordenanzas para la custodia y guarda del Monte y Dehesa de 1526 -que reproducen las disposiciones forales- ni las de 1663, que regulaban los aprovechamientos pecuarios de Valonsadero, con el expreso propósito de simplificar los establecido en el Fuero (Martín de Marco, 1990; Diago Hernándo, 1993; Pérez Romero, 1995). Y sin embargo, quedan en el monte profundas huellas de una treintena larga de explotaciones de su piedra como sillares para la construcción de ermitas, iglesias y caseríos de la ciudad y localidades cercanas (Fig. 5) ${ }^{9}$. Ni siquiera cabe preguntarse por el número de estaciones con arte rupestre perdidas por el uso indiscriminado de estas canteras.

Con todo, y pese a que el mayor peligro para la conservación de las pinturas sea como estamos viendo la actividad humana, no hemos de olvidar, y actuar sobre ella si es posible, la degradación natural.

$Y$ en este sentido, en el núcleo artístico de Valonsadero, llama especialmente la atención el Covacho del Morro, donde una colonia de líquenes va avanzando, lenta pero inexorablemente, por toda la superficie pintada (Gómez-Barrera, 2000). Sabemos de casos, como los de Cueva Cimera y Cueva del Tajo Amarillo en La Laguna de la Janda (Cádiz), cuyas comunidades de líquenes han cubierto la totalidad de la superficie ocupada por las pinturas, perdiéndose éstas para siempre (Mas i Cornellà et alii: 1994: 106; Mas i Cornellà: 1998: 338 y 404, respectivamente). En el propio Valonsadero, Ortego habla de la existencia, en una oquedad situada a la derecha de Peña Somera, de figuras animalísticas de la misma especie y de idéntica coloración que las de su panel principal, sólo que resultan apenas visibles por la acción de musgos (Ortego, 1951: 293); en la

\footnotetext{
9 El tema no bien estudiado aún puede, sin embargo, apreciarse en el texto y en el mapa geológico de Valonsadero realizado por $P$. Latorre Macarrón, E. Sanz Pérez, C. Pascual y M. P. Hernández e incorporados, en 1999, al tríptico divulgativo de la geología del monte que publicó el Excmo. Ayuntamiento de Soria y estos mismos autores redactaron.
} 
actualidad, en dicha oquedad no hay otra cosa que una potente capa liquénica. La posibilidad de que esto mismo ocurra en Covacho del Morro es tan grande que siempre nos ha preocupado, y en la medida de nuestras posibilidades hemos reclamado de la Administración la realización de estudios que valoraran la degradación de las pinturas y las medidas preventivas que pudieran tomarse.

Uno de esos estudios, encargado por la Consejería de Cultura y Bienestar Social de la Junta de Castilla y León, fue llevado a cabo en 1990 por P.L. Yagüe Hoyal; otro más reciente, auspiciado por la Comisión Institucional de Trabajo sobre el Plan de Valonsadero del Excmo. Ayuntamiento de Soria, sería redactado por E. Sanz Pérez. De ambos extraeremos a continuación aquellos datos que nos puedan ayudar a completar nuestra visión sobre el estado actual de conservación de las pinturas y las posibles medidas a tomar para su salvaguarda, no sin antes detenernos, si quiera brevemente, en la situación y geomorfología del monte y en el apoyo analítico en que ambos trabajos se basaron -y el de Sanz Pérez, además, complementó-, consistente en un minucioso y detallado estudio climatológico, en el análisis de la degradación de las areniscas del Abrigo del Tubo y de El Mirador y su incidencias en sus pinturas rupestres llevado a cabo por $R$. Fort y $M$. Bustillo y en un primer, y hasta ahora único, examen del pigmento pictórico utilizado y de las betas rojizas de las propias areniscas que constituyen los abrigos rocosos y de las que aquél sería extraído.

\section{ANALITICA PARTICULAR DE VALONSADERO Y ESTUDIO DE ALTERACIÓN DE LAS ARENISCAS DEL “ABRIGO DEL TUBO» Y DE «EL MIRADOR»}

\subsection{Situación y breves notas geomorfológicas del Monte Valonsadero}

La dehesa y monte de Valonsadero se sitúa a unos $10 \mathrm{Kms}$ al noroeste de la ciudad de Soria, apareciéndonos limitado al Norte por la curva del río Duero que sirve de frontera entre el monte y los términos de Dombellas y Canredondo, al Este con los de Garray y Soria, al Sur con Golmayo y Fuentetoba y al Oeste con el término de Pedrajas. En total, al hablar y referirnos a Valonsadero lo hacemos a un espacio de 2.808 Hectáreas que debió ser mucho más amplio en otros momentos de su Historia y que sin duda se confundiría con las cañadas y praderios de Fuentetoba, Pedrajas y Oteruelos allá cuando, quizá desde el III milenio a. de $C$., sus areniscas fueron utilizadas por sus primitivos y ocasionales 
pobladores para plasmar esquemas, figuras y signos que articulaban creencias, formas de vida o, en todo caso, enigmáticos mensajes.

Desde un punto de vista geológico, la mayor parte de los terrenos que afloran en Valonsadero pertenecen a la Facies Purbeck-Weald constituidos aquí por materiales detríticos, entre los que destacan las alternancias de bancos de arenisca con limos y arcillas de color rojo y verdoso (Fig. 5).

Estas capas de arenisca suelen tener un espesor entre 2 y $10 \mathrm{~m}$, un desarrollo longitudinal variable, un color en superficie amarillento, ocre o rojizo y aspecto homogéneo, aunque hay zonas más blandas; se hace patente la estratificación cruzada de tipo planar y de surco, y petrográficamente pueden ser clasificadas como subarcosas y arcosas, estando constituidas por cuarzo, feldespatos potásicos y mica, de grano medio y matriz de naturaleza arcillosa.

La roca presenta una cementación de tipo ferruginoso, que engloba a los clastos y a la matriz y parcialmente a la porosidad.

Los últimos depósitos reconocibles son los pleistocenos y los cuaternarios antiguos de las cascajeras altas, más los muy recientes de los arrastres pluviales y fluviales del fondo de los cauces y vaguadas.

E. Sanz $(1994,1996)$ ha estudiado, en los últimos años, la alteración y modelado de las areniscas de la facies Purbeck-Weald del Noroeste de la Cordillera Ibérica, presentes en Valonsadero. En los relieves en cuesta propios de la zona, se ha desarrollado un micromodelado por meteorización muy peculiar, que caracteriza de alguna manera a dicha litología: en la superficie desnuda del reverso de las cuestas se localizan numerosas depresiones cerradas de pequeño tamaño o gnammas, canales de desagüe y grietas poligonales, mientras que el frente se encuentra afectado por tafonis y cavidades en la base, cuya formación está directamente relacionada con las características petrológicas de las areniscas y con ciertas condiciones ambientales climáticas actuales o pasadas que las han favorecido.

La tectónica se resuelve en estructuras sencillas, con pliegues de amplio radio y series monoclinales de buzamiento suave, predominando, como se ha dicho, los relieves en cuesta, donde el dorso coincide con el plano de estratificación superior, dando lugar a una plataforma estructural inclinada entre $15^{\circ}$ y $30^{\circ}$, y orientada de manera casi invariable en la dirección Este-Oeste.

La meteorización en la arenisca ha producido un retroceso progresivo del frente de la cuerda, generalizando asi una morfología en abrigos - de entre 0,5 y $6 \mathrm{~m}$ de altura-, en muchos de los cuales se observa 


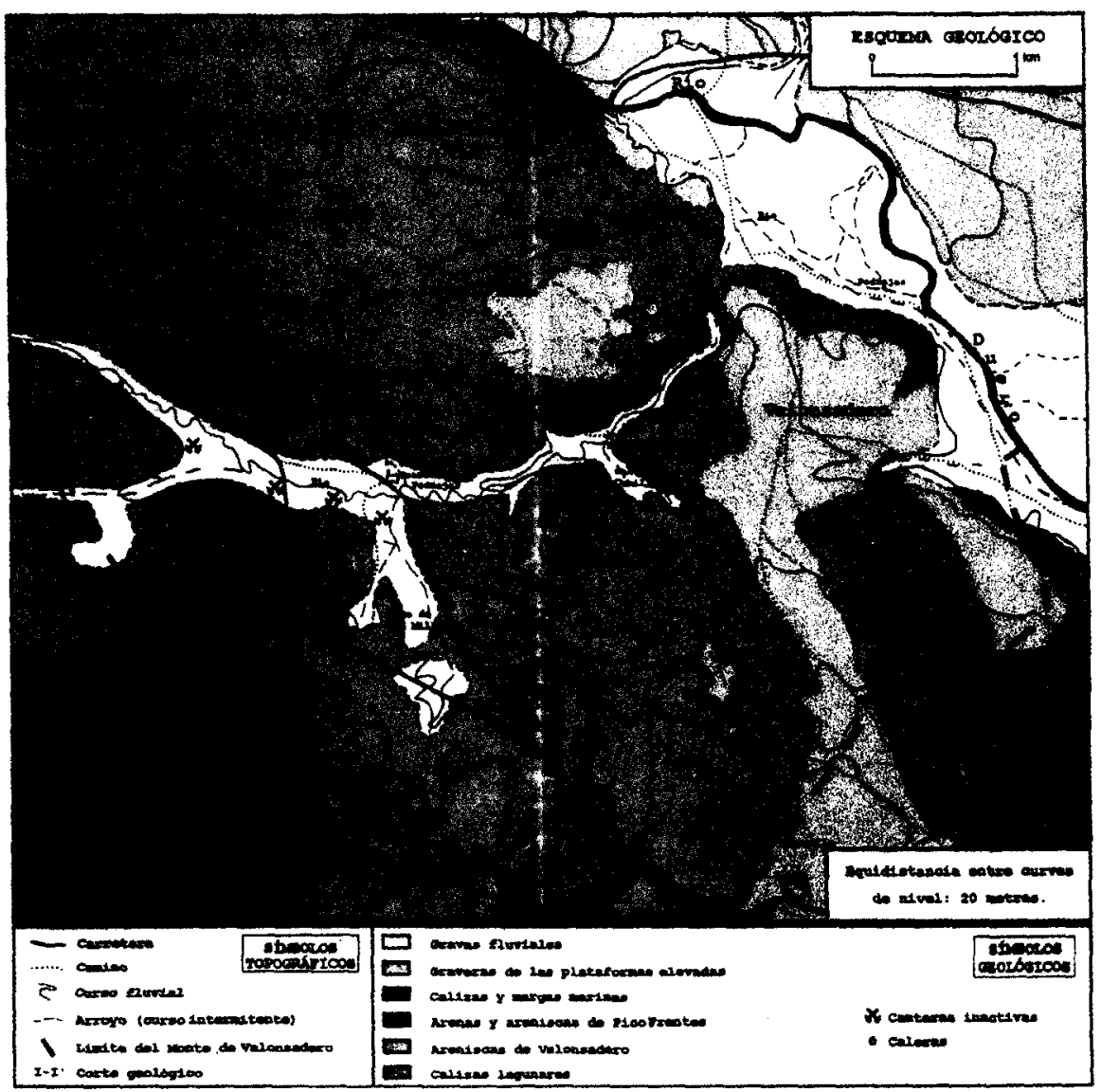

Figura 5. Esquema geológico de Valonsadero y Pico Frentes, según $P$. Latorre, $P$ Hernández, E. Sanz y C. Pascual.

una costra silícea que va desprendiéndose hasta que aflora la roca fresca. Este modelado tiene una tipología uniforme, con grandes abrigos alargados según la estratificación y con las paredes tan intensamente tafonizadas que resulta dificil distinguir cuando se trata de cavidades 0 de tafonis. El desarrollo de estos abrigos parece estar ligado con el alto grado de absorción de agua, característica petrofísica principal de las areniscas de Valonsadero.

Las pinturas rupestres esquemáticas de Valonsadero y su entorno fueron realizadas aprovechando estos micromodelados, y hemos de suponer que Pico Frentes desempeñaría un importante papel en el subconsciente 
de estos artistas y de los grupos poblacionales en general. Pico Frentes, situado al norte de la Sierra de Cabrejas, es un notable relieve definido geomorfológicamente como un típico sinclinal colgado (Sáenz, 1954 y 1955; Muñoz Jiménez, 1986). Sus $6 \mathrm{kms}$ de longitud -en dirección $\mathrm{W}$ a $\mathrm{E}$-, su altura máxima en torno a $1400 \mathrm{~m}$ y su desnivel entre 150 y $300 \mathrm{~m}$ sobre las áreas circundantes, debieron marcar, como lo hacen aún hoy, la vida de los pobladores (o de los visitantes) de la zona. Pico Frentes seria vigía, guía o punto de referencia constante en ese ir y venir, $y$ tal vez su influencia alcanzase cotas más elevadas, dificil de predecir por el hombre actual. Es significativo que a ambos lados de la sierra aparezcan estaciones pintadas y que, desde el pie mismo de éstas, se vea su silueta erguirse majestuosa sobre ellos (Gómez-Barrera, 1994: 19).

Precisamente en paralelo a la Sierra Cabrejas discurre el río Pedrajas (Gómez-Barrera, 1995), cruzando los términos de Villaverde, Cidones, Ocenilla, Pedrajas y Soria (Valonsadero), en una longitud no superior a los 17 $\mathrm{Kms}$. Desde su nacimiento - a la altura del $\mathrm{Km} 123,5$ de la carretera nacional Madrid-Sagunto - a su desembocadura - justo en el límite Este de Valonsadero, en el término de Garray- describe, en su perfil, una pendiente cóncava de no más de $100 \mathrm{~m}$ de diferencia entre la cota inicial $(1.120 \mathrm{~m})$ y la final $(1.020 \mathrm{~m})$, dando forma así a un descenso suave y un recorrido apacible.

Su caudal es escaso. Se alimenta de las aportaciones que le hacen los diferentes arroyos que llegan hasta su cauce; entre éstos cabe citar, por la izquierda, los de las cañadas de las Parideras (Cidones-Pedrajas) y Honda (Valonsadero) y, por la derecha, los de San Millán y Cubillo (ambos en Valonsadero).

Este, en apariencia, limitado caudal sirve, no obstante, para bañar y, a veces, anegar un suelo de monte alto en Villaverde, tierras de labor en Cidones, Ocenilla y Pedrajas y prados y monte alto, nuevamente, en Valonsadero.

\subsection{Climatología}

A partir de los datos obtenidos, entre 1961 y 1988, por el Observatorio Meteorológico "La Rubia», situado a tan sólo $7 \mathrm{kms}$. de Valonsadero, y los estudios de R. Archilla Aldeanueva $(1985,1987), P$. L. Yagüe Hoyal (1990) señalará, junto a la altitud del monte en torno a los $1060 \mathrm{~m}$ sobre el nivel del mar, la temperatura media anual del lugar $\left(10,2^{\circ} \mathrm{C}\right)$, su mínimo invernal en diciembre $\left(-15^{\circ} \mathrm{C}\right)$, su máximo en Julio $\left(37,6^{\circ} \mathrm{C}\right)$ y sus fuertes oscilaciones térmicas alcanzadas, también, en 
este mes. Calificará de muy abundante el número de días de heladas al año (98), alargará estadísticamente el invierno en Valonsadero hasta los 190 días y anotará $532,2 \mathrm{~mm}$ de precipitación media anual. Una humedad relativa de $66,1 \%$ y una presión atmosférica media anual de 670,8 $\mathrm{mm}$, ligeramente superior al valor medio normal $\left(670 \mathrm{~mm}\right.$ a $15^{\circ} \mathrm{C}$ y a $\mathrm{O}$ $m$ sobre el nivel del mar).

\subsection{Estudio de alteración de las areniscas del Abrigo del Tubo y de El Mirador}

El análisis de alteración de las areniscas del Abrigo del Tubo y de El Mirador que aquí se presenta, fue llevado a cabo por R. Fort y M. Bustillo en 1990 y se enmarca en el Estudio del estado de conservación de las pinturas rupestres del Monte Valonsadero (Soria) y proyecto para su restauración que la entonces Consejería de Cultura y Bienestar Social de la Junta de Castilla y León encargó a P. L. Yagüe Hoyal.

Así como la selección de dos abrigos de un total de 34 conocidos hasta el momento en este lugar facilitaría el estudio, la elección del Abrigo del Tubo y El Mirador y no otros se justificó por sus diferencias y por entender que, de alguna manera, podrian, en su diversidad, representar de forma mayoritaria las particularidades del conjunto. El Abrigo del Tubo viene dado por un afloramiento aislado de unos cinco metros de largo y una orientación N-S; El Mirador, por su parte, se localiza en un abrigo continuo con abundantes pinturas, a lo largo de unos $50 \mathrm{~m}$ y con una orientación de los estratos de NNW-SSE. El grado de conservación de las pinturas es, asimismo, diferente y mientras las areniscas del primero muestran gran deterioro las del segundo presentan una buena conservación.

A primera vista, y dadas las características climáticas de la zona y los efectos que se apreciaban sobre el soporte de las pinturas (descamación), parecía evidente que en el origen de la degradación de los distintos abrigos habría que situar la actuación del agua sobre la roca, por lo que se procedió a realizar una serie de ensayos encaminados a determinar el comportamiento de la roca ante la presencia del agua en sus tres estados (sólido, líquido y gaseoso). De este modo se procedió a medir la distribución de humedades en los dos abrigos estudiados, a la vez que se llevaron a cabo mediciones de temperatura y de humedad ambiental, tanto en el interior como en el exterior de los covachos. A estos ensayos in situ se añadió otros en laboratorio, que ayudaron al estudio petrográfico (análisis con microscopio de polarización y por 
Difracción de Rayos $\mathrm{X}$ ), al análisis de la actuación del agua sobre la roca y a la determinación de la alterabilidad por ciclos de humedad-sequedad y hielo-deshielo.

En sintesis, y siguiendo en todo momento el original de estos autores, sus resultados quedan reflejados en el texto que sigue.

\subsubsection{Petrografía}

Las areniscas de los abrigos estudiados de Valonsadero fueron clasificadas por R. Fort y M. Bustillo como abarcosas y arcosas, estando constituidas por cuarzo $(60-85 \%)$, feldespatos potásicos $(10-30 \%)$ y micas $(2-5 \%)$.

Los materiales, analizados por estos autores, correspondientes a los afloramientos del Abrigo del Tubo y El Mirador poseen granulometría muy similar, siendo de grano medio. Las areniscas del Tubo presentan un tamaño medio y máximo de $0,35 \mathrm{~mm}$ y $0,55 \mathrm{~mm}$, respectivamente, mientras que las de El Mirador alcanzan 0,30 $\mathrm{mm}$ y $0,61 \mathrm{~mm}$. Los granos son subangulosos y con una selección de tamaños buena. Los componentes fundamentales, para ambos afloramientos, son cuarzo monocristalino, cuarzo policristalino, feldespato potásico y moscovita. Como componentes accesorios se encuentran chert, circón y turmalina. En los materiales correspondientes a El Mirador aparecen, aunque muy degradadas, algunas biotitas, pero en forma muy minoritaria.

La matriz es de naturaleza arcillosa y no supera el 5\%; está constituida, básicamente, por illitas y en menor medida por caolinitas. Su origen es diagenético, al proceder de los descomposición de cantos blandos de arcilla y de la transformación de los feldespatos potásicos y moscovitas en illitas, y éstas, a su vez, en caolinita. El grado de alteración de estos minerales es diferente en ambos afloramientos, siendo mayor en las areniscas del Abrigo del Tubo.

Los materiales presentan una cementación de tipo ferruginoso que engloba a los clastos y a la matriz, rellenando, incluso, a veces parcialmente la porosidad. Este cemento procede, probablemente, de la alteración de minerales ricos en hierro (biotitas, hematites, otros minerales opacos, etc.). El volumen de cemento en la roca es muy variado, dándose una costra superficial que no liega a superar el centímetro de grosor, en la que disminuye la presencia de micas $y$, en menor grado, la de feldespatos, pero en la que la cementación puede alcanzar hasta un $15-20 \%$ del total.

La porosidad de la roca es del tipo intergranular y no supera el $20 \%$. 


\subsubsection{Análisis mineralógico}

Los resultados mineralógicos obtenidos por Difracción de rayos $X$ concuerdan, a grandes rasgos, con los presentados en el apartado anterior. En la Tabla núm. 1 pueden verse los derivados del análisis semicuantitativo de los difractogramas de cuatro muestras analizadas:

Tabla 1. Resultados del análisis mineralógico semicuantitativo

\begin{tabular}{llccc}
\hline & & \multicolumn{3}{c}{ Mineralogía (\%) } \\
\hline Muestra & Características & Cuarzo & Fto. K & Filosilicatos \\
\hline Abrigo del Tubo & Muestra fresca & 85 & 9 & 6 \\
Abrigo del Tubo & Corteza alteración & 75 & 17 & 8 \\
Abrigo del Tubo & Muestra alterada & 60 & 30 & 10 \\
El Mirador & Muestra fresca & 82 & 11 & 7 \\
\hline
\end{tabular}

\subsubsection{Variaciones de la humedad y de la temperatura ambiental}

Las Tablas núms. 2 y 3 muestran las variaciones apreciadas a lo largo de un día, en la evolución de la temperatura y humedad ambiental en el interior del Abrigo del Tubo y de El Mirador, así como su contraste con respecto a las condiciones ambientales del exterior:

Tabla 2. Resultados de la temperatura ambiental $\left({ }^{\circ} \mathrm{C}\right)$

\begin{tabular}{llrrrrr}
\hline & & \multicolumn{3}{c}{3.1 .1990} & 4.1 .1990 \\
\hline Abrigo del Tubo & & $12 \mathrm{~h}$ & $13,30 \mathrm{~h}$ & $15 \mathrm{~h}$ & $16,30 \mathrm{~h}$ & $10 \mathrm{~h}$ \\
& Exterior & 6,0 & 5,7 & 5,8 & 5,9 & 2,9 \\
& Interior & 6,4 & 6,2 & 6,2 & 6,1 & 3,3 \\
& Variación & $+0,4$ & $+0,5$ & $+0,4$ & $+0,2$ & $+0,4$ \\
El Mirador & Exterior & 5,5 & 5,4 & 5,3 & 5,1 & 2,8 \\
& Interior & 6,0 & 5,9 & 5,6 & 5,4 & 3,7 \\
& Variación & $+0,5$ & $+0,5$ & $+0,3$ & $+0,3$ & $+0,9$ \\
\hline
\end{tabular}

Es decir, en el interior de los abrigos existe una temperatura ligeramente superior con respecto al exterior, pudiendo ser cuantificada esta diferencia entre $0,4^{\circ}$ y $0,5^{\circ}$. Además, dadas las condiciones de orientación del abrigo de El Mirador (hacia zonas más septentrionales), su temperatura es más baja que la existente en el Abrigo del Tubo, con una 
diferencia que llega a ser de $0,6^{\circ}$ a primeras horas de la mañana. Con respecto a la humedad, suele ser más alta (aproximadamente un $0,3 \%$ ) en las zonas internas del abrigo. También comparativamente existen diferencias en las humedades entre los dos abrigos: la media obtenida en el Abrigo del Tubo es de $84,2 \%$, mientras que en El Mirador es de $86,2 \%$.

Tabla 3. Resultados de la humedad relativa ambiental (\%)

\begin{tabular}{lllllll}
\hline & & \multicolumn{4}{c}{3.1 .1990} & \multicolumn{1}{c}{4.1 .1990} \\
\hline & & $12 \mathrm{~h}$ & $13,30 \mathrm{~h}$ & $15 \mathrm{~h}$ & $16,30 \mathrm{~h}$ & $10 \mathrm{~h}$ \\
\hline Abrigo del Tubo & Exterior & 81,8 & 85,7 & 84,5 & 83,3 & 85,7 \\
& Interior & 82,5 & 84,5 & 84,1 & 83,7 & 87,0 \\
& Variación & $+0,7$ & $-1,2$ & $-0,4$ & $+0,4$ & $+1,3$ \\
El Mirador & Exterior & 82,0 & 85,0 & 86,4 & 87,8 & 89,6 \\
& Interior & 82,2 & 85,0 & 86,4 & 88,0 & 89,9 \\
& Variación & $+0,2$ & - & - & $+0,2$ & $+0,3$ \\
\hline
\end{tabular}

Las medidas llevadas a cabo a las horas $13,30,15$ y 16,30 se tomaron con lluvia.

\subsubsection{Distribución de humedades sobre el soporte de la pintura}

La humedad medida directamente sobre la roca muestra el estado de conservación del soporte de las pinturas.

En el Abrigo del Tubo los contenidos más altos de humedad (40-45\%) se presentan en las zonas más deterioradas de la roca, precisamente allí donde los encostramientos han desaparecido por la descamación. Por el contrario, en las zonas donde se conserva el encostramiento, y con él la pintura, la humedad es notablemente inferior (13-18\%).

La distribución de humedades también detecta el efecto de la humedad capilar procedente del sustrato; así, en éste las humedades presentan valores del $430 \%$, que van disminuyendo al ascender hasta alcanzar cantidades del $25 \%$. Este efecto solo alcanza unos $30 \mathrm{~cm}$, aunque en algunos puntos, precisamente donde el grado de alteración de la roca es mayor, puede llegar a alcanzar un metro. También se aprecia como en los bordes del afloramiento, tanto en su lateral derecho como en la parte superior, existen valores de la humedad del $40 \%$, la cual va disminuyendo hacia el interior del abrigo. Este comportamiento es debido, no solo al efecto de la capilaridad, sino también al de la percolación. Sin embargo, desde un punto de vista global, se puede afirmar que las humedades presentes en el Abrigo del Tubo son debidas básicamente a los efectos de capilaridad, junto con la absorción de la humedad ambiental (Fig. 6). 

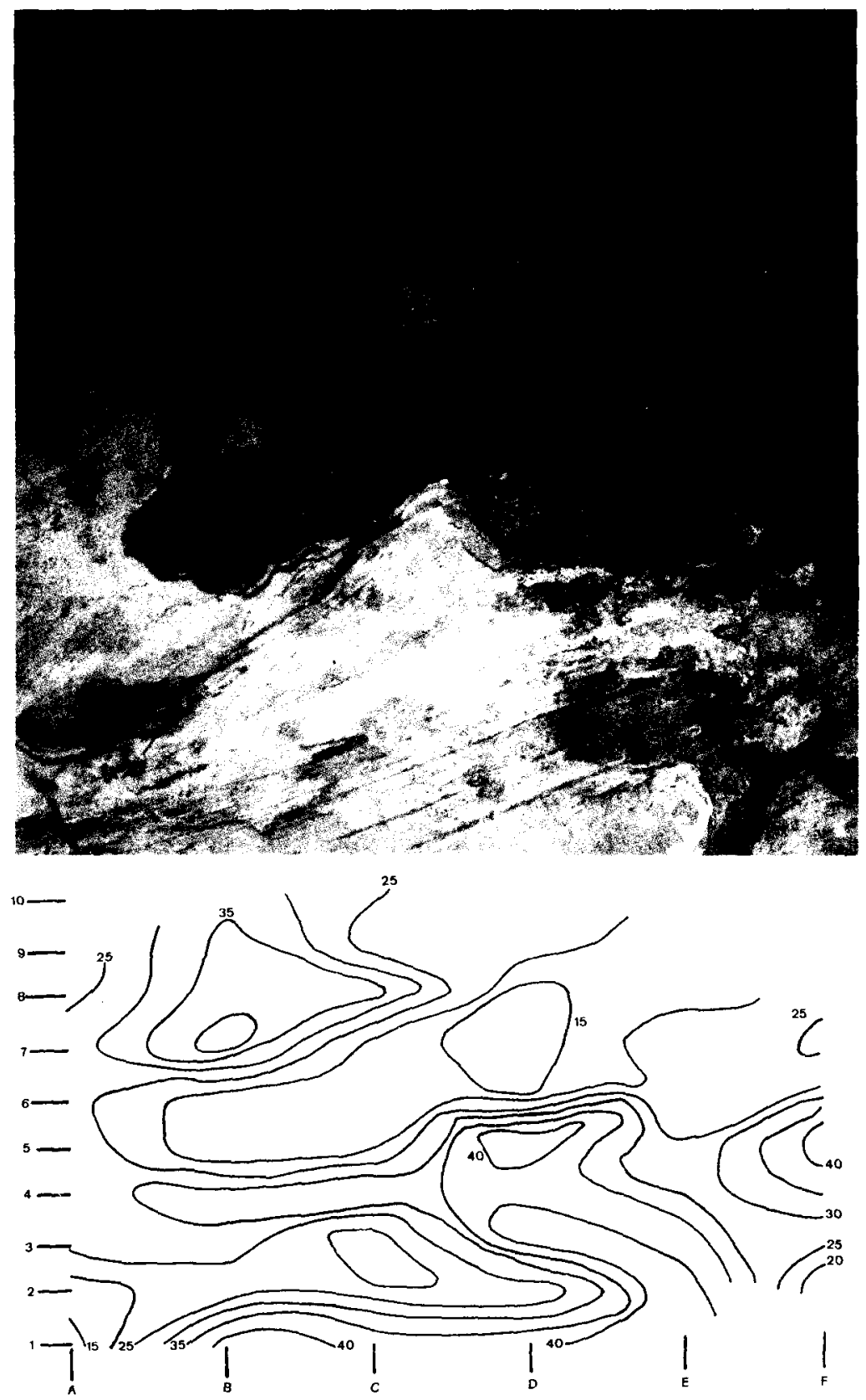

Figura 6. Abrigo del Tubo (fotografía de A. Plaza) y distribución de sus humedades con valores expresados en \%, según R. Fort y $M$. Bustillo. 

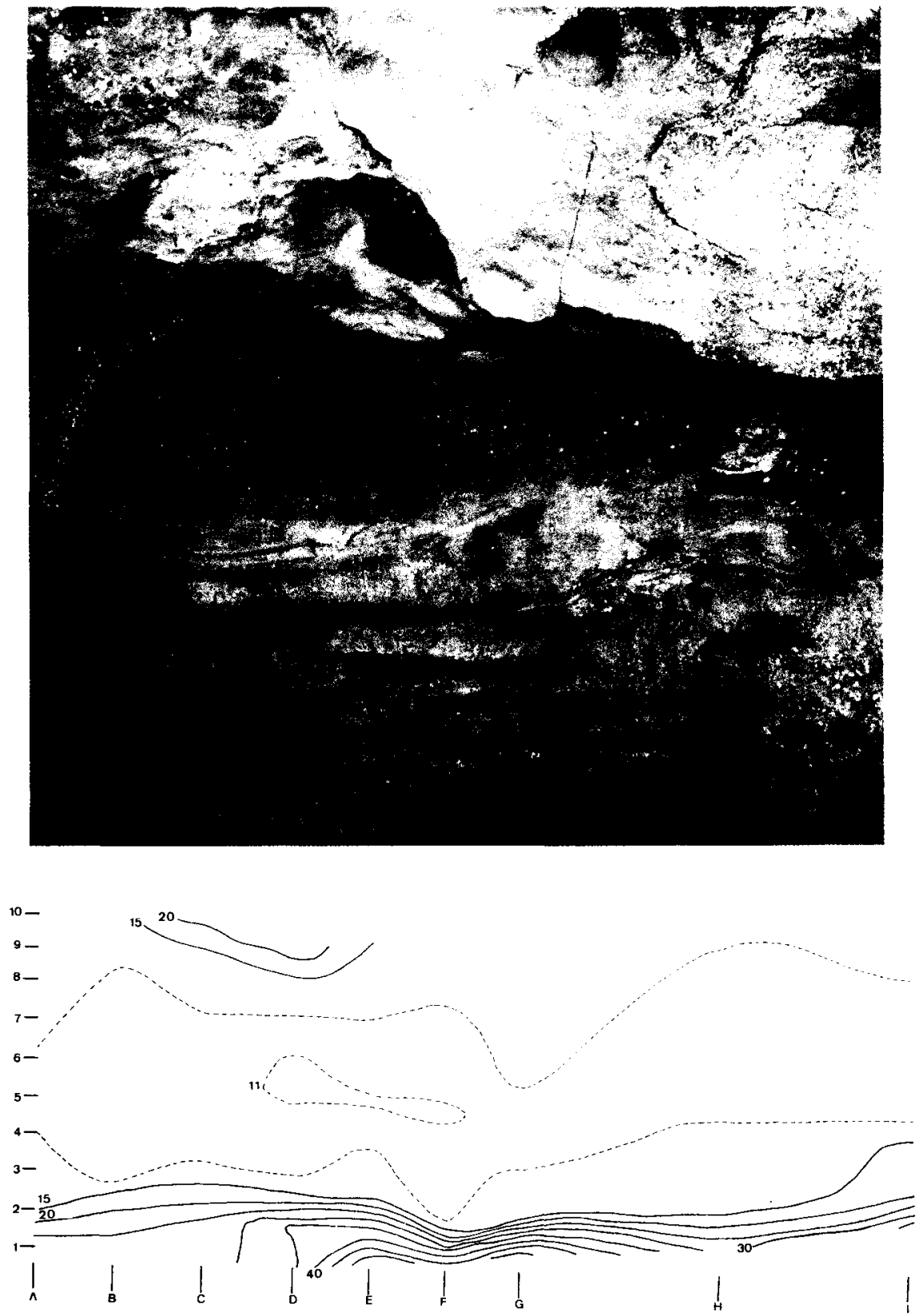

Figura 7. Detalle del abrigo de El Mirador (fotografia de A. Plaza) y distribución de sus humedades con valores expresados en \%, según $R$. Fort y $M$. Bustillo. 
En cuanto al abrigo de El Mirador, la distribución de humedades en la arenisca refleja el escaso grado de alteración, motivado por la conservación del encostramiento, con lo que se obtienen humedades entre el 8 y el $15 \%$. En este abrigo queda patente el efecto de la humedad capilar, existiendo, en las zonas de contacto con el sustrato, humedades del $54 \%$, las cuales disminuyen progresivamente hasta el $15 \%$ a una altura entre $30-45 \mathrm{~cm}$ (Fig. 7).

\subsubsection{Ensayos del comportamiento del agua en el soporte}

Se llevaron a cabo ensayos sobre el contenido del agua en saturación ${ }^{10}$, sobre la absorción libre de agua ${ }^{11}$, la absorción del vapor de agua ${ }^{12}$, la capilaridad ${ }^{13}$ y la evaporación ${ }^{14}$.

Los resultados obtenidos en el ensayo sobre el contenido de agua en saturación quedan sintetizados en la tabla núm. 4 :

Tabla 4. Contenido de agua en saturación

\begin{tabular}{lcc}
\hline & Abrigo del Tubo & El Mirador \\
\hline Agua de saturación (Ws) & $8,92-9,40 \%$ & $7,20-7,71 \%$ \\
Porosidad accesible (no) & $19,04 \%$ & $15,86 \%$ \\
Porosidad total & $23,56 \%$ & $18,85 \%$ \\
Grado de relleno & $80,81 \%$ & $84,14 \%$ \\
Densidad real & $2.638 \mathrm{~kg} / \mathrm{m}^{3}$ & $2.617 \mathrm{~kg} / \mathrm{m}^{3}$ \\
Densidad aparente & $2.135 \mathrm{~kg} / \mathrm{m}^{3}$ & $2.202 \mathrm{~kg} / \mathrm{m}^{3}$ \\
\hline
\end{tabular}

El estudio de la absorción libre de agua con respecto al tiempo, en ambos abrigos, muestra un comportamiento semejante, y viene dado por

10 El coeficiente de saturación define el volumen máximo de agua que puede absorber la roca, expresado en relación al peso o volumen de la misma, e indica, asimismo, la porosidad accesible al agua. El ensayo se llevó a cabo en vacío, sobre probetas cilíndricas de $65 \mathrm{~mm}$ de largo por $21,5 \mathrm{~mm}$ de diámetro.

11 Definida como cantidad de agua que absorbe la roca en un tiempo determinado a la presión atmosférica (por inmersión total en agua), expresado en forma de porcentaje en relación a la roca seca.

12 O cantidad de vapor de agua que absorbe la roca en un tiempo determinado, a presión atmosférica y a unas condiciones concretas de temperatura y humedad ambiental. El resultado se expresa en forma de porcentaje con respecto a la roca seca.

13 Capacidad que tiene la roca para absorber agua procedente de sustratos inferiores, asi como la altura máxima a la que aquella puede ascender.

${ }_{14}$ O pérdida progresiva de agua por evaporación, en condiciones ambientales y en función del tiempo. 
una absorción rápida en los primeros minutos del ensayo y una posterior estabilización. El contenido del agua es ligeramente distinto en ambos afloramientos: mientras la muestra del Abrigo del Tubo absorbe un 4,17\% en los primeros 100 segundos, la muestra de El Mirador tiene una capacidad de absorción de $2,66 \%$ en el tramo de absorción rápida, en un periodo de duración ligeramente superior a 400 segundos. Con respecto al grado de saturación en función del tiempo se observa un comportamiento semejante, tal y como puede verse en la tabla núm. 5. Finalmente el grado de saturación, a la conclusión del ensayo (172 horas), muestra como las areniscas del Abrigo del Tubo alcanzan unos valores mucho más altos $(61,11 \%)$ que las correspondientes al abrigo de El Mirador $(54,32 \%)$.

Tabla 5. Absorción libre de Agua

\begin{tabular}{lcc}
\hline & Abrigo del Tubo & El Mirador \\
\hline Tiempo de absorción rápida (seg) & 100 & 400 \\
Coef. de saturación rápida (seg. 1/2) & 3,92 & 1,37 \\
Coef. de saturación lenta (seg. 1/2) & 0,02 & 0,02 \\
Grado de saturación (1 hora) & $48,08 \%$ & $39,19 \%$ \\
Grado de saturación (48 horas) & $54,97 \%$ & $46,49 \%$ \\
Grado de saturación (172 horas) & $61,11 \%$ & $54,32 \%$ \\
\hline
\end{tabular}

A grandes rasgos, el ensayo de absorción del vapor de agua y el grado de saturación concretó que los resultados son similares para ambas muestras, al presentar un tramo inicial de pendiente elevada, un tramo de estabilidad durante el proceso de absorción y, por último, un tramo de absorción más lenta hasta llegar a su estabilidad final. A pesar de esta similitud, es necesario establecer algunas matizaciones sobre el comportamiento de las muestras durante la absorción del vapor de agua, matizaciones que se recogen en la tabla núm. 6 :

Tabla 6. Absorción de Vapor de Agua

\begin{tabular}{lcc}
\hline & Abrigo del Tubo & El Mirador \\
\hline Inicio de la absorción rápida & $900 \mathrm{seg}$. & $400 \mathrm{seg}$. \\
Inicio de la estabilidad & $1.600 \mathrm{seg}$ & $900 \mathrm{seg}$. \\
Inicio de la absorción lenta & $32.400 \mathrm{seg}$. & $2.500 \mathrm{seg}$. \\
Coeficiente de saturación rápida & 0,278 & 0,025 \\
Coeficiente de saturación estabilidad & $-0,003$ & 0,007 \\
Coeficiente de saturación lenta & 0,014 & 0,014 \\
Grado de saturación inicial & $2,26 \%$ & $0,43 \%$ \\
Grado de saturación final & $9,91 \%$ & $15,15 \%$ \\
\hline
\end{tabular}


Las areniscas del Abrigo del Tubo inician la absorción ligeramente más tarde que las de El Mirador, pero con un coeficiente de saturación muy alto $(=, 278 \%$. seg. $1 / 2)$, lo que produce un grado de saturación del $2,26 \%$ frente al $0,43 \%$ de las areniscas de El Mirador. Por el contrario, estas areniscas tienen un periodo de estabilidad muy corto, ya que la absorción lenta se inicia a los 2.500 segundos, lo que genera un grado de saturación al final del ensayo del $15,15 \%$, manteniéndose constante en tiempos posteriores. Las areniscas del Abrigo del Tubo alcanzan un grado de saturación final del $9,91 \%$, debido a que el inicio de la absorción lenta es a los 32.400 segundos.

El ensayo sobre la capilaridad de la roca de ambos abrigos dejó patente el carácter lineal de la absorción de agua por capilaridad. Los coeficientes de capilaridad para las areniscas del Abrigo del Tubo y de El Mirador son de $7,75 \mathrm{~kg} / \mathrm{m}^{2}$.seg. $1 / 2$ y $45,1.10-3 \mathrm{~kg} / \mathrm{m}^{2}$.seg. $1 / 2$, como puede apreciarse en la tabla núm. 7 .

Tabla 7. Ensayo de Capilaridad

\begin{tabular}{lcc}
\hline & Abrigo del Tubo & El Mirador \\
\hline $\mathrm{C}=$ Coefic. de Absorción capilar $\left(\mathrm{kg} / \mathrm{m}^{3}\right.$.seg. $\left.{ }^{1 / 2}\right)$ & $45,1.10-3$ & $7,75.10-3$ \\
$\mathrm{~A}=$ Coefic. de penetración capilar $(\mathrm{cm} / \mathrm{seg} .1 / 2)$ & 0,56 & 0,14 \\
Saturación final & $54,05 \%$ & $39,52 \%$ \\
\hline
\end{tabular}

La capacidad de absorción por capilaridad es, por lo tanto, bastante mayor en las areniscas del Abrigo del Tubo que en las de El Mirador. Además, el coeficiente de penetración capilar (A), expresado en $\mathrm{cm} / \mathrm{seg}$. es también mucho más alto en aquél abrigo $(0,56)$ que en el de El Mirador $(0,14)$.

El grado de saturación alcanzado al final del ensayo fue de $54,05 \%$ para la muestra del Abrigo del Tubo, valor éste ligeramente por debajo de la absorción libre de agua por inmersión total, fijada en $61,11 \%$. En el caso de El Mirador, el grado de saturación fue del $39,52 \%$, valor muy inferior que el correspondiente a la inmersión total, lo que nos hace pensar en la existencia de un sistema de porosidad no accesible a la succión capilar. En el caso del Abrigo del Tubo, la proximidad de los valores nos indica la importancia del proceso de capilaridad, que además será favorecido por una porosidad más pequeña, hecho éste relacionado de una forma directa con la presencia de un mayor contenido en matriz en esas muestras. 
Por último, los ensayos de evaporación muestran que en las areniscas del Abrigo del Tubo se da en un principio una disminución lenta del grado de evaporación en las primeras 24 horas del ensayo, con un coeficiente de $-0,052 \mathrm{seg} .1 / 2$, mientras que para El Mirador, en un tiempo de 2 horas y 30 minutos tenemos un coeficiente de $-0,04$ seg. $1 / 2$. A continuación, ambas muestras sufren una pérdida más rápida del contenido en agua, con coeficientes de evaporación de $-0,13$ y $-0,21$ para el Abrigo del Tubo y El Mirador, respectivamente, pérdida ésta que dura hasta las 80 horas. Finalmente, se experimenta una velocidad de secado alta, con coeficientes de $-0,37$ para el Abrigo del Tubo y de $-0,81$ para el de El Mirador, lo que da lugar a un secado completo a las 120 horas, con un grado de saturación de $0,4 \%$ para el primer abrigo y de $0,9 \%$ para el segundo.

En la Tabla núm. 8 se muestra la evolución del grado saturación durante la evaporación en los dos abrigos estudiados:

Tabla 8. Grado de Saturación durante la evaporación (Se \%)

\begin{tabular}{rcc}
\hline Tiempo/horas & Abrigo del Tubo & El Mirador \\
\hline 1 & $97,0 \%$ & $97,2 \%$ \\
10 & $89,8 \%$ & $85,3 \%$ \\
24 & $83,5 \%$ & $65,1 \%$ \\
48 & $64,8 \%$ & $30,2 \%$ \\
72 & $56,5 \%$ & $16,0 \%$ \\
96 & $27,1 \%$ & $4,7 \%$ \\
105 & $18,5 \%$ & $3,5 \%$ \\
120 & $0,4 \%$ & $0,9 \%$ \\
\hline
\end{tabular}

Se puede observar como, para las mismas condiciones, las areniscas de El Mirador tienen un proceso de desecado más rápido, lo que produce que los efectos del agua sobre estas rocas sea inferior a los que experimentan las areniscas del Abrigo del Tubo, especialmente para grados de saturación superiores al $20 \%$. Para grados inferiores, el proceso de desecación en el Abrigo del Tubo es más rápido, realizándose en unas 20 horas aproximadamente. Por el contrario, el abrigo de El Mirador, para este intervalo final de evaporación, necesita un tiempo algo superior a las 56 horas, aunque posiblemente, en este grado de saturación, los efectos de los mecanismos de deterioro de la roca son de menor importancia. 


\subsubsection{Ensayo de Alterabilidad}

Una vez visto el comportamiento del agua frente a las areniscas de Valonsadero, se procedió a estudiar la susceptibilidad de esta roca ante agentes deteriorantes como los que generan los ciclos de humedad-sequedad y hielo-deshielo.

Es evidente que los continuos cambios del contenido en humedad de una roca pueden producir un deterioro importante de ésta. Para cuantificar su efectos, en el soporte de las pinturas de Valonsadero, Fort y Bustillo realizaron 24 ciclos de humedad-sequedad en una muestra del Abrigo del Tubo y en dos de El Mirador. Se utilizaron cubos de $5 \mathrm{~cm}$ de lado y se les sometió a inmersión en agua bidestilada durante 16 horas y posterior secado a $10^{\circ} \mathrm{C}$ durante 8 horas, pesando, al término de cada ciclo, la muestra para determinar la pérdida de material.

En la tabla núm. 9 se resumen las pérdidas de masa, expresadas en \% del total de la muestra, observadas para cada muestra estudiada. Se puede apreciar que las pérdidas sufridas son escasas, evaluándose en $0,53 \%$ para las areniscas del Abrigo del Tubo y de $0,23 \%$ y $0,12 \%$ para las muestras alterada y fresca de El Mirador, respectivamente. estas pérdidas son indicativas de la resistencia de las areniscas de Valonsadero a estos procesos. Únicamente, la muestra del Abrigo del Tubo tiene una capacidad de pérdida ligeramente superior, que se refleja, fundamentalmente, en la desagregación de granos de su superficie, no apreciándose, en ningún caso, otros fenómenos como descamaciones ni grietas en la superficie de las probetas.

Tabla 9. Pérdida de masa durante los ciclos de Humedad-Sequedad (\%)

\begin{tabular}{lccccccc}
\hline & Ciclo 4 & Ciclo 8 & Ciclo 12 & Ciclo 16 & Ciclo 20 & Ciclo 24 & $\begin{array}{c}\text { Total } \\
\text { Acumulado }\end{array}$ \\
\hline Abrigo del Tubo & 0,10 & 0,10 & 0,09 & 0,10 & 0,08 & 0,06 & 0,53 \\
El Mirador (1) & 0,06 & 0,00 & 0,03 & 0,09 & 0,02 & 0,03 & 0,23 \\
El Mirador (2) & 0,03 & 0,00 & 0,03 & 0,03 & 0,02 & 0,01 & 0,12 \\
\hline
\end{tabular}

El agua que se encuentra en los poros de la roca, al helarse, sufre un aumento de volumen que genera tensiones y provoca grietas y desmoronamiento de la misma. Para este ensayo, hielo-deshielo, se utilizaron probetas cúbicas de $5 \mathrm{~cm}$ de lado, las cuales fueron medidas y 
pesadas en seco. Posteriormente se saturaron en agua, manteniéndolas tres días en inmersión bajo vacío. A continuación, las muestras se introdujeron en una cámara climática y se las sometió a 24 ciclos de hielo-deshielo. Cada ciclo se iniciaba a $20{ }^{\circ} \mathrm{C}$ para disminuir progresivamente a una velocidad de $0,2{ }^{\circ} \mathrm{C} / \mathrm{min}$. hasta los $-15^{\circ} \mathrm{C}$. A esta temperatura se mantuvo las condiciones durante tres horas para iniciar su deshielo a la misma velocidad que la congelación, hasta alcanzar los $20^{\circ} \mathrm{C}$ en donde se mantuvo durante otras tres horas. Las muestras se mantuvieron a la temperatura de rocío para que tuvieran siempre un grado de humedad lo más alto posible (del orden del 90\%). Cada cuatro ciclos las muestras fueron pesadas en saturación. Al final del ensayo se volvió a realizar la pesada en seco y se midieron de nuevo sus dimensiones.

El comportamiento de las muestras estudiadas determinaron que a partir del cuarto ciclo aparecían pequeñas fisuras que alcanzaban longitudes de 3 a $4 \mathrm{cms}$ y que, en el caso de la muestra fresca de $E l$ Mirador-2, la fisura llegará a afectar a tres caras del cubo. Estas fisuras, en general, se presentaban paralelas a la laminación de la roca y, aproximadamente, en el centro de las caras. Desde el ciclo 4 al 16, aumentó el tamaño y grosor de las grietas, aunque hasta el ciclo 16 no se pudo apreciar el desmoronamiento de granos en la muestra correspondiente al Abrigo del Tubo, apareciendo en este caso, otras grietas perpendiculares a las anteriores. En el ciclo 20, continuó el mismo proceso de desmoronamiento y crecimiento de las grietas en longitud pero, sobre todo, en anchura. El ciclo 24 mostró como la probeta del Abrigo del Tubo se encontraba totalmente degradada con pérdidas importantes de material a lo largo de las fracturas. Esta muestra, al inicio del ciclo 25 , se rompió totalmente a favor de las fracturas previas. Las otras dos muestras, pertenecientes al abrigo de El Mirador, continuaron sin fracturarse totalmente al término del ciclo 28 , si bien se pudo observar un aumento considerable de las grietas que afectaban, incluso, a las tres caras del cubo.

Las pérdidas de peso con respecto al inicio del ensayo pudieron mostrar claramente como las areniscas del Abrigo del Tubo tuvieron unas pérdidas muy altas, iniciándose éstas, fundamentalmente, a partir del ciclo 20. Por el contrario, las pérdidas sufridas por las muestras de El Mirador fueron escasas, aunque ligeramente mayores en el caso de la muestra alterada.

En la tabla núm. 10 se recogen estas variaciones en el peso de las muestras: 
Tabla 10. Pérdida de masa al término del ensayo de Hielo-Deshielo

$\begin{array}{lc}\text { Abrigo del Tubo } & 17,94 \% \\ \text { El Mirador -1 (alterada) } & 0,47 \% \\ \text { El Mirador -2 (fresca) } & 0,36 \%\end{array}$

Las dimensiones de las probetas, al concluir el ensayo, mostraron variaciones interesantes de comentar. En la dirección perpendicular a la laminación de la muestra, se apreció un incremento de las dimensiones de la probeta de $0,05 \mathrm{~mm}$ para el Abrigo del Tubo, 0,13 mm. para El Mirador1 (alterada) y $0,11 \mathrm{~mm}$. para El Mirador-2 (fresca), siendo este aumento explicable por el efecto de las grietas generadas. Por el contrario, en las otras dos direcciones del espacio se observó una ligera disminución, del orden de 0,02-0,05 mm., en todas las muestras, disminución producida fundamentalmente por la pérdida de material por desagregación.

Los resultados obtenidos en cuanto a la variación del agua de saturación al término de cada cuatro ciclos, mostraron un aumento progresivo de la cantidad de agua que puede absorber la roca. Este hecho es indicativo de que el proceso de hielo-deshielo aumenta la porosidad de la roca, al aumentar las fisuras, lo que hace que cada vez que se produce un ciclo de hielo-deshielo, la roca sea más sensible a sus efectos. Esta evolución del contenido en agua de saturación queda reflejada en la Tabla núm. 11, de la que puede destacarse el aumento que experimentó la muestra del Abrigo del Tubo, pasando de $9,40 \%$ a $13,82 \%$, momentos antes de romper. En las otras dos muestras, se observó igualmente este aumento progresivo, aunque sin alcanzar las cotas del anterior, al pasar de $7,71 \%$ a $8,31 \%$ para El Mirador (alterada) y de $7,46 \%$ a $8,52 \%$ para El Mirador (fresca).

Tabla 11. Contenido en agua de Saturación durante el Hielo-Deshielo (5)

Núm. de Ciclos

\begin{tabular}{lccrrrrrc}
\hline & Inicio (0) & 4 & 8 & 12 & 16 & 20 & 24 & 28 \\
\hline Abrigo del Tubo & 9,40 & 9,77 & 9,93 & 10,10 & 10,54 & 10,82 & 13,82 & - \\
El Mirador (alterada) & 7,71 & 7,93 & 8,04 & 8,09 & 8,22 & 8,24 & 8,29 & 8,31 \\
El Mirador (fresca) & 7,46 & $\mathbf{8 , 0 0}$ & 8,10 & 8,04 & 8,34 & 8,37 & 8,43 & 8,52 \\
\hline
\end{tabular}

Atendiendo a cuanto antecede, se puede indicar que, ante los agentes deteriorantes, el comportamiento de las areniscas de los abrigos del Tubo 
y de El Mirador será muy similar en cuanto al tipo de degradación, si bien la velocidad será diferente por efecto de las distintas características petrofísicas que presenten.

Las areniscas del Abrigo del Tubo tienen una porosidad más elevada que las de El Mirador, lo que facilita la acción de circulación del agua, pues su porosidad accesible es del 19,04\%, frente al comportamiento de estas areniscas en los procesos de absorción y desorción de agua, así como la cantidad máxima de agua que pueda contener en sus poros, evaluada en el $8,92 \%$ para el Abrigo del Tubo y de 7,20\% para El Mirador. Hay que hacer notar, no obstante, que el grado de relleno en las areniscas del Abrigo del Tubo es menor $(80,81 \%)$ que en las de El Mirador $(84,14 \%)$. Esta perdida de porosidad accesible puede ser motivada por el proceso de alteración mineralógica de los feldespatos y micas existentes en la roca, lo que genera un mayor contenido de matriz arcillosa que tiende a cerrar la porosidad durante los procesos de compactación de la roca. Lo mismo sucede con las posibles cementaciones por óxidos de hierro. Este hecho puede ser confirmado observando que son las areniscas del Abrigo del Tubo las que presentan un mayor contenido en matriz arcillosa así como un mayor grado de cementación.

La absorción de agua por las areniscas de Valonsadero pudiera ser diferente, por tanto, en función del grado de alteración mineralógica y de cementación de cada abrigo.

El comportamiento de estas areniscas frente a la absorción de vapor de agua, denota la influencia que ejerce la presencia de minerales arcillosos del tipo caolinita, illita, etc., existentes en las rocas, los cuales tienen un poder higroscópico medio-bajo, aunque dada las características de nuestras muestras puede ser debido a una absorción más de tipo físico que químico. Esto hace que aquellas muestras que presentan un mayor contenido en estos minerales, absorben más fácilmente el agua. De esta forma, la evolución de la absorción de vapor de agua nos indica como es la muestra del Abrigo del Tubo la más degradada, y por lo tanto la que posee un mayor contenido en matriz arcillosa, y la que sufre una absorción más rápida. Una vez absorbida este agua, se inicia un aumento del agua retenida por la roca, debido al agua de condensación capilar, en la cual se alcanza un grado de saturación final del $9,91 \%$. Por el contrario, dado que las muestras de El Mirador presentan un menor contenido en minerales arcillosos, el grado de saturación inicial es de $0,43 \%$, el periodo de estabilidad es muy corto y se inicia antes la absorción por condensación capilar, produciendo un grado de saturación final de 15,15\%. Por todo ello, la absorción de vapor de agua es menor en el Abrigo del Tubo en las primeras 
4 horas de absorción, producida fundamentalmente por la absorción higroscópica de los minerales de la arcilla, para después esta absorción ser mayor en las muestras de El Mirador debido a su mayor condensación capilar.

Por otro lado, el comportamiento de las areniscas de los dos abrigos ante los procesos de evaporación en condiciones ambientales es también diferente. Para la absorción de agua libre, de lluvia o de rocío, en la muestra de El Mirador (que posee un grado de saturación más elevado, alcanzándose cotas del $20 \%$ en el primer minuto del ensayo) la desecación es muy rápida, mientras que la muestra del Abrigo del Tubo mantiene este grado de saturación durante un período de tiempo superior, ya que las pérdidas de agua por evaporación son menores. Por el contrario, los efectos producidos por la absorción de vapor de agua procedente de la humedad ambiental es menor, pues sus grados de saturación se encuentran en los valores en donde los procesos de evaporación se acentúan ( $E$ I Mirador $=15,15 \%$ frente al Abrigo del Tubo $=9,91 \%$ ). Esto hace que el Abrigo del Tubo sea más sensible a las variaciones de temperatura que conllevan variaciones de la humedad ambiental y, con ello, una evaporación más fuerte. Esto queda igualmente patente al analizar los resultados de los ciclos de humedad-sequedad, donde se observaba que la muestra del Abrigo del Tubo sufría una desagregación de granos superior a la que se producía en las muestras de El Mirador. Por lo demás habrá que recordar que el afloramiento del Abrigo del Tubo se encuentra a una temperatura ligeramente superior $\left(0,5^{\circ} \mathrm{C}\right)$ que el de El Mirador, probablemente por su orientación, lo que incide aún más en este proceso de desecación.

La absorción de agua por capilaridad es, como ya se indicó, diferente para los dos abrigos. El efecto de la capilaridad es mucho mayor en el Abrigo del Tubo que en El Mirador. Y en este sentido, y atendiendo al coeficiente de penetración capilar, puede establecerse que el tamaño de los poros en las areniscas del Abrigo del Tubo es más pequeño que en las de El Mirador, lo cual facilita el ascenso por capilaridad. Por lo demás, la absorción capilar incide sobre los dos abrigos, y se ha de indicar que el ascenso capilar es de $30-45 \mathrm{~cm}$., y únicamente en aquellas partes del abrigo donde el encostramiento ha desaparecido, se midieron humedades bastante altas (40\%), estando este hecho producido más por la absorción de agua procedente de la humedad ambiental (e incluso de la absorción de agua libre -agua de rocio-), que por el propio efecto de capilaridad. Esta absorción de agua capilar hace que las zonas bajas de los abrigos sufran los efectos de alteración de una formas más rápida que las zonas superiores, siendo ésta posiblemente una de las causas de la génesis de estos abrigos. 
Este proceso de formación del abrigo, o tafonización, está íntimamente ligado con los factores que condicionan la intensidad de la meteorización en puntos concretos de la roca, como por ejemplo el diferente grado de cementación o la presencia/ausencia de matriz arcillosa. Es por esto que el proceso de tafonización tiene una mayor posibilidad de desarrollarse allí donde existen, por cualquier causa, debilidades favorecidas por los procesos de absorción de agua que van a producir variaciones de la humedad y temperatura en el soporte.

Los ensayos de alterabilidad muestran la capacidad de resistencia de estos materiales a la alteración física y, por lo tanto, es indicativo de su grado de durabilidad futura. En los dos ensayos realizados, las variaciones de humedad-sequedad muestran incidencias muy bajas sobre la degradación de la roca, siendo apreciable únicamente por la desagregación de materiales superficiales. Este hecho queda más patente en las zonas de la roca donde existe un mayor contenido de matriz arcillosa, por lo que son las muestras del Abrigo del Tubo las que muestran una mayor pérdida de material. Semejante proceso se acentuará en aquellas partes de la roca donde hay una importante alteración mineralógica que genera un alto contenido en matriz.

Pero son realmente los procesos de hielo y deshielo los que producen una mayor degradación de las areniscas estudiadas, ya que son los causantes de las descamaciones y, por tanto, de la rotura del encostramiento que recubre el afloramiento, produciéndose, con ello, el avance de los procesos de génesis de alveolos o tafonis. No hemos de olvidar que en este proceso también puede incidir una cierta actividad eólica, desagregando y transportando las distintas partículas. Este proceso acentuará su efecto cuanto más saturada en agua se encuentre la arenisca; la cristalización en el interior generará un aumento de volumen y de las tensiones internas y estas tenderán a disiparse formando fisuras y grietas, que serán más importantes cuanto más fina sea la porosidad de la roca (como es el caso de las areniscas del Abrigo del Tubo).

Actualmente este proceso es importante pues hay un alto número de días de heladas al año (estadísticamente en torno a los 98 días/año).

Las características petrofísicas de las areniscas estudiadas muestran un alto grado de absorción de agua, especialmente en su forma de absorción libre y de capilaridad. La absorción libre se realiza fundamentalmente por el agua de rocío, la cual se condensa sobre la superficie del abrigo y posteriormente se absorbe por la roca. Los dias de rocio, en los meses de temperaturas más bajas, son de 44 días anuales y los de escarcha de 41 días anuales. Por el contrario, la absorción capilar se desarrolla debido al 
ascenso de agua a través de los poros de la roca a partir del contacto humedecido por las precipitaciones de lluvia. Las precipitaciones medias en esta zona son de $532 \mathrm{~mm} / a n ̃ o$, de las que 394,5 (74\%) se producen en los meses de temperaturas más bajas, con una frecuencia de lluvia apreciable de 12,3 días/mes, frecuencia ésta que no permite la actuación de la evaporación, pues hay que tener en cuenta que corresponden a los meses de menor temperatura.

Dadas las características de absorción de agua y de volumen de poros, es la arenisca del Abrigo del Tubo la más sensible a los procesos antes citados, tal como ha quedado demostrado a lo largo de su comportamiento ante el ensayo de hielo-deshielo. Además, hay que hacer constar como la actuación de dichos procesos lleva consigo la génesis de fisuras que aumentan la porosidad y, con ello, su grado de saturación, lo que hace cada vez más activo el proceso de hielo-deshielo.

Con todo, se puede afirmar que las causas de la degradación del soporte pictórico del Abrigo del Tubo y de El Mirador, están intimamente ligadas a la capacidad de absorción de agua, básicamente de agua libre de rocio y de capilaridad a partir del agua de lluvia, siendo los procesos de hielo-deshielo los que actúan generando descamaciones que siguen las zonas de debilidad textural y estructural. Estos procesos se acentúa en aquellas zonas del afloramiento donde existe un mayor contenido en matriz arcillosa.

\section{ESTUDIO GENERAL DE LA ALTERACIÓN DE LA ROCA SOPORTE DE LAS PINTURAS RUPESTRES}

Como se ha visto, los estudios anteriores se centraron en dos de los 34 abrigos existentes con pinturas rupestres en Valonsadero. Estos dos abrigos estaban bastante alterados y urgía quizá diagnosticar su estado, aunque no eran representativos para conocer el estado general de conservación de las pinturas rupestres. Sin embargo, si fueron útiles para estudiar gran parte de los procesos de alteración de la roca. Por este motivo, la Comisión Institucional de Trabajo sobre el Plan de Valonsadero impulsó un estudio complementario más global sobre la alteración de la roca soporte de las pinturas y que abarcarse un gran número de abrigos. Con este estudio se pretendía conocer el estado actual de conservación de la roca y profundizar en los procesos de su alteración. El trabajo realizado por $\mathrm{E}$. Sanz (1997) incluyó los siguientes aspectos: reconocimiento geológico de los abrigos, descripción del tipo, grado de alteración y estado de conservación de la roca soporte de las pinturas, y finalmente, en la caracterización 
de los procesos de alteración. A parte de las observaciones de campo, el trabajo se fundamentó en análisis químicos, mineralógicos y ensayos de humedad-sequedad realizados en las muestras de la costra soporte de las pinturas, en la roca de los abrigos (sana y alterada de la base), en las eflorescencias de sales existentes en las paredes de los abrigos, y en los residuos de las gnammas (Tablas núms. 12, 13, 14 y 15 y 16). Los abrigos reconocidos fueron: La Cuerda del Torilejo, Barranco de Valdecaballos, La Peñota, El Pasadizo, La Asomadilla, La Tronera, El Tolmo de Morellán, El Risco del Portón de la Cañada, El Murallón del Puntal, Abrigo del Tubo, Abrigo del Pozo, Peñón del Camino de Pedrajas, Las Covatillas, Covachón del Puntal, La Lastra, El Mirador, Peña Somera, Peñón de la Visera, Covacho del Morro, Peñón del Majuelo y Los Peñascales, abrigos todos -23 de un total de 34 hasta ahora conocidos- que componen el núcleo artístico de Valonsadero, por lo que se trata de una muestra representativa.

Los aspectos más interesantes que se deducen de este estudio se reproducen a continuación, tras la presentación de las tablas arriba citadas:

Tabla 12. Relación de muestras y objeto de análisis

\begin{tabular}{|c|c|c|}
\hline $\begin{array}{c}\text { Núm. } \\
\text { Orden } \\
\text { Muestra }\end{array}$ & Localización & Descripción y objeto del análisis \\
\hline 1 & Abrigo del Tubo & Eflorescencia de Sales. Análisis Quimico \\
\hline 2 & Abrigo del Tubo & $\begin{array}{l}\text { Análisis químico de la costra soporte de las } \\
\text { pinturas }\end{array}$ \\
\hline 3 & Abrigo del Tubo & $\begin{array}{l}\text { Análisis químico de capas situadas debajo de } \\
\text { la costra }\end{array}$ \\
\hline 4 & Abrigo del Tubo & Arenisca de la base. Alterabilidad. Mineralogía \\
\hline 5 & $\begin{array}{l}\text { Peña de Cañada Honda. } \\
\text { Gnamma }\end{array}$ & $\begin{array}{l}\text { Residuos de arenas y musgos. Análisis } \\
\text { Químico }\end{array}$ \\
\hline 6 & $\begin{array}{l}\text { Peña de Cañada Honda. } \\
\text { Gnamma }\end{array}$ & Residuos de arenas. Mineralogía. \\
\hline 7 & $\begin{array}{l}\text { Peña de Cañada Honda. } \\
\text { Gnamma }\end{array}$ & $\begin{array}{l}\text { Residuos de arenas. Mineralogía. Análisis } \\
\text { químico. }\end{array}$ \\
\hline 8 & Covachón del Puntal & Costra delgada del abrigo. Análisis Químico. \\
\hline 9 & Covachón del Puntal & $\begin{array}{l}\text { Arenisca de la base dura. Alterabilidad. } \\
\text { Mineralogía. }\end{array}$ \\
\hline 10 & La Lastra & $\begin{array}{l}\text { Eflorescencia sales situadas debajo de la } \\
\text { costra. An. Quím. }\end{array}$ \\
\hline 11 & El Mirador & $\begin{array}{l}\text { Costra delgada de soporte de pinturas. Análisis } \\
\text { Químico }\end{array}$ \\
\hline
\end{tabular}


JUAN A. GÓMEZ-BARRERA, EUGENIO SANZ PÉREZ, PABLO L. YAGÜE HOYAL, R. FORT..

Tabla 12. (Continuación)

\begin{tabular}{|c|c|c|}
\hline $\begin{array}{l}\text { Núm. } \\
\text { Orden } \\
\text { Muestra }\end{array}$ & Localización & Descripción y objeto del análisis \\
\hline 12 & Peñón de la Visera & $\begin{array}{l}\text { Costra delgada soporte de pinturas. Análisis } \\
\text { Químico. }\end{array}$ \\
\hline 13 & Los Peñascales II & $\begin{array}{l}\text { Eflorescencia de sales. Análisis Químico. } \\
\text { Mineralogía. }\end{array}$ \\
\hline 14 & Los Peñascales II & $\begin{array}{l}\text { Sales y alteración debajo costra de pinturas. } \\
\text { Anál. Quím. }\end{array}$ \\
\hline 15 & Los Peñascales II & Costra sobre pinturas, dura. Análisis Quimico. \\
\hline 16 & Abrigo de La Cuerda del Torilejo & $\begin{array}{l}\text { Eflorescencia de sales de la superticie y de } \\
\text { debajo de la costra. Análisis Químico }\end{array}$ \\
\hline 17 & Abrigo de La Cuerda del Torilejo & Costra dura. Análisis Químico \\
\hline 18 & Abrigo de La Cuerda del Torilejo & Costra delgada. Análisis Quimico. \\
\hline 19 & Abrigo de La Cuerda del Torilejo & $\begin{array}{l}\text { Arenisca. Alterabilidad y petrografía. } \\
\text { Mineralogía }\end{array}$ \\
\hline 20 & Gnamma & $\begin{array}{l}\text { Roca de techo de peñas. Alterabilidad. } \\
\text { Mineralogia. }\end{array}$ \\
\hline
\end{tabular}

Tabla 13. Resultados de los análisis químicos

\begin{tabular}{|c|c|c|c|c|c|c|}
\hline Muestra & $\begin{array}{c}\% \text { Cloruro } \\
(\mathrm{Cl}-)\end{array}$ & $\begin{array}{c}\% \text { Anhidrido } \\
\text { Sulfúrico }\left(\mathrm{SO}_{3}\right)\end{array}$ & $\begin{array}{c}\% \text { Carbonatos } \\
\text { Totales en } \\
\text { (CO3Ca) }\end{array}$ & $\% \mathrm{Fe}_{2} \mathrm{O}_{3}$ & $\% \mathrm{Al}_{2} \mathrm{O}_{3}$ & $\begin{array}{c}\% \text { Mat. } \\
\text { Org. }\end{array}$ \\
\hline 1 & 0,04 & 2,7 & $<1$ & - & - & - \\
\hline 2 & - & - & - & 0,61 & 11,5 & - \\
\hline 3 & 0,14 & 3,0 & $<1$ & - & - & - \\
\hline 5 & 0,01 & $<0,03$ & $<1$ & - & - & 46,7 \\
\hline 6 & 0,02 & 0,18 & $<1$ & - & - & - \\
\hline 7 & 0,02 & $<0,03$ & $<1$ & - & - & - \\
\hline 8 & - & - & - & 0,83 & 10,0 & - \\
\hline 10 & 0,03 & 28,5 & $<1$ & - & - & - \\
\hline 11 & - & - & - & 1,3 & 11,2 & - \\
\hline 12 & - & - & - & 0,51 & 12,5 & - \\
\hline 13 & 0,23 & 5,7 & $<1$ & - & - & - \\
\hline 14 & 0,03 & 9,7 & $<1$ & - & - & - \\
\hline 15 & - & - & $<1$ & - & - & - \\
\hline 16 & 0,29 & 12,9 & $<1$ & - & - & - \\
\hline 17 & - & - & - & 0,67 & 7,1 & - \\
\hline 18 & 一 & - & - & 0,44 & 9,4 & - \\
\hline
\end{tabular}


Estado actual de los estudios de conservación de las pinturas rupestres..

Tabla 14. Características Petrográficas

\begin{tabular}{|c|c|c|c|c|c|c|c|}
\hline \multirow[b]{2}{*}{$\begin{array}{l}\text { Núm. } \\
\text { Muestra }\end{array}$} & \multirow[b]{2}{*}{ Composición } & \multicolumn{3}{|c|}{ Principales minerales (en \%) } & \multicolumn{2}{|c|}{ T. Granos $(\mathrm{mm})$} & \multirow{2}{*}{$\begin{array}{l}\text { Clasifi- } \\
\text { cación }\end{array}$} \\
\hline & & $\begin{array}{l}\text { Granos } \\
\text { Siliceos }\end{array}$ & Feldespato & $\begin{array}{l}\text { Óxidos } \\
\text { de Hierro }\end{array}$ & Medio & Máximo & \\
\hline \multirow[t]{3}{*}{6} & Granos de cuarzo, & & & & & & Arena \\
\hline & chert, feldespato, & & & & & & Silicea \\
\hline & Óxidos de hierro & 80 & 15 & 5 & 0,22 & 0,54 & \\
\hline \multirow[t]{2}{*}{7} & $\begin{array}{l}\text { Granos de cuarzo, } \\
\text { chert, feldespato }\end{array}$ & & & & & & \\
\hline & Óxidos de hierro & 95 & - & 5 & 0,27 & 0,63 & $"$ \\
\hline \multirow[t]{2}{*}{13} & Cuarzo, mica, & & & & & & \\
\hline & Óxidos de hierro & 70 & 20 & 5 & 0,31 & 0,54 & $"$ \\
\hline \multirow[t]{2}{*}{19} & Cuarzo, chert, & & & & & & \\
\hline & $\begin{array}{l}\text { esquisto siliceo, } \\
\text { mica, feldespato, } \\
\text { cemento ferruginoso }\end{array}$ & 90 & 10 & - & - & - & $"$ \\
\hline \multirow[t]{2}{*}{4} & $\begin{array}{l}\text { Cuarzo, mica, } \\
\text { cemento silíceo }\end{array}$ & & & & & & \\
\hline & Óxidos de hierro & - & - & - & 0,18 & 0,50 & $"$ \\
\hline \multirow[t]{2}{*}{9} & $\begin{array}{l}\text { Cuarzo, chert, } \\
\text { feldespato }\end{array}$ & & & & & & \\
\hline & cemento silíceo- & - & - & - & 0,18 & 0,45 & $"$ \\
\hline \multirow[t]{2}{*}{20} & $\begin{array}{l}\text { Cuarzo, feldespato, } \\
\text { mica, cemento }\end{array}$ & & & & & & \\
\hline & siliceo y ferruginoso & - & - & - & 0,20 & 0,60 & " \\
\hline
\end{tabular}

Tabla 15. Análisis químicos de las costras y de la roca arenisca (en \%)

\begin{tabular}{lccccccccc}
\hline & $\mathrm{SiO}_{2}$ & $\mathrm{Al}_{2} \mathrm{O}_{3}$ & $\mathrm{Fe}_{2} \mathrm{O}_{3}$ & $\mathrm{CaO}$ & $\mathrm{MgO}$ & $\mathrm{Na}_{2} \mathrm{O}$ & $\mathrm{K} 2 \mathrm{O}$ & $\mathrm{TiO}_{2}$ & $\mathrm{SO}_{3}$ \\
\hline COSTRAS & 77,2 & 11,6 & 0,63 & 0,31 & 0,30 & 0,27 & 4,1 & 0,57 & 0,25 \\
ARENISCAS & 76,0 & 10,0 & 5,9 & 0,06 & 0,08 & 0,24 & 3,6 & 0,23 & $<0,03$ \\
\hline
\end{tabular}


Tabla 16. Pérdida de masa durante los ciclos de humedad-sequedad

\begin{tabular}{cccccc}
\hline Muestra & Ciclo 4 & Ciclo 8 & Ciclo 12 & Ciclo 48 & Ciclo 64 \\
\hline 4 & 0,6 & 0,0 & 0,18 & - & - \\
9 & 1,34 & 0,34 & 0,78 & - & - \\
19 & 9,0 & 2,78 & 2,42 & 2,4 & 0,6 \\
20 & 1,3 & 0,08 & 0,12 & 2,4 & 0,6 \\
21 & 0,66 & 0,04 & 0,1 & - & - \\
\hline
\end{tabular}

- Los autores de las pinturas eligieron las partes más duras y resistentes de los abrigos que son las costras: por eso seguramente se han conservado muchas de ellas. La situación de las costras quedaba a una altura cómoda para pintarlas por personas de estatura mediana. Son menos abundantes las pinturas en diaclasas, planos de estratificación o paredes diversas.

- Las costras duras y delgadas, soporte de la mayor parte de las pinturas, son químicamente muy parecidas: $1 \%$ de óxidos de hierro, $10 \%$ de alúmina y el resto de sílice, supuestamente en geles. No son costras ferruginosas propiamente dichas sino más bien silíceas. Desde el punto de vista químico no hay diferencias entre la roca arenisca y las costras. La distinción más notable es precisamente que las costras tienen un menor contenido en hierro que las areniscas (relación 1/6).

- Las costras gruesas y duras parecen son heredadas, no se han formado recientemente. Esto no es de extrañar ya que los microrrelieves que actualmente tiene la arenisca (gnammas, tafonis, grietas de piel de elefante, etc.) son producto de diversos factores entre los que interviene decisivamente las condiciones climáticas, las cuales han podido variar a lo largo del tiempo. Así, por ejemplo, los canales de desagüe que surcan el dorso de las cuestas de las peñas de arenisca se han formado seguramente en condiciones más húmedas que las actuales.

- Los procesos de alteración observados en campo son muy parecidos en todos los abrigos:

a) Las costras gruesas están en proceso de degradación por desprendimiento, aunque parece un proceso muy lento.

b) Esta descamación se efectúa de abajo a arriba, por efecto sobre todo de la humedad del suelo que sube por capilaridad y acelera los procesos de hielo-deshielo y del haloclastismo.

c) A partir de los 1,5 m de altura, las costras están en buenas condiciones, son duras, están bien soldadas a la pared del abrigo. No se parten 
con facilidad si se golpean con un martillo salvo en los bordes. Esto es debido a que la humedad que sube por capilaridad, que es la principal fuente de suministro de agua, no alcanza los $1,5 \mathrm{~m}$ de altura. La composición silícea ( $y$ no ferruginosa) de las costras hacen que sus superficies sean poco alterables.

Seguramente ha habido una fase anterior de desprendimiento rápido de las costras de la base y, a partir de la citada altura este proceso va a ser muy lento y será difícil que existan más desprendimientos. Como se comprenderá, es imposible conocer la velocidad de este proceso degenerativo de descamación aunque sí es factible detectar las partes más inestables para poder fijarlas con métodos artificiales.

d) Se observa que cuando caen las costras la roca se altera más rápidamente. Es decir, las costras hacen de escudo protector de los abrigos.

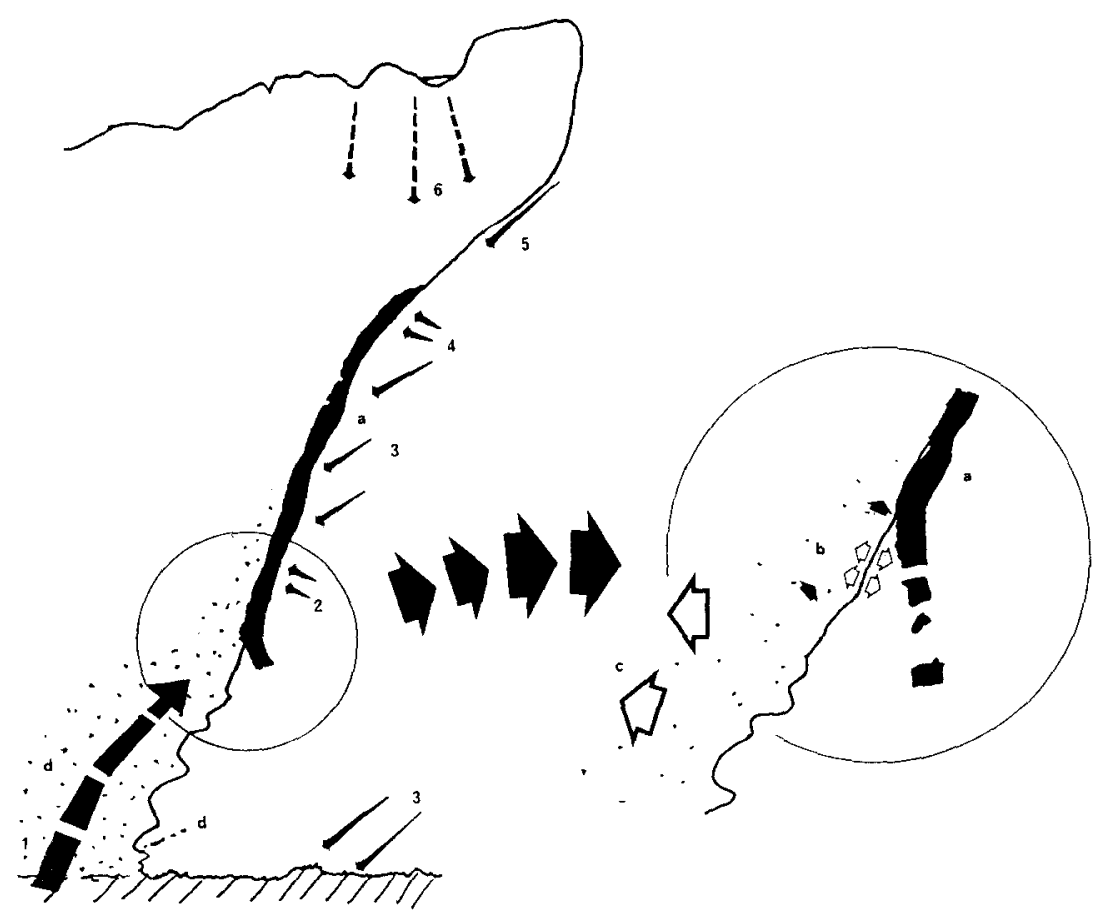

Figura 8. Proceso de degradación de la costra con pinturas rupestres de Valonsadero: a) costra con pinturas; b) entrada de agua y procesos de hielo-deshielo y haloclastismo; c) deterioro progresivo; d) zona húmeda y alterada. Origen del agua: t: agua de capilaridad; 2: rocio; 3: lluvia; 4: vapor de agua; 5: escurriduras; 6: infiltración desde gnnamas.

(Según E. Sanz Pérez). 
e) Se observan eflorescencias salinas en casi todos los abrigos, bajo las costras en los bordes y periferia, que están más ahuecadas. Estas eflorescencias son de sulfatos, y apenas hay cloruros y carbonatos. Las eflorescencias pueden llegar a tener un $28 \%$ de sulfatos. En el interior de las costras no suele haber sales.

f) No hay exudaciones salinas debajo de las patinas ferruginosas de las diaclasas.

g) Según los ensayos de la Tabla 16, se constata la poca alterabilidad de la roca a los procesos de humedad-sequedad salvo la roca que se sitúa en la parte inferior de los abrigos y que está ya arenizada.

h) La costra se ahueca por los bordes, sobre todo el interior y rompe por efecto de la cuña de hielo y de la cristalización de las sales, íntimamente relacionado con la humedad del suelo que sube por capilaridad. Aunque el proceso del hielo-deshielo inhibe el haloclastismo no tienen por que ser incompatibles. En las condiciones climáticas actuales quizá el hielo-deshielo sea más relevante en invierno y el haloclastismo en verano. Pero la importancia relativa de uno $u$ otro proceso ha podido variar a lo largo del tiempo según el clima.

i) La presencia de cavidades estrechas y profundas en la base de las peñas de arenisca a favor de los planos de estratificación por erosión de capas más blandas, hace de cámara de aire aislante que de forma natural ha impedido la progresión de la humedad del suelo por capilaridad.

j) Ha influido también la existencia de un pie en los abrigos de estratos de arenisca dura menos alterable, con menos finos, y menor capacidad de capilaridad, que ha impedido la progresión de la humedad hacia arriba.

k) Las condiciones topográficas también han influido en favorecer o dificultar el drenaje del agua del suelo. Así, los abrigos situados a media ladera impiden la acumulación de charcos y humedades que luego subirían por capilaridad.

1) La presencia de abrigos con visera natural de roca, a veces pronunciadas, ha hecho de tejado y protegido del azote directo del agua de lluvia $y$ de escurriduras.

m) El arbolado y los matorrales son en general beneficiosos pues hacen de efecto de paraguas en las paredes pintadas, y resecan el suelo con sus raíces, sustrayendo agua disponible para la ascensión capilar a través de la roca. Todo ello impide la proliferación de líquenes y musgos que, en las partes altas del abrigo se alimentan del agua de rocío y de la lluvia. 
n) Hay un alto contenido en materia orgánica en los residuos de las gnammas, escasez de feldespatos y presencia de sales. Todo ello parece indicar en la alteración, la importancia de la acidez de las aguas, la disolución de los feldespatos y el haloclastismo.

El trabajo de Sanz Pérez concluía que el estudio de la roca soporte de las pinturas rupestres de la mayor parte de los abrigos es bueno, aunque existan algunos casos puntuales muy degradados.

Después de este diagnóstico, considera que hay que ser extremadamente cuidadosos con las medidas artificiales a realizar para su protección ya que podrían romper el equilibrio natural. Sanz Pérez (1997) proponía, finalmente, medidas preventivas sencillas y poco sofisticadas, encaminadas a evitar el agua, pues es este elemento el que favorece y acelera los procesos de alteración de hielo-deshielo y del haloclastismo que son los que más intervienen en la alteración de la roca. Las medidas se refieren a valiados para evitar la acción antrópica, no alterar el arbolado ni el matorral, evitar el riego, colocar pequeños tejadillos para que no haya escurriduras, muretes para desviar las aguas y favorecer el drenaje del suelo. En casos puntuales más degradados se podrian hacer actuaciones especiales como soldar las costras más deterioradas, etc.

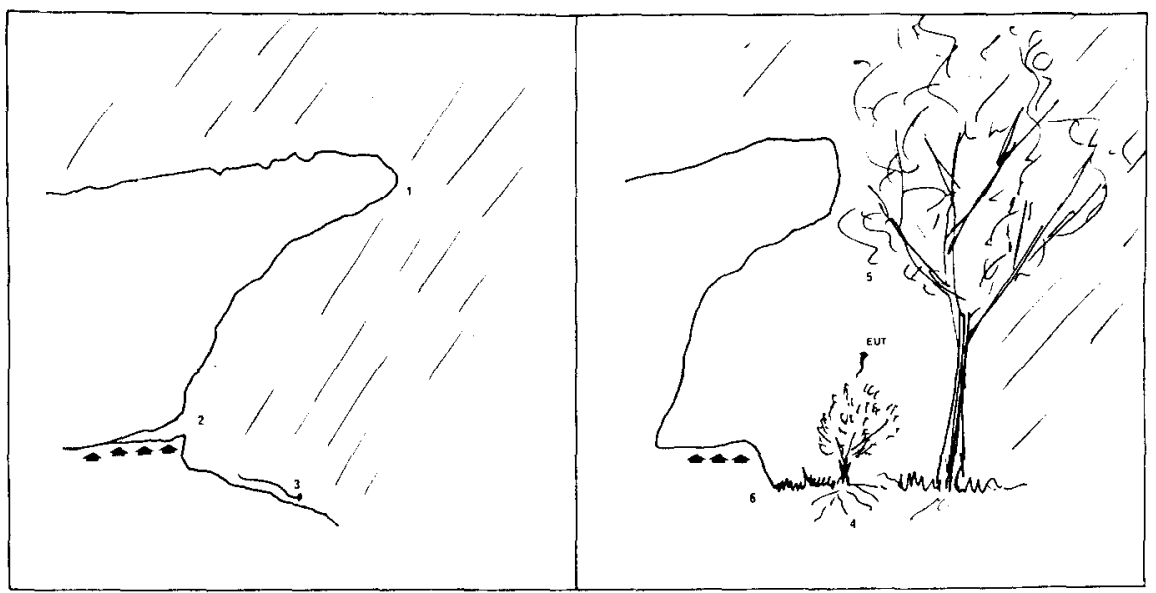

Fig. 9. Protección natural de los abrigos a la entrada de agua: 1: existencia de viseras; 2: presencia de grietas según la estratificación que frenan la progresión de la capilaridad; 3 : pendiente natural de la ladera que favorece el drenaje; 4: resecamiento por evapotranspiración; 5 : bases pétreas poco alterables bajo los abrigos que frenan la capilaridad del suelo. (Dibujos y propuesta de E. Sanz Pérez). 


\section{ANÁLISIS DE PIGMENTOS PICTÓRICOS Y BETAS ROJIZAS DE LAS ARENISCAS}

Las muestras tomadas por P.L. Yagüe en 1989 -1: una lasca de piedra con pintura de 1,5 mm de espesor extraída del Abrigo de las Marmitas; 2: muestra de pintura de la zona derecha del Abrigo del Tubo; y 3: un fragmento de arenisca disgregada tomada de una beta roja a nivel del suelo del último abrigo citado- fueron analizadas por Maria Ruiz, Técnico del Departamento de Análisis pictórico de la Escuela Taller de la Alameda de Osuna del Excmo Ayuntamiento de Madrid, arrojando las siguientes conclusiones:

a) que el pigmento utilizado para la realización de las pinturas de Valonsadero se obtuvo a partir de una molienda de un mineral, piedra arenisca, con una alta proporción en óxidos de Hierro ( $\mathrm{Fe} \mathrm{O}, \mathrm{Fe}_{2} \mathrm{O}_{3}$ y Feз 04 );

b) que el mineral pigmentado se obtuvo de las betas rojizas de las propias areniscas que dan forma a los abrigos rocosos del lugar;

c) que el aglutinante empleado es de naturaleza proteínica, sin poder precisar más dada su total degradación por ser materia orgánica; y, finalmente,

d) que, aunque el aglutinante está muy alterado, el pigmento mantiene muy bien su cohesión y adhesión al soporte debido, seguramente, a su buena molienda. Por lo demás, una carbonatación en la superficie, procedente de las sales constitutivas de la roca, ha favorecido la perdurabilidad de los motivos pictóricos.

Otros datos de interés, que pueden ser extraídos de esta analítica, señalarán, por una parte, que en las dos muestras pictóricas existían restos sólidos de una combustión vegetal adheridos a la superficie porosa de la arenisca, posiblemente como resultado de las hogueras habituales al pie de estos abrigos hasta que en 1982 se empezó a instalar las verjas protectoras ya comentadas. $\mathrm{Y}$, por otro lado, el análisis microscópico de la muestra pictórica del Abrigo del Tubo denunció la presencia de restos de yeso - posiblemente constitutivos de la roca- que, por lo general, favorecen la proliferación biológica de determinados tipos de liquenes, algo, también, muy habitual en los abrigos sorianos, tal y como se ha comentado en páginas anteriores y se volverá a hacer en las siguientes. 


\section{FACTORES DEGRADANTES Y ESTADO ACTUAL DE CONSERVACIÓN DE LAS PINTURAS RUPESTRES DE VALONSADERO}

Teniendo en cuenta la analítica particular de Valonsadero vista en el apartado anterior, P. L. Yagüe afirmará que la perdurabilidad de las pinturas rupestres del Monte Valonsadero dependerá de la conservación de la arenisca-soporte que, por lo demás, presenta un avanzado estado de degradación. Anotó que los factores que alteran la roca son muchos y de muy diversa índole y señaló la meteorización como uno de los más activos. Por lo demás, aparte la acción antrópica ya vista, concretó cuatro grandes causas de alteración de los soportes pictóricos (físicas, químicas, petrológicas y biológicas) y las analizó del modo que a continuación, y en breve síntesis, exponemos.

\subsection{Causas de alteración físicas}

Son las que provocan daños de tipo mecánico a partir de la acción del agua (capilar, de lluvia y rocío), de las sales solubles, del hielo, del viento, de la tensión y de los procesos de termoexpansión.

El agua se presenta en Valonsadero de diferentes formas y según éstas afectará de una manera u otra a la conservación de las areniscas. EI agua capilar provoca una notable alteración en las zonas bajas de los abrigos, siendo responsable de la creación de la mayoría de éstos, por el proceso de tafonización. El agua de lluvia, puede penetrar en la roca de forma directa o por capilaridad. Ya dijimos que las precipitaciones alcanzan en Valonsadero una media de $532 \mathrm{~mm}$ al año, lo que hace que refleje una cantidad superior a la teórica en un $20 \%$.

Los daños que provoca el agua de lluvia son originados al entrar ésta por filtración en las rocas, o bien al escurrir sobre ella lavando las pinturas y dejando "chorretones" en la superficie. Y, por último, el rocio, que crea una película acuosa fácilmente absorbida por la superficie porosa de la arenisca. Los días de rocío al año en Valonsadero son 83 , y se dan sobre todo en verano; esto supone que casi la cuarta parte del año las pinturas de Valonsadero aparecen con una capa acuosa, que se evapora en pocas horas gracias a la acción del sol.

Las sales solubles existentes en la arenisca de Valonsadero proceden del suelo o de la propia constitución de la roca. La presencia de agua las pone en movimiento; si están en el suelo subirán a la roca por capilaridad, introduciéndose en los poros de la piedra; cuando el agua se evapore por 

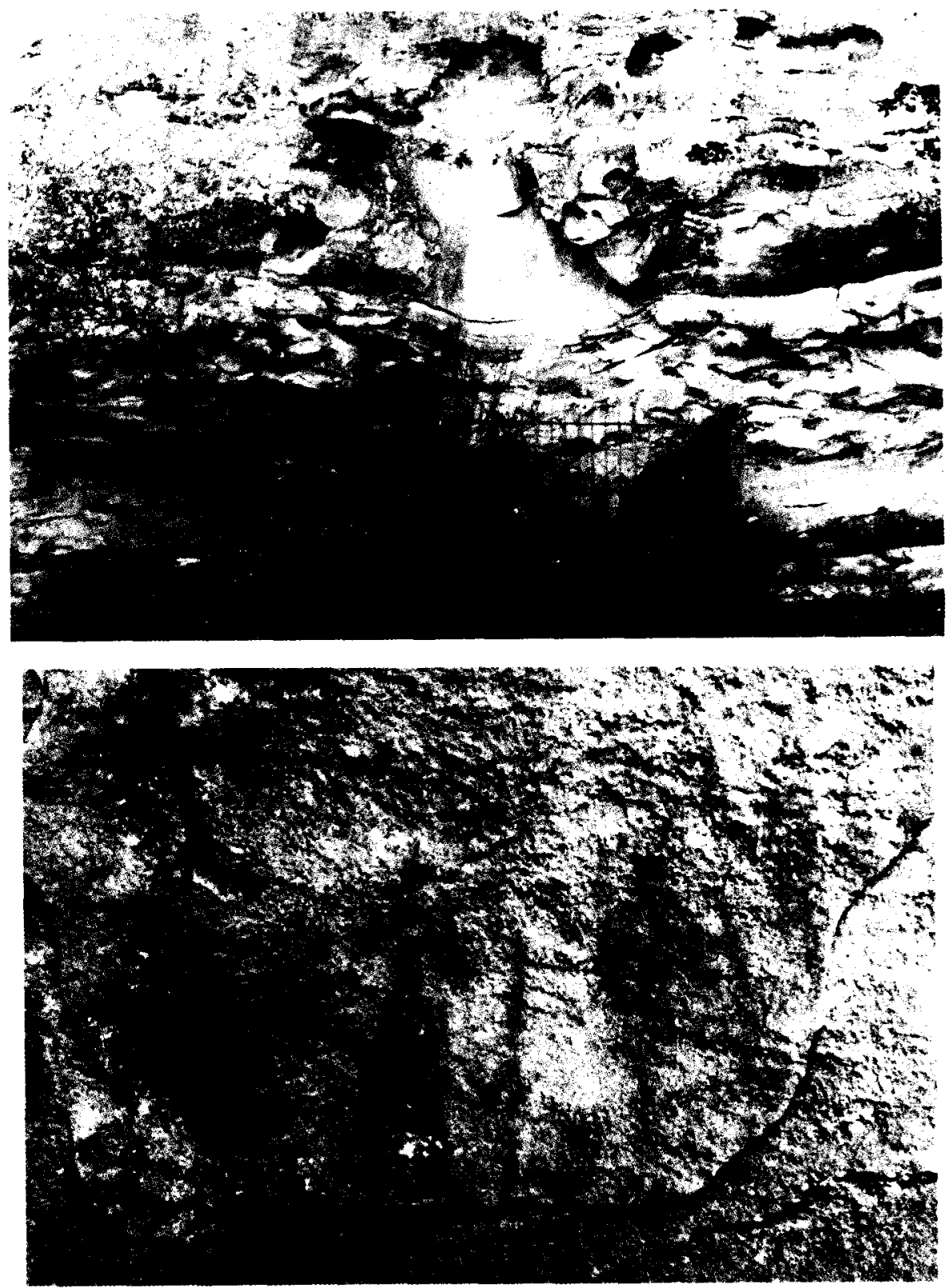

Fig. 10. La imagen superior muestra el abrigo de La Lastra muy castigado por la acción del agua de lluvia (ácida y escurrida), mientras que en la inferior podemos apreciar el friso del Peñón de la Visera pintado sobre una placa o costra ahora semidesprendida

(Fotografias de P.L. Yagüe). 
aumento de la temperatura, las sales, todavía disueltas en aquélla, serán arrastradas hacia la superficie; pero cuando el agua se gasifique las sales se acumularán en los poros. Al quedarse sin agua cristalizan, lo que llevará consigo un aumento de volumen. La reacción física de este fenómeno se traduce en una tensión en los poros exteriores de la roca, que provoca roturas estructurales de la arenisca, en la zona baja de los abrigos.

Dependiendo de la porosidad y morfología porosa de la piedra, el hielo actuará de distintas formas, pero siempre provocando tensiones.

El viento puede atacar la piedra, bien combinado con el agua, o bien ligado a agentes abrasivos. En su primera forma es muy peligroso, al provocar una evaporación muy rápida del agua y como consecuencia tensiones, roturas y disgregaciones. En la segunda, lo hace con erosión mecánica: la abrasión eólica provoca un desgaste en la capa superficial de la arenisca y en las pinturas. En Valonsadero predominan los vientos del Norte y el Oeste, de ahí que los abrigos orientados al primer cuadrante sean los más afectados.

Las tensiones, internas o externas, a que están sometidos todos los cuerpos se concentran y multiplican en los puntos en que la materia está debilitada; las grietas y fisuras son especialmente propicias para la acumulación de tensiones y éstas pueden agrandar a aquéllas en un orden de 10 a 100 veces, dependiendo del tamaño de la grieta y la tensión acumulada. Además, como ocurre con todos los materiales, la arenisca se dilata con el calor -entre un 0,3 y $0,4 \mathrm{~mm}$ por metro a una temperatura de $30^{\circ} \mathrm{C}-\mathrm{y}$, como cualquier masa rocosa, no capta la temperatura de forma uniforme lo que ocasiona una diferencia de dilatación en el mismo cuerpo, generando tensiones. Este proceso de termoexpansión se acelera con las diferencias térmicas entre el día y la noche, algo que en Valonsadero es considerable en el mes de Julio.

\subsection{Causas de alteración química}

Las alteraciones químicas son los daños producidos por reacciones de diferente índole, como contaminación y polución, agua de lluvia, agua y temperatura y luz. Afortunadamente en Valonsadero la reacción química producida por productos contaminantes o restos ácidos de combustiones es mínima o inexistente. Por contra el agua de lluvia es ligeramente ácida y penetra con mucha facilidad en la arenisca. Al evaporarse el agua el ácido queda en el interior en una proporción más concentrada, y aunque las cantidades de ácido y la constitución de la arenisca de Valonsadero 
hacen de esta alteración un factor poco peligroso, sí hay que señalar que hay zonas con pinturas por donde escurre el agua de lluvia lavándolas en exceso. La lluvia ácida decolora las pinturas, provocando incluso su desaparición, como podría ser el caso del panel superior de La Lastra.

El calor unido al agua provoca una evaporación y una concentración de las sales y los ácidos. Por el contrario, cuando la temperatura es inferior a $0^{\circ} \mathrm{C}$ se produce la reacción de congelación en el agua. El calor por si sólo no es un factor de alteración, pero es un acelerador y activador de muchas actuaciones deteriorantes, tanto de naturaleza química como física y biológica. En consecuencia, las subidas de temperaturas que se aprecian en Valonsadero durante los meses de verano (máxima en Julio de $37,6^{\circ} \mathrm{C}$ ) nos obliga a considerar el calor como un factor dañino.

La luz es otro factor que no interviene directamente en la degradación de los materiales, pero sí actúa como acelerador: aumenta la temperatura y permite y favorece el desarrollo vegetal. Además los rayos infrarrojos y ultravioletas han favorecido la decoloración de alguna de las pinturas de Valonsadero.

\subsection{Causas de alteración petrológicas}

Son las que tienen su origen en la propia constitución de la piedra y de sus materiales. La alteración petrológica es, como ya se ha indicado en varias ocasiones a lo largo de este trabajo, la génesis de los abrigos que albergan las pinturas. Tales alteraciones aún continúan y son, a muy largo plazo, un peligro para la perdurabilidad del estrato donde se encuentran las pinturas. Los abrigos se han originado en las partes de los afloramientos rocosos más débiles y es en estos lugares donde se centran los procesos de humedad, hielo, sales y otros factores intrínsecos a la propia roca, causas de esta alteración.

En la capa exterior de los abrigos se observa una cementación, formando una costra de no más de un centímetro de espesor, de tipo silícea y constituida por clastos y matriz; es impermeable y dura, en contraposición con el interior de la arenisca, al acumularse los materiales que transmiten dureza y cohesión en la superficie. La matriz es el aglutinante de los granos que constituyen la arenisca. La matriz de la arenisca de Valonsadero es de origen diagenético, producida por la descomposición de cantos blandos de arcilla y la transformación de micas y feldespatos. La alteración de las micas y los feldespatos se produce en superficie, favoreciendo con ello la creación de la costra cementosa. Esta costra impermeable impide que la al- 
teración siga hacia el interior, al actuar como aislante, no permitiendo los intercambios de agua entre el interior y el exterior. Sin embargo la barrera que supone la costra termina por saltar cuando la abundancia de humedad, en la base del abrigo, facilita la acumulación de sales y la acción del hielo.

$Y$, en fin, la tafonización - proceso que tiene como resultado la creación de formas cavernosas en los frentes de los estratos, a consecuencia de la disgregación de la roca por la presencia de humedad- ha originado en Valonsadero un micromodelado muy especial, utilizado por los "pintores esquemáticos" para albergar sus pinturas. A muy largo plazo este fenómeno podría afectar directamente a la conservación de las pinturas.

\subsection{Causas de alteración biológicas}

Hablamos de plantas superiores, musgos, algas, líquenes y animales. Las primeras (hierbas, helechos, ombligos de Adán) se desarrollan con mucha facilidad, por la humedad y el resguardo, al pie de los abrigos y en sus grietas cercanas al suelo, y deterioran la piedra por la acción mecánica producida por el crecimiento de las raíces y el aumento del tamaño de aquéllas, que termina por desmoronar la piedra. La humedad que atraen y los ácidos que desprenden, podrian aumentar la problemática destructiva de estas plantas.

Los musgos, por contra, podrían resultar hasta beneficiosos para la conservación de las pinturas, siempre y cuando se mantengan en el lugar que les es propio: la base techal de los abrigos. Alli absorben y regulan la humedad del abrigo y sus raices, que pueden penetrar hasta un centímetro en la roca, no afectarian a las pinturas que ocupan las oquedades bajas.

Las algas encuentran en las escurrideras de agua, que proceden de la parte alta de los abrigos, un ambiente propicio para su desarrolio. En muchos casos estas chorreras pasan por encima de las pinturas, donde además de lavar, y por tanto decolorar, dejan algas y verdines. El daño que pueden causar es casi insignificante, pues es muy poco frecuente que se introduzca en la roca y tenga fuerza para disgregarla, sin embargo distorsionan la legibilidad de las pinturas y contienen un grado de humedad elevado.

Una asociación entre algas y hongos desarrollan líquenes, que en Valonsadero aparecen muy frecuentemente sobre las pinturas. Los líquenes se adhieren a las superficies rocosas mediante los rizoides y chupan componentes de la roca, que son necesarios para sus funciones vitales. Hay líquenes blancos y negros, que extraen de la matriz de las rocas sulfatos cálcicos, y rojos que absorben el sulfato férrico existente en las cos- 
JUAN A. GÓMEZ-BARRERA, EUGENIO SANZ PÉREZ, PABLO L. YAGÜE HOYAL, R. FORT...

\begin{tabular}{|c|c|c|c|c|c|c|c|c|c|c|c|c|c|c|c|c|c|c|c|c|c|c|c|}
\hline \multicolumn{2}{|c|}{$\begin{array}{l}\text { ESTADO ACTUAL DE } \\
\text { CONSEVACION DE LAS } \\
\text { PINIURAS RUPESTRES } \\
\text { DEVALONSADERO }\end{array}$} & 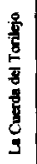 & $\frac{5}{2}$ & $\frac{8}{3}$ & $\frac{5}{\frac{5}{9}}$ & $\begin{array}{l}5 \\
5 \\
\frac{8}{2} \\
3\end{array}$ & $\begin{array}{l}\text { 昌 } \\
\text { 类 } \\
\text { ह } \\
\frac{8}{8} \\
8 \\
\frac{8}{5} \\
\frac{5}{2}\end{array}$ & 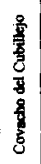 & 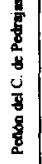 & 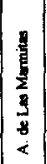 & $\begin{array}{l}8 \\
8 \\
8 \\
2\end{array}$ & $\begin{array}{l}8 \\
z \\
\frac{3}{8} \\
<\end{array}$ & 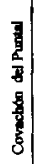 & 5 & $\frac{5}{5}$ & $\begin{array}{l}5 \\
5 \\
\frac{5}{8} \\
\frac{5}{8} \\
5 \\
2\end{array}$ & 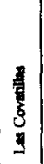 & 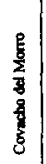 & $\begin{array}{l}\frac{9}{9} \\
\frac{3}{3} \\
\frac{3}{8} \\
\frac{5}{2}\end{array}$ & 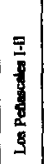 & $\begin{array}{l}7 \\
8 \\
8 \\
8 \\
3 \\
3\end{array}$ & $\begin{array}{l}\frac{9}{7} \\
\frac{8}{2} \\
\frac{8}{8} \\
\frac{1}{2} \\
\frac{8}{2}\end{array}$ & 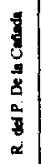 \\
\hline \multirow{18}{*}{ 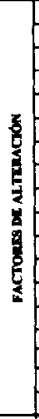 } & Asun Copile & 13,2 & 8,5 & 11,5 & 11,5 & 7 & 12 & 12,5 & 11 & 10,8 & 6,4 & 19.4 & 13 & 3 & 13 & 8,5 & 7.5 & 3,5 & 11,5 & 7,5 & 9 & \begin{tabular}{|l|}
14,2 \\
\end{tabular} & 13,4 \\
\hline & Ague de llavie (filtracion) & 4,4 & 11,5 & 7 & 14,5 & 14 & 10,5 & 8,5 & 9 & 21,6 & 12,8 & 9,1 & 4 & 8 & 8,5 & 8 & 14 & 16,5 & 10 & 12 & 12,5 & 3,8 & 2,8 \\
\hline & Agou de luwis Escantide & 6,6 & 9,5 & 7,5 & 6,5 & 3 & 6,5 & 2 & 6 & 5,4 & 4,2 & 7,2 & 3 & 12 & 4 & 6 & 9 & 3,5 & 11,5 & II & 12 & 3,2 & 4,1 \\
\hline & Apan de Rocio & 1,4 & 2,5 & 2,5 & 2,5 & 2,5 & 2,3 & 1,5 & 3 & 2,7 & 2,1 & 1,7 & 3 & 2,5 & 4,5 & 3 & 1,5 & 6 & 3 & 2,5 & 3 & 1,5 & 1,8 \\
\hline & Anu por Condansecion & 1,4 & 4,5 & 1,5 & 1,5 & 1,5 & 1,5 & 2 & 1,5 & 2,6 & 2,1 & 0,9 & 2 & 1 & 3 & 1,5 & 0,5 & 3 & 1,5 & 1 & 1 & 1,5 & 1,6 \\
\hline & Hielo-Deshiclo & 7,3 & 10 & 12 & 11 & 14,5 & 11 & 6 & 12,5 & 0,7 & 8,5 & 16,4 & 8 & 6,5 & 5,5 & 12 & 8,5 & 75 & 10 & 11 & 12,3 & 5,5 & 8,3 \\
\hline & Soles & 13,9 & 10 & 10.5 & 15,5 & 12 & 12 & 7 & 11,5 & 7.7 & 10.5 & 7,3 & 12 & 16 & 1,5 & 2,5 & 3 & 2 & 6,5 & 12 & 8,5 & 3,2 & 10 \\
\hline & Erocicion Alvealer & 2,2 & 7 & 2 & 10,5 & 12,5 & 2 & 3 & 9.5 & 8,8 & 7.5 & 5.4 & 1 & 13 & 7 & 1,5 & 10 & 14 & 5 & 9,5 & 11 & 2,4 & 5 \\
\hline & Iermoergension & 0,7 & 0,5 & 0,5 & 0,5 & 0,5 & 0,5 & 15 & 0,5 & 1,2 & 2,1 & 0,0 & 0,5 & 1 & 1 & 1 & 0,5 & 1 & 1 & 0,5 & 0,5 & 0,8 & 0.8 \\
\hline & Derendecion perolopica & 11,8 & 11,5 & 8 & 13 & 10 & 12,5 & 11,5 & 11,5 & 12,1 & 16 & 16,4 & 12 & 6,5 & 12 & 14 & 12,5 & 9 & 10,5 & 10,5 & 12 & 13,5 & 12,6 \\
\hline & Tffonizacion & 12,8 & 12 & 7.5 & 9.5 & 11 & 12,5 & 13 & 10 & 4 & 14 & 14,4 & 6 & 5,5 & 15 & 111 & 11 & 0,5 & 12 & 10,5 & 11 & 13,5 & 111,6 \\
\hline & Plantes Superiones & 8 & 2,5 & 4 & 1,5 & 1,5 & 8 & 2 & 1.5 & 1,2 & 2,1 & 2,7 & 3 & 3 & 2 & 0 & 1 & 0 & 3 & 2 & 1 & 15,7 & 4.7 \\
\hline & Mures & 1.4 & 2 & 1,5 & 1 & 4.5 & 1,5 & 0 & 3 & 0 & 5,2 & 0 & 0,5 & 2,5 & 0,5 & 1,5 & 1,5 & 2,5 & 2 & 1,5 & 1 & 1,5 & 1,7 \\
\hline & Alrom & 1,4 & 0 & 0 & 0 & 0 & 0 & 0 & 0 & 8,1 & 0 & 0 & 8 & 0 & 1 & 0 & 3 & 2,5 & 2 & 0,5 & 0 & 0 & 0 \\
\hline & Liquon & 4.4 & 2 & 4 & 1,5 & 3.5 & 2,5 & 1 & 3,5 & 0 & 6,4 & 0,9 & II & 12 & 13 & \begin{tabular}{|l|l}
2 \\
\end{tabular} & 0,5 & \begin{tabular}{|l|}
21 \\
\end{tabular} & 10,3 & 8 & 3 & 3,2 & 3,8 \\
\hline & Animeles & 0 & 0 & 1,5 & 0 & 0 & 0 & 0 & 2 & 0 & 0 & 0 & 3 & 3 & 0 & 1,5 & D & 0 & 0 & 0 & 0 & 1,5 & 0 \\
\hline & Accion Antroporens & 5,8 & 6 & 6.5 & 0 & 0 & 0 & 13,5 & 4. & 0 & 0 & 1,8 & 5 & 25 & 5,5 & iI & 3 & 5,5 & 0 & 0 & 2 & 4.7 & 5 \\
\hline & Fus:o & 3,3 & 0 & 12 & 0 & 0 & 4.9 & 15 & 0 & 0 & 0 & 0 & 5 & 0 & 3 & 15 & 13 & 0 & 0 & 0 & 0 & 10,2 & 10,8 \\
\hline \multirow{16}{*}{ 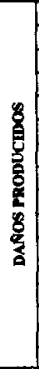 } & Sucioded Gereral & 20 & 15 & 95 & 10 & 20 & 41 & 100 & 70 & 20 & 30 & 10 & 10 & 8 & 10 & 50 & 20 & 90 & 60 & .55 & 65 & 65 & 75 \\
\hline & Encostrenivento & 95 & 100 & 100 & 92 & 100 & 100 & 100 & 95 & 60 & 75 & 100 & 65 & 95 & 90 & 100 & 95 & 99 & 100 & 100 & 100 & 95 & 90 \\
\hline & Dispreac. interion pieds & 70 & 70 & 46 & 15 & 18 & 65 & 65 & 12 & 10 & 20 & 85 & 15 & 40 & 15 & 15 & 15 & 5 & 40 & 80 & 68 & 30 & 15 \\
\hline & Exfoliaxcion y Escamecion & 90 & 80 & 68 & 22 & 20 & 70 & 80 & 81 & 40 & 45 & 76 & 60 & 22 & 15 & 20 & 93 & 3 & 30 & 40 & 35 & 78 & 60 \\
\hline & Oquededer & 69 & 75 & 45 & 42 & 88 & 20 & 60 & 5 & 2 & 12 & 15 & 5 & 20 & 15 & 20 & 22 & 13 & 25 & -35 & 15 & 27 & 35 \\
\hline & Givens & 70 & 65 & 30 & 35 & 83 & 55 & 65 & 67,5 & 15 & 30 & 60 & 40 & 41 & 30 & 70 & 30 & 30 & 30 & 60 & 17 & 15 & 65 \\
\hline & Superficie picade & 95 & 90 & 80 & 42 & 18 & 00 & 86 & 72 & 80 & 60 & 15 & 9 & 60 & 80 & 50 & 22 & 45 & 60 & 22 & 88 & 42 & 35 \\
\hline & Menches origen biologico & 20 & 10 & 40 & 10 & 35 & 30 & 0 & 0 & 75 & 75 & 10 & 70 & 30 & 70 & 10 & 20 & 90 & 70 & 20 & 20 & 15 & 30 \\
\hline & Pinuminesaules & 20 & 0 & - & 0 & 0 & 0 & 0 & 0 & 0 & 0 & 0 & 10 & 13 & 0 & 0 & 0 & 15 & 0 & 0 & 15 & 0 & 0 \\
\hline & Encouramiento pendido & 68 & 63 & 78 & 30 & 15 & 40 & 68 & 60 & 15 & 27 & 87 & 20 & 22 & 15 & 42 & 70 & 7 & 35 & 30 & 52 & 60 & 55 \\
\hline & Grobedion scturles & 0 & 21 & 0 & 0 & 0 & 0 & 0 & 17 & $\overline{0}$ & 0 & 15 & 6 & 0 & 17 & 0 & 0 & 0 & 0 & 0 & 0 & 0 & 0 \\
\hline & Hollm & 25 & 0 & 22 & 0 & 0 & 15 & 100 & 0 & 0 & 0 & 0 & 20 & 0 & 15 & 35 & 30 & 0 & 0 & 0 & 0 & 65 & 68 \\
\hline & \begin{tabular}{|l|l} 
Cinton \\
\end{tabular} & 20 & 0 & 85 & 0 & 0 & 10 & 100 & 0 & 0 & 0 & 0 & 0 & 0 & 10 & 50 & 85 & 0 & 0 & 0 & 0 & 82 & 40 \\
\hline & Pintura pendida & & & & & & & & & & 35 & & & & & 40 & & & & & & & \\
\hline & \begin{tabular}{|l} 
Docolo \\
\end{tabular} & 40 & 35 & 20 & 76 & 15 & 46 & & 20 & 60 & 25 & 30 & 30 & 40 & 10 & \begin{tabular}{|l|}
20 \\
\end{tabular} & 20 & 17. & 20 & 10 & 30 & 20 & 13 \\
\hline & Pinuin rovede o picade & 20 & 42 & 17 & 60 & 18 & 39 & 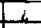 & 35 & & 0 & 20 & 10 & 23 & 30 & 23 & 30 & 30 & 40 & 35 & 23 & 0 & 10 \\
\hline \multirow{12}{*}{ 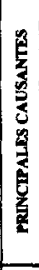 } & Axua & 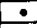 & - & $\because$ & & & & $\therefore$ & & & $\div$ & $\div$ & & . & & & & & & & & $\bullet$ & $\because$ \\
\hline & Anan & & & & & & & & & 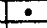 & & & & -7 & & & & & - & & & & \\
\hline & fitrecions & &. & & $\div$ & - & & & & & $\div$ & & & & & & $\div$ & $\because$ & & & $\div$ & & \\
\hline & perolopica & & - & & - & $\because$ & 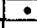 & & - & & - & - & & & & $\cdot$ & & & - & - & - & & \\
\hline & Hiclo-denhido & & & & & & & & & & & & & $\cdot$ & & & & & & & & & \\
\hline & \begin{tabular}{|l|l|} 
Salters \\
\end{tabular} & - & & & $\cdot$ & & $\cdot$ & & - & & & & $\cdot$ &. & & & & & & $\cdot$ & & & \\
\hline & Erovida trooder & & & & & & & & & & & & & $\div$ & & & & & & & & & \\
\hline & Tefoniz & 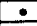 & $\bullet$ & & & & 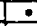 & $\div$ & & $\cdot$ & $\cdot$ & & & & $\div$ & & & & $\div$ & & & & 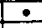 \\
\hline & Fuepo & & & I. & & & & & & & & & $\cdot$ & & & $\bullet$ & $\cdot$ & & & & & 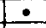 & $\bullet$ \\
\hline & Fuepo-T & & & & & & & - & & & & & & & & & & & & & & & $\cdot$ \\
\hline & Pinotin $\mathrm{SH}$ & & & & & & & & & & & & & & & & & & & & & $\because$ & \\
\hline & Lifuragen & & & & & & & & & & & & & & $\div$ & & & 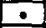 & & & & & \\
\hline \multirow{7}{*}{ 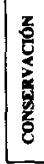 } & Exodonte & & & & & & & & & & & & & & & & & & & & & & \\
\hline & Muy Bupene & & & & & & & & & & & & & & & & & & & & & & \\
\hline & Bumen & & & & & & & & & & & & & & & & & & & & & & \\
\hline & Nomine & & & & & & & & & & - & & & & 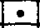 & & & 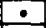 & & & & & \\
\hline & \begin{tabular}{|l} 
Meng \\
\end{tabular} & & & & - & & $\rightarrow$ & & $\div$ & $\bullet$ & & & & & & - & & & & & & & \\
\hline & Muy Mall & & & & & - & - & & & & & & $\cdot$ & $\bullet$ & & & $\bullet$ & & - & & $\bullet$ & $\cdot$ & $\cdot$ \\
\hline & Petaim & 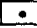 & - & $\bullet$ & & & & $\bullet$ & & & & $\bullet$ & & & & & & & & - & & & \\
\hline
\end{tabular}

Cuadro resumen del estado actual de consenvación de las pinturas rupestres de Valonsadero, elaborado por Juan A. Gómez-Barrera a partir de la información del estudio de Yagüe Hoyal. 


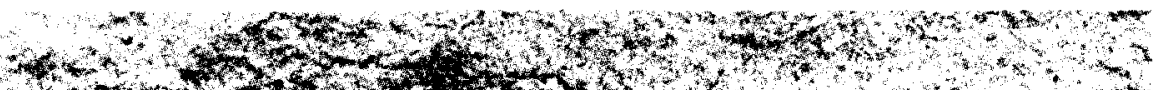

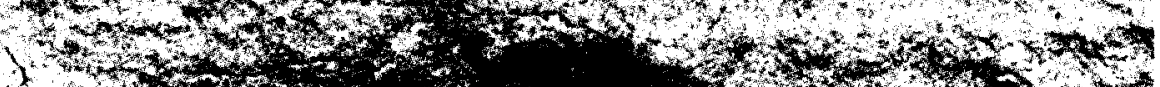

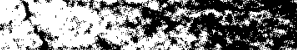

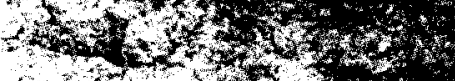

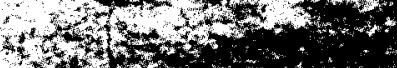

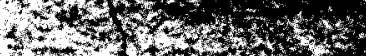

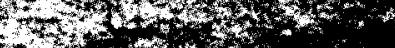

$+3,+1,+2,26$

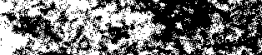

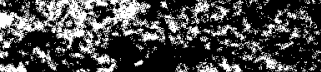

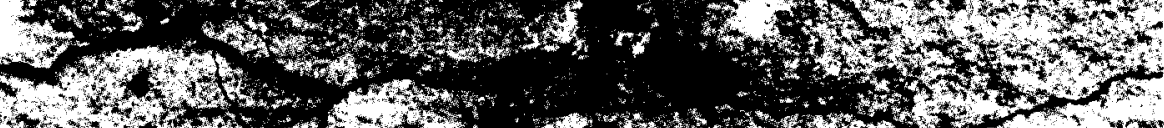

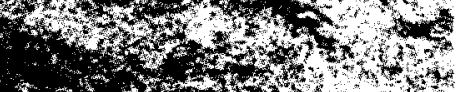

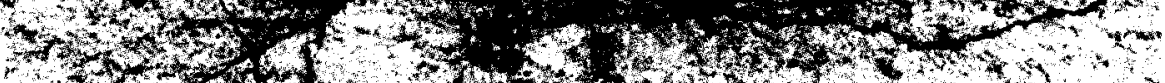

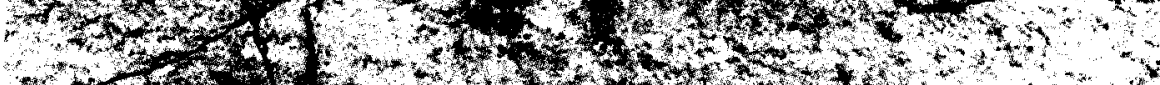

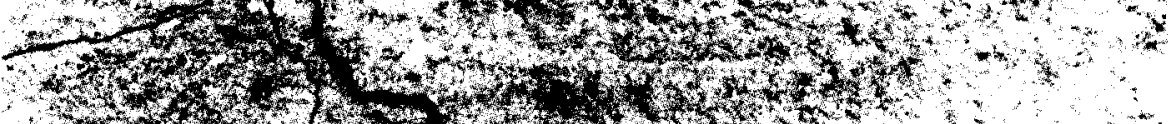

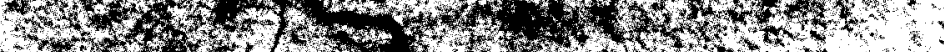

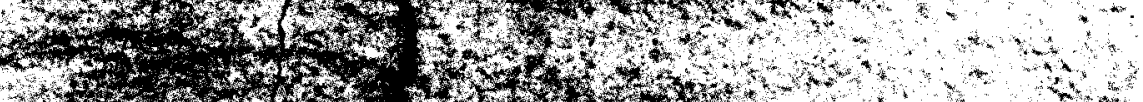

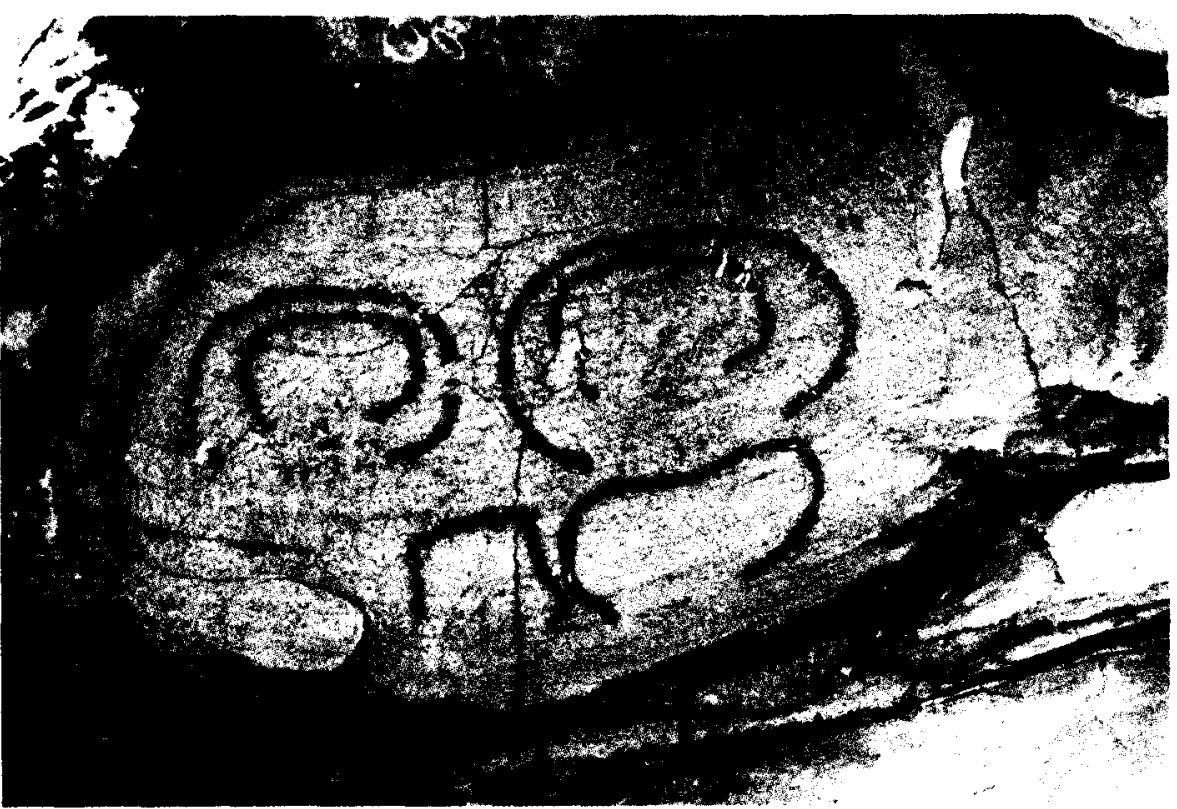

Figura 11. Los Peñascales I y La Asomadilla son alguno de los ejemplos más notables donde pueden apreciarse el picado antrópico y las grietas provocadas por la acción natural (hielo) (Fotografias de P.L. Yagüe Hoyal). 

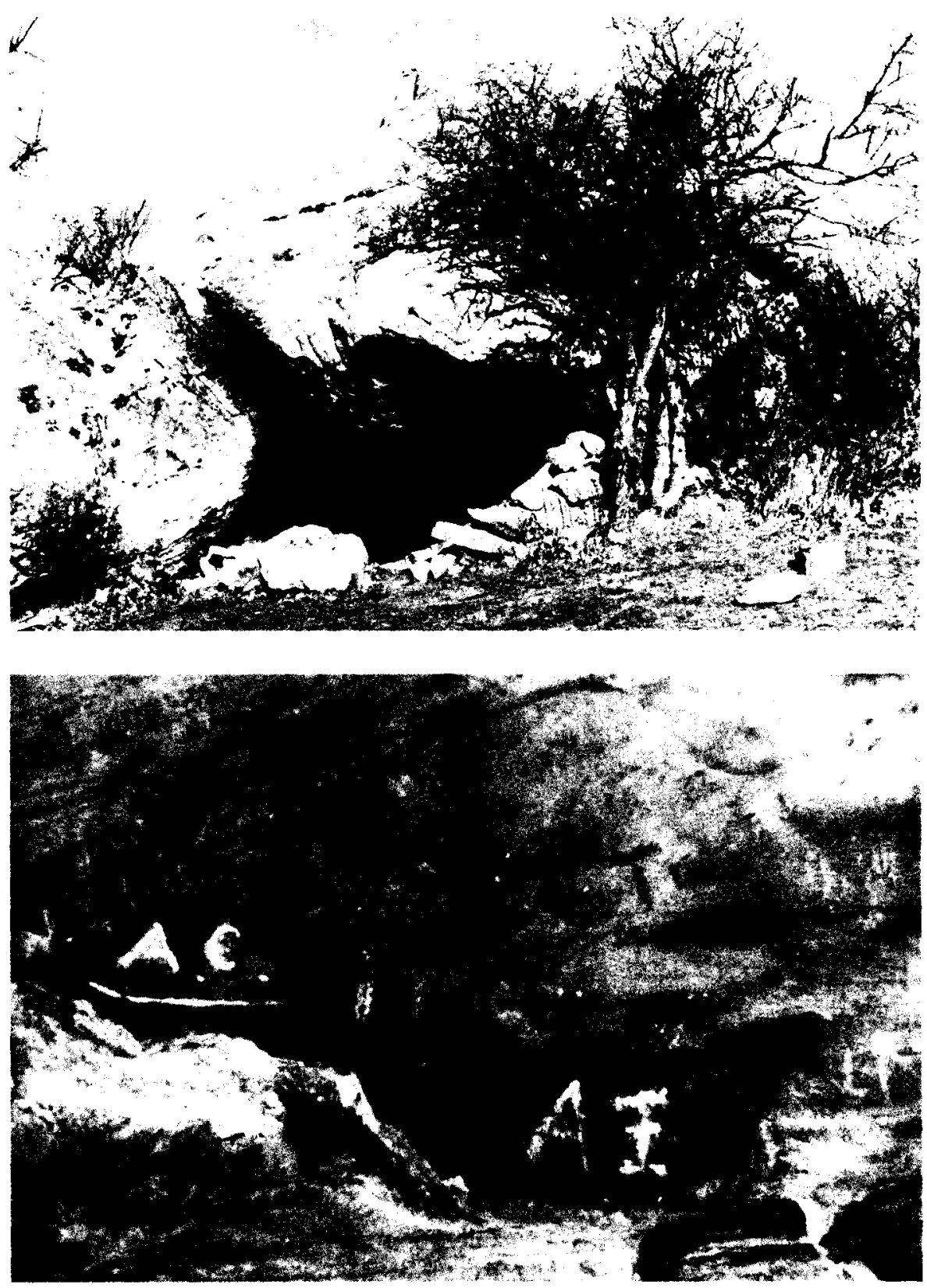

Figura 12. Las imágenes del Covacho del Cubillejo y del panel pintado de La Tronera son otros claros ejemplos de la alteración de sus pinturas por la acción, intencionada o no, de sus visitantes (Fotografía J.P. Yagüe Hoyal). 
tras de los abrigos. Por lo general el ataque de los líquenes no es muy dañino, por la escasa penetración de los rizoides, pero los cambios de humedad producen movimientos de expansión y contracción, que provocan la meteorización de la roca. Por lo demás la segregación de ácidos es mínima -desprenden ácido oxálico y carbónico en bajas densidades-, de ahí que el mayor problema de los líquenes en los abrigos de Valonsadero sea la ilegibilidad que crea al aparecer sobre las pinturas.

Por último, los daños causados por los animales no se pueden evaluar y en todo caso se limitarían a posibles rozamientos de las superficies pictóricas con su lomo; tal vez en épocas de frío y lluvia se refugiaron en los abrigos más accesibles, pero actualmente esto es imposible gracias a las vallas que los protegen.

Analizadas así las causas de alteración de las pinturas rupestres esquemáticas de Valonsadero, Yagüe Hoyal particularizó el problema en 22 de los 34 abrigos hasta ahora conocidos. Pormenorizó su estudio teniendo en cuenta, en cada estación, los factores de alteración, los daños producidos, los principales causantes de estos daños y la calificación del estado de conservación de cada uno de ellos. Toda esa información, cuantificada en 22 fichas y 53 páginas de su Memoria, la hemos recogido ahora en el cuadro adjunto, respetando incluso el pesimismo del autor en la valoración final.

\section{PROPUESTAS PARA LA PROTECCIÓN, CONSERVACIÓN Y GESTIÓN DEL PATRIMONIO ARTÍSTICO DE VALONSADERO}

Expuesto así el estado de conservación de las pinturas rupestres esquemáticas de Valonsadero, quedaría tan sólo concretar las diferentes propuestas que sobre protección, conservación y gestión de su patrimonio artístico han ido surgiendo a medida que se avanzaba en la formulación de aquél y en su propia investigación. Valoraremos las propuestas de Yagüe Hoyal y Sanz Pérez, las que hizo suyas el $2^{\circ}$ Symposium de Arqueología Soriana y las más recientes de la Comisión Institucional de Trabajo Plan Valonsadero, enmarcadas todas ellas, desde nuestro punto de vista, en un plan de gestión a todas luces viable.

\subsection{Las propuestas de P.L. Yagüe Hoyal y E. Sanz Pérez}

P.L. Yagüe Hoyal formulará su propuesta de protección y conservación de tan interesante núcleo artístico desde una óptica restauradora y estrictos criterios de reversibilidad de cualquier intervención. Las causas de alteración 
por él analizadas en el conjunto de las pinturas rupestres de Valonsadero, le aconsejarían aplicar ocho propuestas de intervención, de las que cuatro tendrían carácter preventivo y las otras cuatro de urgencia. Las medidas preventivas consistirian en la limpieza de la vegetación superior, instalación de tejados en forma de visera en aquellos abrigos por los que escurre el agua de lluvia, realización de zanjas de drenaje rellenas con guijarros de río y tubo de evacuación de agua en lucha contra la humedad y aplicación en el suelo del abrigo de herbicidas que eviten la proliferación vegetal y su posible daño a las pinturas. Por contra, consideraría urgentes en su aplicación la limpieza de la roca soporte y de los paneles pintados, la consolidación de la roca en zonas críticas con ésteres orgánicos de ácido silícico para conseguir una reestructuración de la trabazón minerálica de la piedra arenisca, la fijación a la roca, con ésteres de silicio y resinas eposídicas, de todas aquellas lascas, escamas y placas que contengan pinturas y puedan desprenderse $y$, finalmente, el relleno y consolidación de las oquedades que se encuentran en el interior de la roca.

E. Sanz Pérez, por su parte y como ya vimos en el tercer apartado de este trabajo, planteará aplicar una propuesta de mínima actuación, limitándose ésta a tareas de drenaje en La Cuerda del Torilejo, Abrigo del Tubo, Covachón del Puntal, El Mirador y Peña Somera y a la colocación, en todo caso, de pequeños tejadillos en la zona techal de los abrigos de La Lastra y Murallón del Puntal. Sugerirá, también, mantener el ambiente natural actual de los abrigos y en algunos, como en Peña Somera, plantar nuevos árboles dado que los que rodeaban al abrigo fueron talados recientemente. Es decir, medidas todas ellas contra el agua y la abundancia de humedad, factores determinantes, al menos en parte, del estado actual de las pinturas y de su posible deterioro.

Diagnosticada la enfermedad, tan sólo quedaría aplicar el tratamiento propuesto, mas la intervención no resulta sencilla. Pese a que cada vez proliferan más los análisis de alteración físico-químicos de los soportes y consolidación y conservación del arte rupestre (Carrera Ramírez, 1987; Benito, Machado y Sancho, 1991-1992; Sancho, Peña, Mata y González, 1994; Arias Giménez, Martín-Chivelet y Vilas, 1994), los especialistas en éste siguen considerando que el agente más destructivo es la ignorancia humana y contra ella sólo se puede luchar con el conocimiento, la divulgación y la sensibilización ${ }^{15}$.

15 La preocupación de los investigadores por cuestiones de conservación, protección y salvaguarda de las manifestaciones artísticas es cada vez mayor y esto queda claramente reflejado en la bibliografía específica de la que, sin ánimo de exhaustividad, podemos citar las referencias 
$Y$ en esas estamos en Valonsadero. Es seguro que muchas de las propuestas de Yagüe Hoyal y Sanz Pérez puedan ser llevadas a la práctica, corrigiendo así daños inmediatos. Pero la salvaguarda del conjunto artístico de Valonsadero requiere medidas de mayor calado. Algunas se han dado ya, como la declaración, el 6 de Julio de 1994, del Monte Valonsadero como Bien de Interés Cultural con categoría de Zona Arqueológica, decretada por la Junta de Castilla y León. Otras están en camino, como la acción de la guía redactada a tal fin, el tríptico informativo y los carteles y atriles explicativos que, al pie de una docena de abrigos, se habrán de instalar, creando así, por iniciativa de la Junta de Castilla y León y del Excmo. Ayuntamiento de Soria, un itinerario básico de visita a tan excepcional núcleo artístico.

\subsection{Hacia un Plan de Gestión de Valonsadero}

En realidad todo cuanto antecede se ajusta, en buena medida, con el desarrollo de un plan de gestión del patrimonio artístico y arqueológico de Valonsadero que - si no de forma ordenada y administrativamente establecido, sí de hecho- se está llevando a cabo en los últimos años.

En efecto, analizadas las propuestas de otros autores para gestionar ora el Patrimonio Arqueológico (Velasco, 1992; Barbi y Carrera, 1995) ora el Arte Rupestre (Sicari, 1990; Carrera, Costas, Peña y Rey, 1994 y 1995), bien podemos admitir que en el espacio natural del Monte Valonsadero se han efectuado actuaciones que entrarían de lleno en la filosofía de cualquiera de estos planes.

siguientes: R. VINAAS (1970): «Informe sobre un microorganismo detectado en las pinturas rupestres del Barranco de la Valltorta", C.P.A.C, Barcelona, p. 75-79; S. SANTos GaLlego (1976): "La conservación de las pinturas rupestres en los abrigos del levante español», I Congreso de Conservación de Bienes Culturales. Comité Nacional del ICOM, Sevilla; R. LuCAS PeLliCER (1977): "Conservación del arte rupestre al aire libre», Cuadernos de Prehistoria y Arqueología, 4, Universidad Autónoma, Madrid,, p. 1-14; R. VIÑAS y E. RıPOLL (1979): "Degradación del arte rupestre en las áreas levantinas y sur de la Península", Altamira Symposium, p. 677-680; R. LuCAS (1980): “Posibilidades de conservar el arte rupestre postpaleolítico", Altamira Symposium, p. 695702; M. MAS I CORNELLÀ (1987): “Algunas consideraciones sobre la conservación del arte prehistórico en el 「ajo de las Figuras", XIX Congreso Nacional de Arqueología, p. ; A. BELTRÁN (19871988): "La conservación del arte rupestre", Cuadernos de Prehistoria y Arqueologia Castellonense, 13, p. 61-81; F. Carrefa Ramirez, F.J. Costas Goberna. A. de la Peña Santos y J.M. REY GARCIA (1994): “El arte rupestre galaico: una reflexión crítica sobre el presente y una propuesta para el futuro", Trabajos de Prehistoria, 51, núm. 2, p. 41-54; A. Beltrán MaRtinez y J. ROYO LASARTE (1999): "Nota sobre una pintura desaparecida en el abrigo de Los Borriquitos, en Alacón, y los problemas de conservación de las pinturas al aire libre", BARA (Boletín de Arte Rupestre de Aragón), 2, p. 87-90. 
La idea básica de un correcto plan de gestión será la determinación de un Patrimonio real, su evaluación y una actuación directa sobre él con la finalidad de obtener una protección más efectiva y una mayor rentabilidad social.

La determinación de los recursos o, lo que es lo mismo, la realización de un exhaustivo inventario y catálogo de cuantas estaciones con arte rupestre son conocidas en Valonsadero es tarea absolutamente concluida. Las iniciales y constantes publicaciones de T. Ortego $(1962,1966$, 1974,1983 , además de las ya citadas en páginas anteriores), nuestros posteriores estudios (Gómez-Barrera, 1982; 1992b) y artículos y comunicaciones de nuevos hallazgos (Gómez-Barrera, 1984-1985; 1989; 1992a; 1994; Fernández Moreno y Gómez-Barrera, 1991) y, de forma especial, los catálogos e inventarios elaborados por nosotros mismos para el Servicio Territorial de Cultura de Soria y la Dirección General de Patrimonio de la Junta de Castilla y León (Inventario Arqueológico e Inventario de Arte Rupestre) ${ }^{16}$, dan cumplida cuenta de esta primera fase, esencial en cualquier plan de gestión. Por lo demás, lo adecuado o no de esta estrategia de documentación y registro de las manifestaciones artísticas de Valonsadero viene dado incluso por haberse abordado en ella, como puntualmente se anota en este escrito, la recogida sistemática del estado de conservación de cada abrigo y los factores potenciales de alteración ${ }^{17}$.

Se dispone, así, de una adecuada cartografía que refleja con detalle la distribución y la concentración de la pintura rupestre esquemática de Valonsadero y, por lo mismo, una "carta de riesgo" (Carrera, Costas, Peña y Rey, 1994: 46) frente a los diversos agentes de alteración (Fig. 11).

16 Si no simultáneos, si se redactaron teniendo en cuenta el mismo fondo documental. El Inventario Arqueológico de Castilla y León, dirigido en la provincia de Soria por A. Jimeno, y el propio de arte rupestre de la comunidad castellano-leonesa, bajo la supervisión y coordinación de $S$. Corchón, lievaron consigo la cumplimentación de una ficha que en el primero era de carácter general y en el segundo se especificaba en cuestiones más concretas como el horizonte artistico, la morfologia del yacimiento, el contenido artístico del mismo, el entorno arqueológico y monumental si lo hubiera, la historiografía, la situación jurídica, la conservación del abrigo o cueva y de los paneles y motivos, la protección y las propuestas de posibles actuaciones en estos últimos supuestos. El primero de los inventarios se redactó en noviembre de 1988 y el segundo en 1993 y ambos fueron entregados en la Dirección General de Patrimonio y Promoción Cultural de la Consejeria de Educación y Cultura de la Junta de Castilla y León y de ellos debería existir copia en el Servicio Territorial de Cultura de Soria.

17 Idea sugerida por Carrera Ramirez, Costas Goberna, De la Peña Santos y Rey García en el primero de los articulos de ellos citados y que en Soria se llevó a cabo con anterioridad. 
Estado actual de los estudios de conservación de las pinturas rupestres...

\section{Vlunte Valonsaderu. Suria}

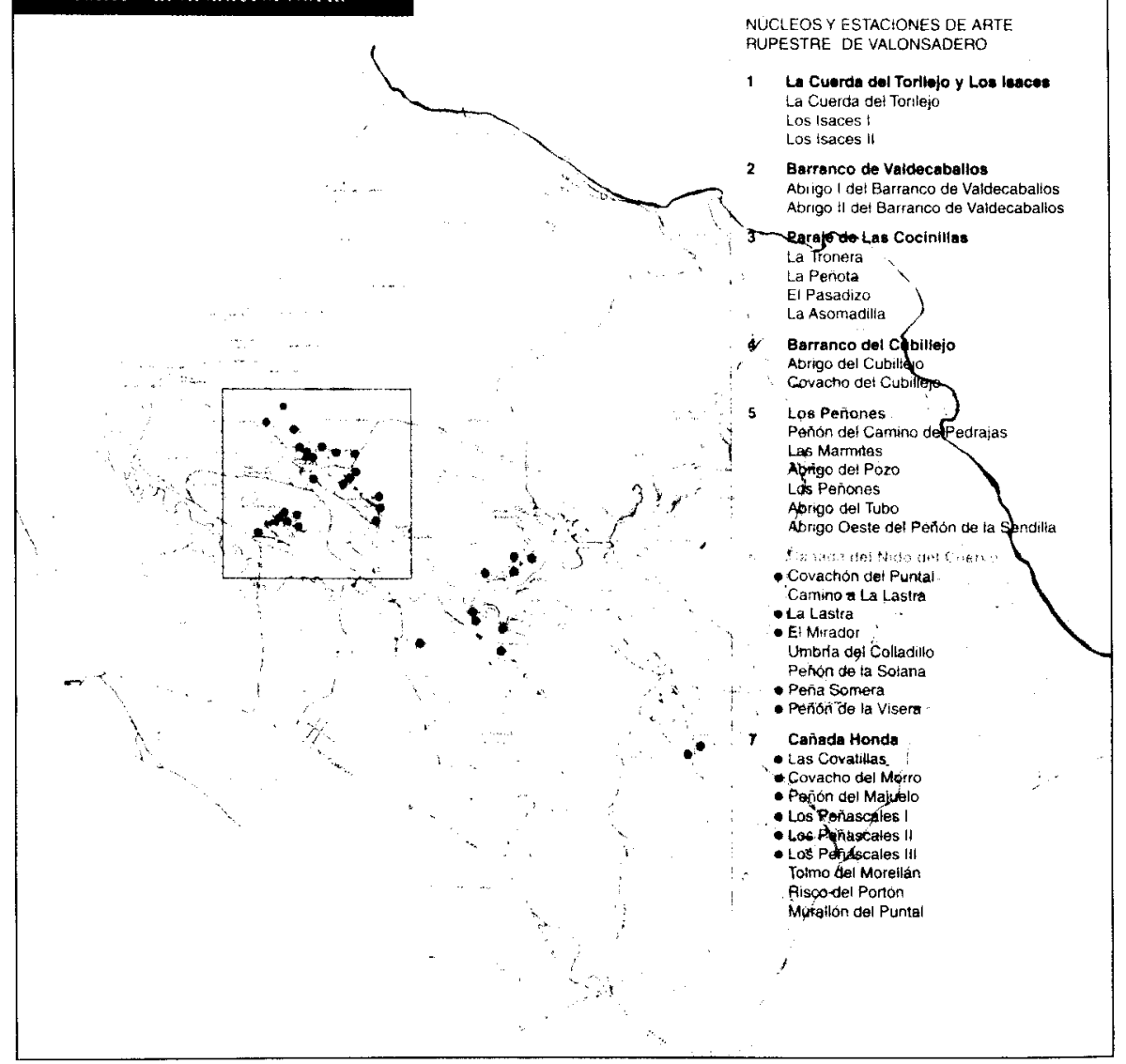

Figura 13. Mapa general del Monte Valonsadero con la distribución de sus pinturas agrupadas en siete núcleos. El recuadro señala los abrigos pintados seleccionados en el itinerario propuesto para su visita.

El grado de conocimiento que de Valonsadero y de la riqueza de su patrimonio artístico teníamos permitió que en el transcurso de las sesiones de 2. Symposium de Arqueologia Soriana, celebrado en octubre de 1989, se hiciera pública una propuesta del Monte Valonsadero como Zona Arqueológica (Gómez-Barrera, Jimeno Martínez, Fernández Moreno y Yusta Bonilla, 1992), figura jurídica contemplada ya en la Ley del Patrimonio Histórico Español, en su artículo 14.5, como «lugar o paraje natural donde existen bienes muebles o inmuebles susceptibles de ser es- 
tudiados con metodología arqueológica", y cuya regulación quedaba recogida en el artículo 20.1 de la misma Ley, con la obligación, para el municipio en que se encuentre, de redactar un Plan Especial de Protección.

Aquella propuesta, además de la declaración de Valonsadero como Zona Arqueológica - cosa que ocurrió, como ya se indicó en el comienzo de este trabajo, en 1994- proponía llevar a cabo una serie de actuaciones concretas encaminadas a la conservación y difusión de las pinturas rupestres de la zona. Se proponían medidas de conservación tendentes a actuar sobre la degradación producida por los agentes climáticos y contaminantes y sobre la constante, y más dañina, acción antrópica. Para llevar a cabo las primeras se hacían imprescindibles estudios físico-químicos que permitieran conocer las características del soporte, los componentes de la pintura y el tipo de aglutinante empleado para adherir ésta a la roca. Para las segundas se precisaba de una buena documentación - a base de calcos y reproducciones gráficas recopilables- que pudieran preservar, al menos, la información aportada por las pinturas; la generalización de vallados o barreras físicas que distanciaran los paneles pintados del espectador, eliminando así el continuo roce de la pared por el ganado, la realización de hogueras al pie de los abrigos o la de grafitos, rallados o picoteados sobre los propios motivos esquemáticos; y la limpieza periódica del espacio resultante entre las verjas y la pared pintada, evitando que la vegetación llegara a ocultar los restos que se tratan de proteger y enseñar.

A todas estas medidas de conservación, en gran parte realizadas como se ha dejado entrever a lo largo de este trabajo, se añadirían medidas de difusión: carteles informativos a la entrada del monte y visibles desde la C.N.-234, un Punto de Información situado en la propia Casa del Guarda o en otro recinto del lugar que actuara como edificio de carácter público permanentemente abierto, pequeños trípticos o guías que dieran una visión global y divulgativa de la Zona Arqueológica y el Espacio Natural que conformarian el Monte Valonsadero y la forma de utilizarlo y respetarlo, y, finalmente, además de un distintivo identificativo que, a modo de banderola numerada, marcara el lugar y su toponimia, se instalaría, al pie de cada uno de los abrigos componentes de las tres rutas diseñadas al efecto, un panel explicativo, con una descripción somera del objeto tratado y su cronología así como los elementos gráficos necesarios para su comprensión.

En semejante actuación, además de los abrigos pintados, se incluirían los restos arqueológicos existentes en el monte: un tramo de la calzada romana - número 27 del Itinerario de Antonino- que desde la zona de Villaciervos se internaría por el monte para salvar el Duero y buscar la 
ciudad de Numancia ${ }^{18}$; una necrópolis rupestre, de la que se conocen tres tumbas antropomorfas excavadas en la roca (Ortego Frías, 1983: 214215; De la Casa Martínez, 1992: 393-394) y el afloramiento de algunas tumbas de lajas (Gómez-Barrera et alii, 1992: 1149), localizada en la vega del río Pedrajas; restos etnográficos como majadas y posibles neveros modernos o cortados artificiales en las rocas que dejan cubículos de distinta capacidad o vierten al exterior; y el hallazgo reciente de un fragmento de calzada empedrada, junto a la Casa del Guarda, bien medieval o moderna, que formaría parte de la infraestructura de servicios necesarios para la explotación del monte, hecho éste del que tenemos noticias desde 1256 en que se fecha el Fuero de Soria dado por Alfonso X.

Al concluir sus sesiones de trabajo, el 2. ${ }^{\circ}$ Symposium de Arqueología Soriana hizo suya la propuesta del Monte Valonsadero como Parque Arqueológico y poco después la propia Junta de Castilla y León, a través de su Consejería de Cultura y Bienestar Social, encargaría a tres de los firmantes de este artículo, la realización de los estudios que sobre conservación de las pinturas y degradación de las areniscas soporte de las mismas se han comentado y analizado en los capítulos precedentes.

Como también se ha señalado, el 15 de enero de 1991 la Dirección General de Patrimonio y Promoción Cultural de la citada Consejería acordó incoar expediente de declaración de Bienes de Interés Cultural como Zona Arqueológica a favor del Monte Valonsadero y el 30 de junio de 1994 se publicó el decreto que confirmaba tal declaración.

Mas, con ser un principio esperanzador, las actuaciones parecieron quedarse ahí paradas. Se contaba con una resolución legal, con un mejor conocimiento del estado de conservación de los Bienes de Interés Cultural a proteger y de serias y documentadas propuestas para acometer un plan de gestión satisfactorio que cumpliera con el doble objetivo de conservar y divulgar. Se habian seleccionado los recursos sobre los que diseñar las estrategias de actuación y, sobre todo, se habían evaluado criterios tan relevantes para la sociedad en general como los económico/utilitario y estético/artístico frente a los meramente históricos o científicos, considerando las posibilidades de Valonsadero como lugar y centro de recreo natural de

18 E. Saavedra, en su Descripción de la via romana entre Uxama y Augustóbriga (Madrid, 1879 , p. 25 , lám. $1 .^{a}$ ), describió este tramo como «... el más bello trozo de calzada de toda la línea comprendida en el plano, cubierta su superficie por la yerba de las praderas adyacentes que se ha extendido sobre ella, conservándola y señalando de la manera más perfecta el bombeo central y hasta las cunetas laterales destinadas a recoger el agua llovediza. Este trozo que, incluyendo los terraplenes del principio, tiene 3840 metros de longitud, atraviesa al monte y dehesa de Valhonsadero, del término de Soria, y se conoce con el nombre de Camino de los Serranos". 
una parte importante de la población soriana y de sus visitantes. $Y$, sin embargo, la propuesta parecía no ir hacia adelante pese a que se descubrieran nuevos abrigos (Abrigo de los Peñones) o motivos hasta entonces ignorados (ramiforme del Abrigo del Tubo), se levantaran plantas, alzados y secciones de una buena parte de los covachos pintados, se fotografiaran continuamente sus pinturas, se realizaran nuevas y más fieles copias de las mismas y se citara el núcleo artístico de Valonsadero en un buen número de publicaciones lo que, de alguna manera y por modestas que estas fueran, contribuía a un mayor conocimiento científico del lugar.

El 24 de enero de 1993 hubo que denunciar en la prensa local «los dos últimos y más salvajes atentados cometidos en los últimos quince años contra las manifestaciones artísticas de carácter prehistórico del Monte Valonsadero" (Gómez-Barrera, 1993b). Y es que, en el Abrigo del Tubo, a escasos centímetros de sus conocidas pinturas -es posible que encima de los restos de otras ya perdidas- un improvisado, mal intencionado y torpe "pintor» dejó su delincuente huella personal al trazar, con pintura azul de tipo industrial, un cuadrúpedo, una mancha informe y varias figuras humanas. Por si fuera poco, en el mismo paraje de Los Peñones y próximo al citado abrigo, al del mismo nombre del paraje (Abrigo de los Peñones) y al denominado Abrigo del Pozo, otro aventajado artista - si bien más juicioso al escoger una roca sin restos pictóricos- esculpió en bajorrelieve un amplio y reposado caballo. La denuncia tan sólo surtió el efecto de que las «nuevas pinturas" del Abrigo del Tubo fueran limpiadas inmediatamente por indicación del Excmo. Ayuntamiento de Soria, pero, aunque en el mismo artículo periodístico se recordaba la recomendación que los arqueólogos habiamos hecho en la última sesión del $2 .^{\circ}$ Symposium, no se fue más allá, de ahí que tres años más tarde, tras conocer el Museo de La Valltorta y el Parque Cultural de Albarracín, volviéramos a recordar a las Administraciones competentes aquella propuesta y nos atreviéramos a sugerirles tuvieran a estos núcleos de arte prehistórico como modelos para Valonsadero (Gómez-Barrera, 1996).

\subsection{Comisión Institucional de Trabajo Plan Valonsadero}

Tal vez impulsados por este escrito, pero, sobre todo, obligados por la propia Ley 16/1985 de 25 de junio de Patrimonio Histórico Español, el Excmo. Ayuntamiento de Soria, a través de su Concejalía de Montes, decidió, en noviembre de 1996, constituir una Comisión Institucional de trabajo que llevara a cabo un Plan Especial de Ordenación y Conservación 
del Monte Valonsadero ${ }^{19}$. Se trataba de garantizar, como se anotaba al comienzo de este escrito, el uso y disfrute de este monte público y en el mismo se incluirían una amplia actuación que, retomando las sugerencias del $2^{\circ}$ Symposium de Arqueología Soriana, pusiera en valor la Zona Arqueológica del lugar.

La propuesta de 1989 fue ahora renovada y ampliada y la Comisión hizo suyo, a petición nuestra, un plan de actuación que habria de llevarse a cabo en los tres próximos años. Y así, para 1997, se proponía:

a) Limpieza y saneamiento de los espacios comprendidos por el vallado de los abrigos y su entorno más próximo. Esta limpieza habría de ser periódica y siempre por las brigadas municipales.

b) Instalación de verjas o vallados - según los diseños existentes o aquellos que se determinase valorando individualmente cada estaciónen el Abrigo del Pozo, Abrigo del Oeste del Peñón de la Sendilla, Abrigo de Las Marmitas, Abrigo de los Peñones, Peñón de la Solana, Abrigo del Portón de la Cañada, Murallón del Puntal, La Tronera, El Pasadizo, Abrigo Il del Barranco de Valdecaballos y Abrigo del Cubillejo.

c) Rectificación de aquellas verjas desproporcionadas estética y formalmente o de las que, por descubrimiento de nuevos motivos, se hubieran quedado cortas (Abrigo del Tubo).

d) Adecuar una de las tres rutas propuestas en 1989; tal adecuación supondría: 1) Instalación, en espera de la formalización del Punto de Información definitivo, de un cartel-expositor - superada la Casa del Guarda, en la cuesta que antecede al paraje de Los Peñones y al Mirador de Cañada Honda - que ofreciera un croquis de la ruta, una fotografía o un dibujo de un motivo pictórico que sirviera de reclamo y una información mínima en torno al estilo del arte rupestre que se trata de visitar y su cronología y período cultural en que se sitúan, así como una recomendación res-

19 Estaría formada por un representante de cada grupo político presente en el Consistorio, un técnico municipal, un técnico del Departamento de Medio Ambiente de la Junta de Castilla y León, un representante del Centro de Investigación Forestal del Monte Valonsadero, un experto en temas de Geología perteneciente al colectivo universitario soriano y un especialista en temas históricos. Tal relación se concretaria en las personas siguientes: D. ' Yolanda Martínez Hernando, como Presidenta, y D. Manuel Revilla Lavilla, D. Nicasio Martinez García, D. Lorenzo Lorenzo Lerma, y D. Carlos de la Iglesia Domingo, como representantes políticos; los demás miembros, según la relación descrita, serían: D. José María Pérez Miranda, D. Manuel Melendo Garcia Serrano, D. a Ana Hernández Fernández de Rojas, D. a Pilar Hernández González y D. Juan A. Gómez-Barrera, este último en su condición de estudioso de las pinturas rupestres del monte. 
pecto al respeto debido a los abrigos y su contenido.; 2) Tríptico explicativo, según modelos de la Junta de Castilla y León; se distribuiría, provisionalmente, en la Casa del Guarda y junto a él podría entregarse una hoja/encuesta personalizada para que cada visitante pudiera hacer constar su procedencia, su edad, su interés y su valoración, etc. de tal manera que la propia Comisión pudiera, en su día, cuantificar el impacto y la repercusión social del proyecto; y 3) En la misma estación pictórica, atril que reflejase mediante un calco y una breve descripción el contenido del abrigo visitado, según lo indicado y el modelo sugerido en la propuesta inicial.

Durante el segundo año, es decir en 1998, se llevaría a cabo todo el proyecto de adecuación de la Zona Arqueológica de Valonsadero, lo que determinaría:

a) Punto de Información o lugar de encuentro de los visitantes. El lugar adecuado sería, a nuestro modo de ver, la Casa de Autoridades o el recinto de servicios y vestuarios de la piscina, donde se debería instalar una pequeña exposición permanente a base de carteles informativos, calcos a tamaño natural de alguno de los paneles pictóricos, construcción de una maqueta de $1 \times 1$ de uno de los Abrigos más representativos, etc. Sería el lugar adecuado para que el turista o visitante se acopiase de información de mano (trípticos, postales, posters e incluso colección de diapositivas comentadas);

b) Adecuación de todas las rutas establecidas de acuerdo al esquema puesto en práctica en la ruta inicial. Sería de gran interés diseñar las rutas mezclando la información del arte rupestre con la puramente medioambiental. El recorrido sería más agradable y el sentido didáctico más adecuado en tanto en cuanto el artista convivió con el espacio y éste, en buena lógica, debió condicionar lo pintado;

c) Edición de uno o varios folletos. Podría hacerse uno tipo acordeón que por una cara ofreciera el plano/mapa de Valonsadero con la información precisa y por el otro aparecieran los textos, las figuras y las láminas necesarias para una correcta y didáctica explicación. No hemos de olvidar aquí la necesidad de confeccionar material escolar;

d) Edición de una guía arqueológica de Valonsadero, siguiendo las pautas establecidas para este tipo de publicaciones por la Junta de Castilla y León;

y e) Valoración de una actuación directa en abrigos que como La Lastra, Covacho del Morro o Los Peñascales // muestran grandes peligros de conservación y precisan de tareas de protección de las aguas pluviales, de limpieza de líquenes $o$ de consolidación de la arenisca respectivamente. Para este punto, como para el primero, seria de interés contar o al menos 
Estado actual de los estudios de conservación de las pinturas rupestres...

valorar lo dispuesto en el trabajo de P.L. Yagüe anteriormente citado o, en su defecto, encargar nuevos estudios de conservación y protección de las estaciones y abrigos pintados.

$\mathrm{Y}$, finalmente, para 1999 se determinaba que, llevado a cabo el objetivo básico y fundamental, culturalmente hablando, sería el momento de posibilitar la publicación de una Monografía interdisciplinar sobre el Monte. El libro se aglutinaría en torno a las manifestaciones de arte rupestre. Llevaría un estudio geológico y ambiental, un estudio histórico-institucional del Monte, un estudio etnológico y etnográfico y un estudio arqueológico alusivo a la interpretación del arte. Todo ello arroparía un estudio pormenorizado del arte rupestre esquemático que vendria a sustituir al libro que en 1982 publicó el propio Ayuntamiento de Soria.

En función de su realización, y con el fin de que se ajustara lo más posible su carácter social con su papel científico, los trabajos de las distintas subcomisiones afectadas y los de J.A. Gómez-Barrera deberían completarse con: 1) Prospección sistemática e intensiva del Monte y de los términos colindantes de Pedrajas, Oteruelos y Fuentetoba. Tal prospección debería ser llevada a cabo por un equipo profesional de arqueólogos de acuerdo con la normativa y precio establecido por la Dirección General de Patrimonio de la Junta de Castilla y León; 2) Alzado y sección topográfica de aquellos abrigos carentes de semejantes trabajos; gran parte de este trabajo está ya realizado con cargo al presupuesto del Inventario de Arte Rupestre de Castilla y León; 3) Aplicación de ultravioletas e infrarrojos a alguno de los lienzos pintados, en un intento de recuperar una mayor información de los mismos; 4) Análisis de pigmentos; y 5) Calcos de aquellos abrigos necesitados de revisión.

Muchos fueron los trabajos efectuados por esta Comisión a lo largo de sus tres años de vigencia, mas en absoluto llegó a cumplimentar el plan anterior. Se elaboraron, en efecto, nuevos estudios geológicos y físico-químicos de la alteración de las areniscas soporte de las pinturas - alguna de cuyas conclusiones ya vimos en el apartado 2-; se analizó y ordenó la masa arbolada del monte; se redactaron detallados informes sobre los pastos de Valonsadero y la adecuación de su carga ganadera; y se cuantificó y valoró la fauna del lugar ${ }^{20}$. Desde el punto de vista cultural, se redactó un

20 Para llevar a cabo buena parte de estos trabajos se convocó una serie de becas que permitieron a Maria Gines García y a Federico Meijide y Juan Luis Hernández elaborar sus estudios de vegetación y fauna respectivamente; los trabajos geológicos fueron dirigidos por $\mathrm{E}$. Sanz Pérez, uno de los firmantes del presente artículo, y en ellos participaron Pilar Hernández, Pedro Latorre y Carlos Pascual; por su parte, la Escuela Universitaria de Ingenieros Técnicos Agrícolas de Soria analizaría los pastos y la adecuación de la carga ganadera del monte. 
tríptico informativo del contenido artístico y prehistórico de Valonsadero; se diseñó una ruta arqueológica por once de los treinta y cuatro covachos pintados, con el texto y los dibujos que habían de rellenar los atriles explicativos a colocar al pie de cada una de esas estaciones rupestres; $y$, finalmente, se redactó un libro-guía de todo el núcleo de arte rupestre esquemático del alto Duero, que comprendería no sólo las pinturas de Valonsadero sino también las próximas de Pedrajas, Oteruelos y Fuentetoba.

\subsection{Y en espera de actuaciones... una conclusión reflexiva}

Sin embargo, de todos estos trabajos —realizados por el personal técnico adscritos a la Comisión- tan sólo han visto la luz pública el tríptico citado alusivo a las pinturas rupestres (Gómez-Barrera, 1999a) y otro, de similares características, que trata de acercar a los ciudadanos las particularidades geomorfológicas del monte (Sanz Pérez et alii, 1999).

Distintos avatares políticos y el hecho, no menor, de que cualquier actuación en tan mítico lugar deba poner en relación directa a dos administraciones diferentes - Ayuntamiento de Soria y Junta de Castilla y Leónestán ralentizando un proyecto que, curiosamente, parecen asumir de buena gana ambos organismos haciendo causa común ante posibles nuevos contratiempos exteriores (Gómez-Barrera, 1999b).

Por lo demás, y como reflexiva conclusión, se ha de recordar que mientras en Soria se ha trabajado, desde una modesta comisión institucional de carácter municipal, en favor del desarrolio integral de la Zona Arqueológica propuesta por la Ley de Patrimonio Histórico, en otros círculos se ha discutido la propia aplicación práctica de esta figura legal y su más conveniente sustitución por la de Parque Cultural o Arqueológico. En la Comunidad Autónoma de Aragón se cuenta desde diciembre de 1997 con una Ley de Parques Culturales donde se contempla específicamente los Parques Culturales con Arte Rupestre. El éxito de los Parques Culturales con Arte Rupestre de Albarracín, Río Vero y Río Martín, tal vez debieran ser motivo de análisis y, por qué no, de simple imitación.

Mas, con todo, la gran reflexión conclusiva que cabría hacerse como final de este ensayo no sería otra que la que se deriva del esfuerzo colectivo de las Comunidades Autónomas de Valencia, Cataluña, Aragón, Murcia, Andalucía y Castilla-La Mancha que han sabido trabajar conjuntamente para obtener de la UNESCO la inclusión en la lista del Patrimonio Mundial de 757 estaciones con pinturas rupestres del Arco Mediterráneo de la Península Ibérica, comprometiendo así a la Administración del 
Estado, a las 6 Comunidades Autónomas citadas, a 163 municipios y a todos los ciudadanos con la conservación y protección de estos conjuntos al ser, no ya un Bien de Interés Nacional (BIC) protegido por la ley 16/1985 del Patrimonio Histórico Español, sino también, y sobre todo, un Patrimonio de la Humanidad, del que se ha de reconocer su relevancia universal como expresión cultural excepcional y el deber inexcusable de preservar, dada su enorme vulnerabilidad y fragilidad, a fin de legarles a las generaciones futuras en las mejores condiciones posibles ${ }^{21}$.

Nuestros políticos, los de la administración local soriana y los de la comunidad autónoma castellano leonesa, han de saber que la única diferencia entre las manifestaciones artísticas prehistóricas del Monte Valonsadero y la de muchos de los 757 conjuntos a los que alude tan reconocido acontecimiento viene dada por su situación espacial, y esta no debería ser sinónimo de discriminación e ignorancia.

\section{BIBLIOGRAFIA}

Acin FANLO, J.L. (Coord.) (1990): Jornadas sobre Parques con arte Rupestre, Diputación General de Aragón. Departamento de Cultura y Educación, Zaragoza, 214 pp.

Archilla Aldeanueva, R. (1985): Caracterización climática de la provincia de Soria, Memoria de Licenciatura, inédita, Madrid.

- (1987): Características climáticas y agricolas de la provincia de Soria, Excma. Diputación Provincial de Soria, Soria.

Apralz, R. (1951): “Pinturas neolíticas en Valonsadero», Campo, sábado 11 de agosto.

Afias, C.; Giménez, R.; Martín-Chivelet, J. y Vilas, L. (1994): Marco geológico de los abrigos con pinturas rupestres situados en el entorno de la Cueva de La Vieja (Alpera), Instituto de Estudios Albacetenses de la Excma. Diputación de Albacete, Serie I. Estudios, 77, Albacete.

Barbi Alonso, V. y Carrera Ramírez, F. (1995): "Protección del Patrimonio Arqueológico inmueble: un incómodo reparto de tareas y responsabilidades", Actas del XXII Congreso Nacional de Arqueologia (Vigo, 1993), vol. p.

Beltrán Martinez, A. (1998): “El Centro de Arte Rupestre de la Diputación General de Aragón. Antecedentes. Propósitos y fundamentos", BARA (Boletín de Arte Rupestre de Aragón), 1 , septiembre, Zaragoza, p. 9-20.

Benito, G; MACHADO, M.J. y SANCHO, C. (1991-1992): "Alteración de las areniscas y la conservación de las pinturas rupestres del Rodeno de Albarracín (Teruel)", Kalathos, 11-12, p. 7-24.

Carrera Ramirez, F. (1987): "Degradación del granito por efecto de los ,líquenes. Aplicación a la conservación de los petroglifos gallegos", Pátina. Revista de la Escuela de Conservación y Restauración de Bienes Culturales, 2, p. 19-21.

Carrera Ramirez, F.; Costas Goberna, F.J.; Peña Santos, A. de la y Rey Garcia, J. M. (1994): $«$ El arte rupestre galaico: una reflexión crítica sobre el presente y una propuesta para el futuro", Trabajos de Prehistoria, 51, núm. 2, p. 41-54.

- (1995): "Una propuesta para la gestión del Patrimonio Rupestre Galaico», Actas del XXII Congreso Nacional de Arqueología" (Vigo, 1993), vol. I, p. 277-281.

21 Véase, al respecto, los diferentes catálogos, uno por Comunidad participante, de la exposición Arte Rupestre del Arco Mediterráneo de la Peninsula Ibérica, Barcelona, 1999. 
CAMÓN AZNAR, J. (1954): Las artes y los pueblos de la España primitiva, Espasa Calpe, Madrid.

Casanovas i Romeu, A. y Alonso Tejada, A. (1984): “Problemática en torno a la conservación del arte rupestre en abrigos", Congreso de Historia de Albacete (diciembre, 1983), Albacete, vol. I, p. 67-76.

Collado VILLALBA, O. (1998): "Parques Culturales con arte rupestre. El Parque Cultural de Albarracín, argumentos para un museo al aire libre", BARA (Boletín de Arte Rupestre de Aragón), 1, septiembre, Zaragoza, p. 41-59.

De la CASA MARTínez. C. (1992): Las necrópolis medievales en la provincia de Soria, Valladolid, $439 \mathrm{pp}$.

De Miguel Gonzalez, R. (1998): "La Ley de Parques Culturales de Aragón", BARA (Boletín de Arte Rupestre de Aragón), 1, septiembre, Zaragoza, p. 129-134.

Juste Arruga, M. ${ }^{a}$ N. (1998): “El Parque Cultural del Río Vero», BARA (Boletín de Arte Rupestre de Aragón), 1, septiembre, Zaragoza, p. 61.78.

Diago Hernando, M. (1993): Soria en la Baja Edad Media: espacio rural y economía agraria, Ed. Complutense, Madrid.

Fernández Moreno, J.J. y Gómez-BARRera, J.A. (1991): "Dos nuevos abrigos con pinturas rupestres esquemáticas en 'El Cubillejo' (Valonsadero, Soria), Soria Arqueológica, 1, p. 103-120.

Gómez-BARRera, J. A. (1982): La pintura rupestre esquemática en la altimeseta soriana, Excmo. Ayuntamiento de Soria, Soria, 285 págs., 91 figs. y XV láms.

- (1984-1985): El Abrigo de "La Peña los Plantíos": nuevo hallazgo de pinturas rupestres esquemáticas en Fuentetoba (Soria), en Ars Praehistórica, t. III/IV, p. 139180,36 figs.

- (1989): Las pinturas rupestres del Abrigo II del Barranco de Valdecaballos (Valonsadero, Soria), Boletín de la Asociación Española de Arte Rupestre, n. ${ }^{\circ} 2$ p. 3-10, 4 figs.

- (1991): El motivo-estela de "La Peña los Plantíos" (Fuentetoba, Soria), en Soria Arqueológica, 1, p. 87-101, 3 figs. y II lám.

- (1992a): Arte rupestre en la provincia de Soria, en Actas del $2^{\circ}$ Symposium de Arqueologia Soriana, Soria, p. 11-64, 18 fig. y $V$ láms.

- (1992b): Grabados rupestres postpaleolíticos del Alto Duero, Serie de Investigación del Museo Numantino, 1, Soria, 408 págs., 259 figs. y CXC láms.

- (1993a): Arte Rupestre Prehistórico en la Meseta Castellano-Leonesa, Junta de Castilla y León, Valladolid, 263 págs y 149 figs. y láms.

- (1993b): SOS: !Salvemos Valonsadero!, Diario de Soria, domingo 24 de enero, p. 6-7.

- (1994): Fuentetoba: nuevas pinturas esquemáticas en la altimeseta soriana, Revista de Arqueología, 164, p. 12-19, 17 figs.

- (1995): El río Pedrajas. Un pequeño, e ignorado, curso fluvial con importantes muestras de arte rupestre prehistórico en su vega, en Por los ríos de Soria, Soria Edita, p. 165184, XI láms.

- (1996): La Valltorta y Albarracín... ¿modelos para Valonsadero?, Diario de Soria, domingo 11 de Agosto, p. 8.

- (1999a): Valonsadero (Soria). Pinturas Rupestres Esquemáticas, Junta de Castilla y León-Excmo. Ayuntamiento de Soria, Soria, tríptico.

- (1999b): “Valonsadero: ¿parque arqueológico o eólico?, Diario de Soria y Heraldo Soria 7 dias, miércoles 8 de septiembre.

- (1999c): "La Comisión Institucional y el Aula de Interpretación de Valonsadero", Diario de Soria, Martes 21 de diciembre.

- (2000): "Ensayo de interpretación gráfica y espacial de las pinturas rupestres esquemáticas del "Covacho del Morro" (Valonsadero, Soria)», Soria Arqueológica, 2, Homenaje al Dr. José Luis Argente Oliver, Soria, p. 165-203

Gómez-Barrera, J.A.; Jimeno Martinez, A.; Fernández Moreno, J.J. y Yusta Bonilla, J.F. (1992):

Propuesta del Monte Valonsadero como parque arqueológico, Actas del $2^{\rho}$ Symposium de Arqueología Soriana (Octubre, 1989), Excma. Diputación de Soria, Col. "Temas Sorianos", 20, t. II, p. 1145-1167, 7 figs, y III láms.

Hernandez Gonzalez, M. ${ }^{a}$ P.; Latorre Macarrón. P.A.; Pascual arribas, C. y Sanz Pérez, E. (1999): Valonsadero. Monte Público, Soria. Geología, Junta de Castilla y León-Excmo. Ayuntamiento de Soria, Soria, tríptico.

MARTIN DE MARCO, J.A. (1990): La institución de Caballeros Hijosdalgos de Los Doce Linajes de la Ciudad de Soria, Publicaciones del Excmo. Ayuntamiento de Soria, Soria. 
Mas I Cornellà, M.; Jordá Pardo, J.F.; Cambra Sánchez, J.; Mas Riera, J. y Lombarte Carrera, A. (1994): «La conservación del arte rupestre en las Sierras del Campo de Gibraltar. Un primer diagnóstico", Espacio, Tiempo y Forma. Serie l: Prehist. y Arqueol., 7, p. 93-128.

MAS I CORNELLA, M. (1998): Las manifestaciones rupestres prehistóricas en las sierras que bordean la antigua Laguna de la Janda (Campo de Gibraltar, Cádiz), Tesis Doctoral. Dpto. de Prehistoria e Historia Antigua. Facultad de Geografía e Historia, Universidad Nacional de Educación a Distancia, Madrid.

MuÑoz JiMÉNEZ, J. (1986): “El sinclinal colgado de Picofrentes (Soria)», en Atlas de Geomortología, Alianza Atlas, Madrid, p. 45-62.

Ortego Frias, T. (1951): "Las estaciones de arte rupestre en el Monte Valonsadero de Soria", Celtiberia, 2, p. 275-305, VIII láms.

- (1952): "Recientes hallazgos de arte rupestre neo-eneolítico en el Monte Valonsadero, de Soria, Archivo Español de Arqueologia, t. XXV, p. 1-5, 3 figs.

- (1953): "Nuevos grupos de pinturas rupestres en el término de Soria", Actas del $1 / 1$ Congreso Nacional de Arqueologia, Galicia 1953 (Zaragoza, 1955), p. 63-67, 8 figs.

- (1954):" Nuevos hallazgos de arte rupestre en el Alto Duero", Zephyrus, V, p. 23-28, 4 figs.

- (1958): "Nuevos grupos de arte rupestre en la zona oriental de la altimeseta castellana», $\checkmark$ Congreso Internacional de Ciencias Prehistóricas y Protohistóricas, Hamburgo 1958 (Berlín, 1961), p. 622-625, 15 figs.

- (1962): «Un nuevo abrigo con pinturas rupestres en el término de Pedrajas de Soria. La Cueva de "El Prado de Santa María", en Actas del VII Congreso Nacional de Arqueología, Zaragoza, p. 140-147, 8 figs.

- (1965):" Valdecaballos, nueva estación de arte rupestre esquemático en el término de Soria", Miscelánea en Homenaje al Abate H. Breuil, Barcelona, p. 207-216, IV láms.

- (1966): "Nuovi ritrovamenti di arte rupestre schematica a Soria (Spagna)", Bollettino del Centro Camuno di Studi Preistorici, II, p. 93-102, 4 figs.

- (1967): "Avance al estudio de las pinturas rupestres de El Prado de Santa María, en el término de Pedrajas de Soria», Celtiberia, 33, p. 83-90, IV láms.

- (1969): «Nueva estación de arte rupestre en el término de Oteruelos (Soria)», Actas del $X$ Congreso Nacional de Arqueologia (Mahón, 1967), Zaragoza, p. 205-215, 15 figs.

- (1974): “Las pinturas rupestres del Peñón de la Sendilla, en el Monte Valonsadero de Soria", Boletín de la Asociación Española de Amigos de la Arqueologia, 1, Madrid, p. 715,5 figs.

- (1983): “Por la vega del río Pedrajas. Otras estaciones de arte rupestre", Celtiberia, 66 , p. 209-216, 12 figs.

Pérez Romero, E. (1995): Patrimonios comunales, ganadería trashumante y sociedad en la Tierra de Soria. Siglos Xvil-xix, Junta de Castilla y León. Consejeria de Educación y Cultura, Salamanca.

RoYo LASARTE, J. (1998): “El arte rupestre como fundamento de delimitación y organización de un Parque Cultural en torno al tramo medio del Río Martín (Teruel)", BARA (Boletín de Arte Rupestre de Aragón), 1, septiembre, Zaragoza, p. 79-92.

SaAvedra, E. (1879): Descripción de la via romana entre Uxama y Augustóbriga, Madrid, 116 págs. y $\vee$ láms.

SANCHO, C.; PEÑA, J.L.; MATA, M.P. y GonzÁlez, J.R. (1994): “Estudio alterológico de la arenisca soporte de las pinturas y grabados de La Roca dels Moros de El Cogul (Lleida)", Cuaternario y Geomorfologia, 8 (3-4), p. 103-118.

SaEnz Garcia, C. (1954): “Pico Frentes», Celtiberia, 8, p. 229-253.

- (1955): «Pico Frentes», Celtiberia, 10, p. 245-274.

SAnz PERez, E. (1994): "El micromodelado de las areniscas de Valonsadero (Soria)", Geomorfología en España (J. Arnáez, J.M. Garcia Ruiz \& A. Gómez Villar, Edrs), Sociedad Española de Geomorfología, Logroño, p. 91-105, 3 figs.

- (1996): "Alteración y modelado de las areniscas de la facies Purbeck-Weald del Noroeste de la Cordillera Ibérica", Cuaternario y Geomorfología, 10 (3-4), p. 47-61, 5 figs.

- (1998): Estudio de la alteración de la roca soporte de las pinturas rupestres de Valonsadero y medidas para su protección, Comisión Institucional de Trabajos Plan Valonsadero, Concejalia de Montes, Excmo. Ayuntamiento de Soria, 26 págs. mecanografiadas. 
JUAN A. GÓMEZ-BARRERA, EUGENIO SANZ PÉREZ, PABLO L. YAGÜE HOYAL, R. FORT...

Sanz Pérez, E., Latorre Macarrón, P., Pascual, C. y Hernández, P. (1999): Valonsadero (Soria). Geología, Junta de Castilla y León-Excmo. Ayuntamiento de Soria, tríptico.

SiCARI, R. (1990): "Conservación del Arte Rupestree en Australia: filosofia, política, infraestructura y ordenación", Jornadas sobre Parques con Arte Rupestre, Zaragoza, 1989, p. 101-110.

Yagüe Hoyal, P.L. (1990): Estudio del estado de conservación de las pinturas rupestres del Monte Valonsadero (Soria) y proyecto para su restauración, Junta de Castilla y León. Consejería de Cultura y Bienestar Social, Madrid, 226 págs. mecanografiadas.

Terrel, F. (1994): "Conejos en Valonsadero", Diario de Soria, domingo 23 de octubre, p. 8-9.

Velasco SteIGRAD, F. (1992): "Un modelo de gestión a partir de la declaración de zonas arqueológicas amplias", Jornadas Internacionales de Arqueología de Intervención, San Sebastián, 1991, Departamento de Cultura del Gobierno Vasco, Bilbao, p. 75-84. 